\title{
Volume : 4, Issue : 1
}

ISSN: 2309-6241

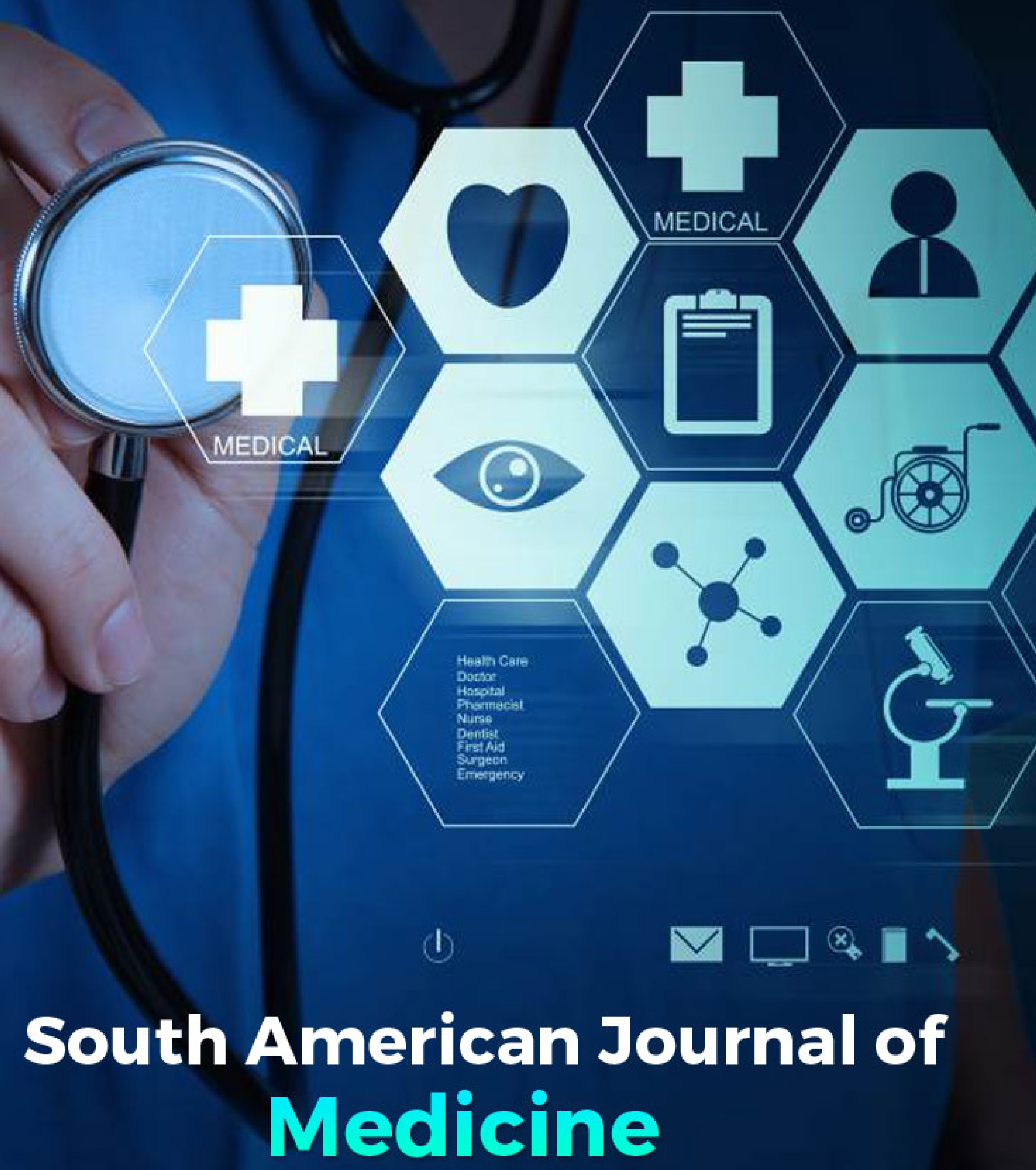




\title{
Clinical Radiological and Immunohistochemical Profile of Non Small Cell Lung Carcinoma
}

\author{
Article by Suhail Neliyathodi ${ }^{1}$, Asha Krishnan ${ }^{2}$, Dhwani Gopinath ${ }^{3}$ \\ ${ }^{1}$ Professor and HOD, Department of pulmonology \\ ${ }^{2}$ Resident, Department of pulmonology, ashakvk@gmail.com \\ ${ }^{3}$ Senior resident, Department of pulmonology, dhwani.gopinath@gmail.com \\ MES Medical College, Malappuram, Kerala, India \\ Email: sneliyath@yahoo.com
}

\begin{abstract}
Objectives: To evaluate clinical, radiological and immunohistochemichal profile of non small cell lung carcinoma (NSCLC). Settings and study design: A cross sectional study conducted among all diagnosed cases of primary lung malignancy in the Department of Respiratory Medicine MES Medical College Perinthalmanna . Materials and methods: The 41 biopsy proven cases of NSCLC was studied during a period of $1 \frac{1}{2}$ years, A detailed history, clinical evaluation and the relevant investigation is done, small biopsy specimens are collected, a histopathological evaluation was done and the markers Thyroid Transcription Factor-1(TTF1), Epidermal Growth Factor Receptor (EGFR) and p-63 status was determine by immunohistochemistry(IHC) Results: Of the 41 cases, Squamous cell carcinoma was the predominant histological type with a male predominance and a peak incidence in 61-70 yrs of age. (58.53\%) cases showed EGFR positivity. TTF1 positivity was predominant with adenocarcinoma and 663 positivity with squamous cell carcinoma. Smoking status and EGFR in adenocarcinoma shown that there is a significant number of EGFR positivity associated with non-smokers and all were females. The study could attain a $85.71 \%$ sensitivity and 92.59\% specificity for ttf1 in adenocarcinoma and 88\% sensitivity and 100\% specificity for p63 in squamous cell carcinoma. Conclusion: IHC can be used as a rapid and effective tool for diagnosing the histologic type of NSCLC because of its high sensitivity and specificity. In adenocarcinoma, there is a significant number of EGFR positivity associated with nonsmokers females.
\end{abstract}

\section{Introduction}

Lung cancer was considered as a rare disease in the beginning of the century. But it is now the leading cause of cancer related mortality in developed countries and is rising in alarming rates in developing countries. In India, lung cancer constitutes $6.9 \%$ of all new cancer cases and $9.3 \%$ of cancer related deaths in both sexes. In men, lung cancer is the leading cause of cancer related deaths and $2^{\text {nd }}$ leading cause of cancer related death in women. Kerala is one of the most affected state in India with lung cancer. Cigarette smoking is the most important modifiable risk factor for lung cancer accounting for about $80 \%$ of lung cancer death in men and $50 \%$ in women. Our understanding about the disease biology has improved over the past years and the classification is expanding from histological to molecular level.

Molecular targets and driver mutation play a major role in pathogenesis and has lead to the development of targeted therapy. Diagnostic markers and prognostic markers for evaluating the survival of patients in lung carcinomas are the latest developments in this field in which studies are in progress. Mutation of the EGFR gene in lung carcinomas makes the disease more responsive to treatment with Tyrosine Kinase inhibitor (TKI). TTF-1 is a nuclear protein expressed mainly in thyroid and lung (type II pneumocytes). It is a master regulatory transcription factor for tissue specific gene. It is a highly specific marker for primary lung adenocarcinoma and is associated with better survival in NSCLC. P-63 is considered as the single best marker to separate squamous cell carcinoma and adenocarcinoma. These proteins 
South American Journal of Medicine

Volume 4, Issue 1, 2016

can be identified with the help of specific Immunohistochemichal markers in small biopsy specimens.

Studies on the EGFR mutation and other molecular markers are available in the literature. But no much studies in this aspect is available from India especially Kerala where lung cancer is a major killer disease.

\section{Materials and methods}

All biopsy proven case of NSCLC coming to the Respiratory Medicine Department of MES Medical College from $1^{\text {st }}$ January 2014 to $31^{\text {st }}$ September 2015 were included in the study. The study had a cross sectional study design and the sample size was calculated as minimum 30 cases.

A detailed history, clinical evaluation and the relevant investigations are done, small biopsy specimens are collected, a histopathological evaluation was done and the markers TTF1, EGFR and p-63 status was determine by IHC (avidin-biotin complex).

EGFR scoring is done by H-Score method. Here a score of 0-300 is assigned to each patient. This is obtained by multiplying percentage of cells stained and intensity of staining. Intensity of staining is divided into absent, mild, moderate and severe staining. Absent staining is given 0 staining, mild staining is given 1 score, moderate staining is given 2 score and strong staining is given 3 score. H-Score $</=200$ is considered as negative and $>200$ is taken as positive. The data is accumulated in a preformed proforma and statistical analysis done.

\section{Results}

A total of 41 patients were included in the study that had biopsy proven diagnosis of NSCLC. Squamous cell carcinoma was the predominant histological type identified from my study (table:1).

Table 1

\begin{tabular}{|l|l|l|}
\hline total & adenocarcnoma & Squamous cell carcinoma \\
\hline 41 & 14 & 27 \\
\hline
\end{tabular}

Mean age at diagnosis was calculated as 62.66 years. Among the total cases studied, $80.49 \%$ were males and $19.51 \%$ cases were males. Squamous cell carcinoma was the predominant histological type among males and adenocarcinoma among female (fig: 1) s. Squamous cell carcinoma was more among smokers and adenocarcinoma among nonsmokers (fig: 2). All females were non smokers but gave a history of passive smoking.

Most of the patients had dyspnoea as the presenting symptom and cough was the next commonest symptom. Chest pain and haemoptysis were more common among squamous cell carcinoma. Clubbing was more associated with squamous cell carcinoma (73\%). The most common radiological presentation was mass lesion (54\%) both in adenocarcinoma and squamous cell carcinoma. The next commonest presentation among squamous cell carcinoma was collapse (22\%) and in adenocarcinoma, it was pleural effusion (28\%) (Fig: 3). Most of the cases presented at a late stage of the disease, $56 \%$ of cases presented as Stage 4 disease (fig: 4).

Small biopsy specimens were collected for histopathlogical diagnosis. The commonest procedure used was CT guided biopsy (table: 2). Squamous cell carcinoma were more centrally placed whereas adenocarcinomas were more peripheral in distribution. 


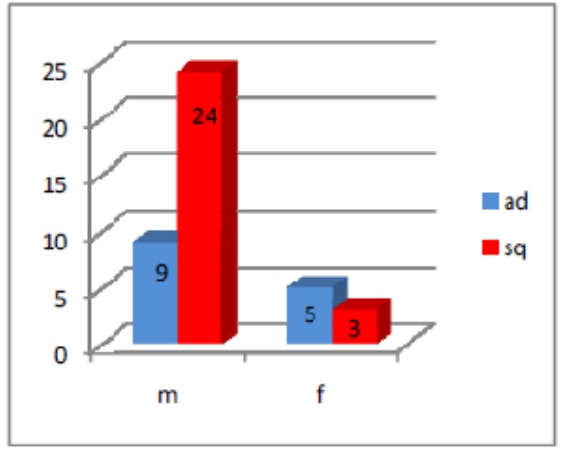

Figure 1. male female distribution.

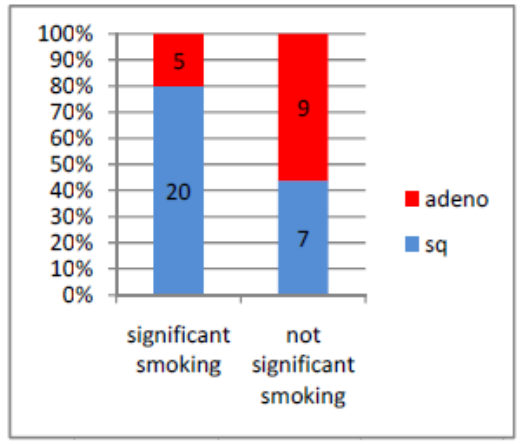

Figure 2. smoking status in the histological types.

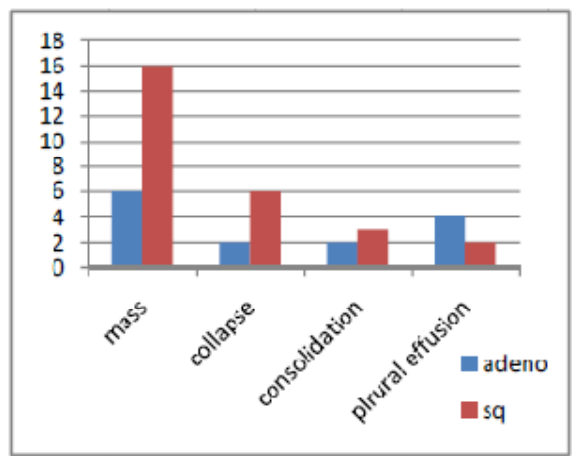

Figure 3. Radiological presentation of NSCLC

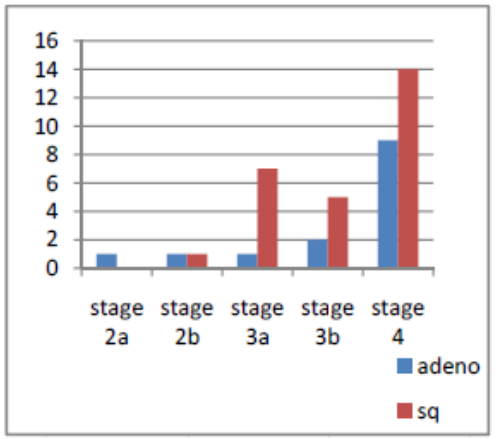

Figure 4. Stage at presentation. 
South American Journal of Medicine

Volume 4, Issue 1, 2016

Table 2 common procedures to get histological specimen.

\begin{tabular}{|l|l|l|l|}
\hline PROCEDURE & total & adenocarcinoma & Squamous cell carcinoma \\
\hline CT guided biopsy & 22 & 9 & 13 \\
\hline Lymphnode biopsy & 4 & 2 & 2 \\
\hline Bronchoscopic biopsy & 11 & 2 & 9 \\
\hline Pleural biopsy & 4 & 1 & 3 \\
\hline
\end{tabular}

The immunohistchemichal markers which were considered in this study were EGFR, TT1, p63. Of the total, 24 cases (58.53\%) cases showed EGFR positivity (fig: 5). EGFR protein expression by IHC was associated with squamous cell carcinoma (79.16\%) (Fig: 6). TTF1 positivity was predominant with adenocarcinoma (fig: 7 ). the study could attain an $85.71 \%$ sensitivity and $92.59 \%$ specificity for ttf1 in adenocarcinoma. Majority of the squamous cell carcinoma showed P63 positivity (fig 8) and none of the adenocarcinoma showed P63 positivity. $88 \%$ sensitivity and $100 \%$ specificity for p63 in squamous cell carcinoma was attained from this study (Table 3).

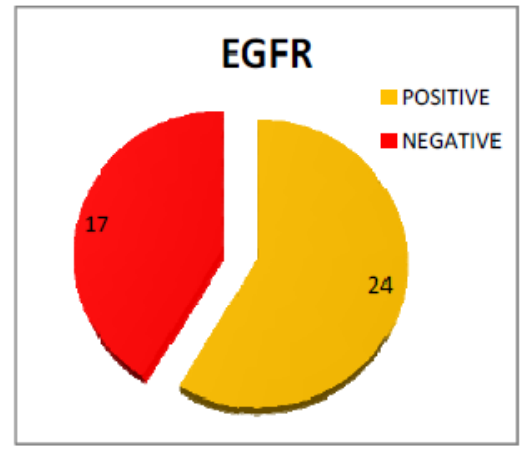

Figure 5. EGFR positivity in total

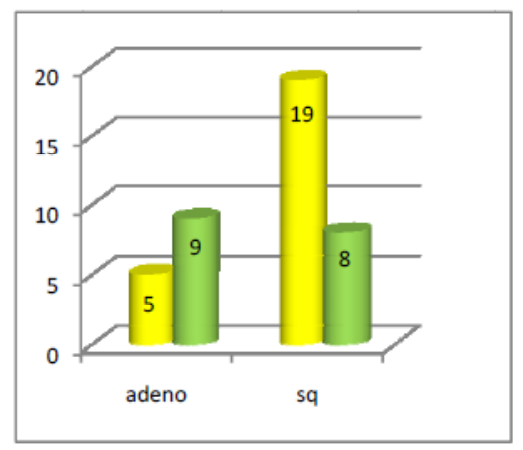

Figure 6. EGFR protein expression by IHC

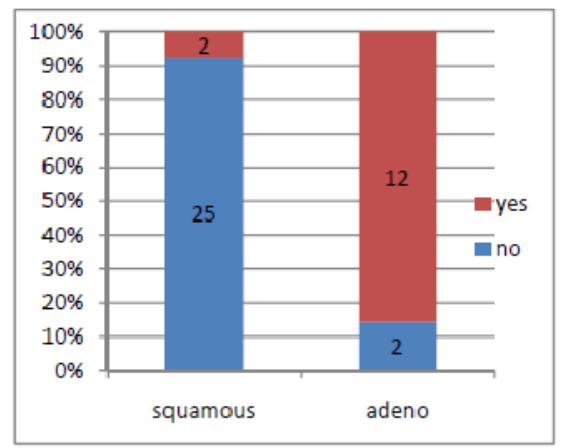

Figure 7. TTF1 Positivity was predominant with adenocarcinoma. 


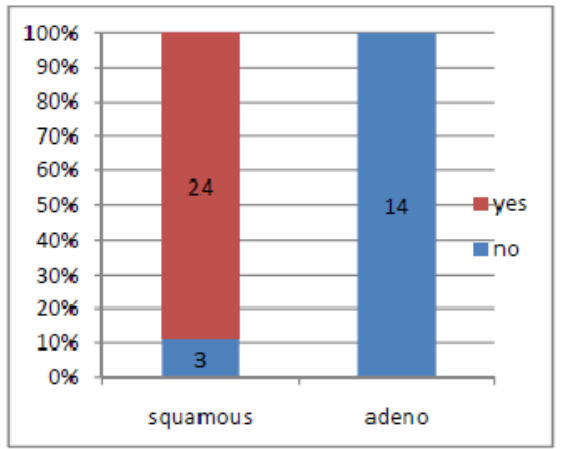

Figure 8. p63 positivity was more with squamous cell carcinoma.

Table 3. Adenocarcinoma

\begin{tabular}{|l|l|}
\hline sensitivity & $85.71 \%$ \\
\hline specificity & $92.59 \%$ \\
\hline
\end{tabular}

Squamous cell carcinoma

\begin{tabular}{|l|l|}
\hline sensitivity & $88 \%$ \\
\hline specificity & $100 \%$ \\
\hline
\end{tabular}

Smoking status and EGFR in adenocarcinoma shown that there is a significant number of EGFR positivity associated with non-smokers (fig: 9) and all were females (fig: 10). There was no relation between stage at diagnosis and EGFR status.

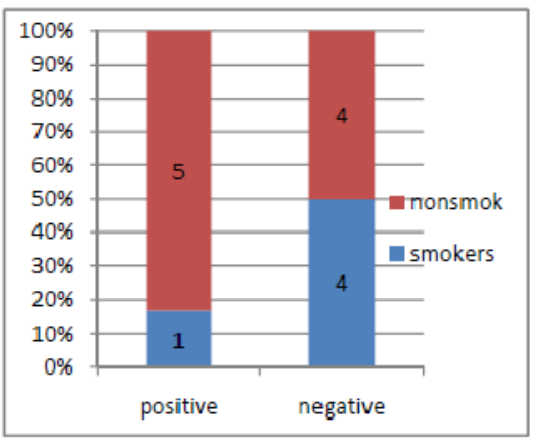

Figure 9. EGFR positivity was associated with Non-smokers

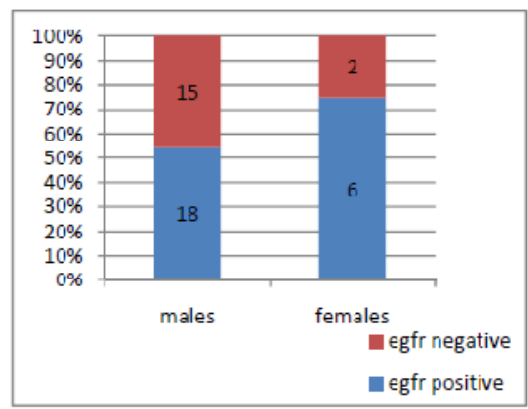

Figure 10. EGFR status and gender

\section{Discussion}

The world wide statistics shows that lung cancer is the most commonly diagnosed cancers (1.61 million, $12.7 \%$ of the total) and the most common causes of cancer deaths (1.38 million, $18.2 \%$ of the total) . The incidence of lung carcinoma in India is on the rise, Non-small-cell 
lung cancer constitutes $75-80 \%$ of lung cancers with a male predominance (M: F ratio: $1.7: 1)^{1}$ and Kerala is one of the most affected state in India ${ }^{2,3}$. More than $70 \%$ of them are in Stages III and IV thus curative surgery is not an option for treatment.

When age group affected was considered, this study results showed that the maximum number of cases were diagnosed in 61-70 year age group, which were consistent with the World wide Globcon statistics and studies done in India by D.Behra ${ }^{4.5}$. The male female ratio was calculated to be 4.1:1 and the datas from various studies over years shows that even though lung cancer is seen more in males, there is an increasing trend in occurrence of lung cancer in females ${ }^{4}$.

Smoking remains the most important preventable risk factor associated with lung cancer ${ }^{6,7,8}$. It is being well proved that Passive smoking or second hand smoking can cause cancer in non-smokers. The main mechanism of tobacco smoking induced lung cancer is the damage to the DNA, including the genes that protect against cancer.

Lung cancer is broadly classified as Small cell and NSCLC. NSCLC is further classified into squamous cell, adenocarcinoma and large cell carcinoma ${ }^{9}$. The statistical data from India has shown that the most prevalent lung cancer is NSCLC and Squamous cell carcinoma accounts for $44.73 \%$ and Adenocarcinoma $30.26 \%$. With newer advanced techniques, our understanding about the disease biology has improved. This has helped us to expand the diagnostic modalities from histological to molecular level. Until recently, a non confirmatory diagnosis of non-small cell lung carcinoma-not otherwise specified (NSCLC-NOS) was accepted because of the inability of morphology to distinguish some poorly differentiated tumors usually because of inadequacy of $\operatorname{specimen~}^{10}$. Now with the advancement in the therapeutic strategy, accurate histological diagnosis of non-small cell carcinoma and its sub typing in small specimens is important ${ }^{11,12}$ and evidence suggest that IHC is a highly effective supporting tools for distinguishing adenocarcinoma and squamous cell carcinoma and its subtype $^{13}$. The ESMO consensus conference that predictive IHC can reduce the NSCLC-NOS rate to $<10 \%$, typically $5 \%-6 \%{ }^{14}$ and so, IHC can be used in the routine diagnosis of lung cancer, in order to identify biological markers (diagnostic and prognostic). The role of IHC is to recognize antigens and, thus to identify and classify specific cells within a cell population whose morphology is heterogenous or apparently homogenous. Common markers used for non-small cell carcinoma subtyping include TTF-1 for adenocarcinoma whereas p63 and high-molecular weight keratins (CK5/6 and 34bE12/CK903) for squamous cell carcinoma ${ }^{15}$. TTF1 is a transcription factor that regulates the expression of multiple genes involved in lung development. It is predominantly expressed in lung adenocarcinomas and is been evaluated as a potential prognostic parameter in patients with lung cancer ${ }^{16,17}$. TTF1 is most commonly used to distinguish primary lung adenocarcinoma and metastatic lung cancer and also for differentiating primary lung adenocarcinoma from pleural mesothelioma ${ }^{18,19}$. P63 is a P53 homologous nuclear protein, which is expressed in basal cells of stratified squamous and glandular epithelia. In the lung, the highest expression is being consistently noted in squamous cell carcinomas.

Other markers associated with squamous cell carcinomas are, p40 and cytokeratin CK 5/6, while TTF1, Napsin A and CK7, as well as mucin stains, are associated with adenocarcinomas. The problem is that none are individually entirely tumor-type sensitive and specific. But the least IHC panel for subtyping NSCLC was TTF1 for adenocarcinoma and P63 for squamous cell carcinoma. The IATC/ATS/ERS has subtyped NSCLC based on the IHC status (table 4) 
Table 4. Subtyping of NSCLC based on IHC markers

\begin{tabular}{|l|l|l|l|l|}
\hline Markers & Adenocarcinoma & $\begin{array}{l}\text { Squamous } \\
\text { cell } \\
\text { carcinoma }\end{array}$ & $\begin{array}{l}\text { Adenosquamous } \\
\text { carcinoma }\end{array}$ & $\begin{array}{l}\text { NSCLC-NOS/ } \\
\text { metastasis }\end{array}$ \\
\hline TTF-1 & + & - & + & - \\
\hline p-63 & - & + & + & - \\
\hline
\end{tabular}

EGFR is a trans membrane glycoprotein with an extra cellular ligand -binding domain and an intracellular domain possessing intrinsic tyrosine kinase(TK) activity ${ }^{20}$. In-frame deletions in exon 19 and the exon 21 L858R substitutions are the most common EGFR mutations ${ }^{21}$ and, combined, represent approximately $90 \%$ of all mutants ${ }^{22}$. The cause of EGFR mutation is unknown, but is not related to tobacco carcinogenesis. Eventhough not exclusive, these mutations are therefore more common in never smokers and distant ex-smokers, and females of younger age ${ }^{23,24}$. EGFR gene copy number determined by FISH, protein expression determined by IHC and EGFR tyrosine kinase mutations are all potential markers to be used as selection criteria in EGFR-targeted therapy of which IHC seems to be a simple, rapid, sensitive and reliable method to identify the commonest EGFR mutation in NSCLC and can be used as a rapid screening method. Phase III trials involving Asian, European and North American patients with metastatic disease whose tumours have activating EGFR mutations have demonstrated high response rates (70\%) and significantly longer progression-free survival (PFS) in patients treated with EGFR TKIs, (Gefitinib, Erlotinib, Afatinib) as initial treatment when compared with those receiving chemotherapy ${ }^{25,26}$. The identification of active mutation in tyrosine kinase domain of EGFR and their response to novel tyrosine kinase inhibitors was one of the greatest leap in the management of NSCLC in selected cases. From multiple studies, it was identified that the phenotypes that respond to EGFR-TKI (Gefitinib, Erlotinib) were adenocarcinoma, non-smoker females-East Asian descent which was due to the presence of mutation in EGFR domain. Gefitinib is approved by the Food and Drug Administration (FDA) to treat locally advanced or metastatic non-small cell lung cancer (NSCLC) that has not gotten better after treatment with other chemotherapy ${ }^{27}$.

NSCLC corresponds to $80 \%-85 \%$ of lung cancer and, although there is progression in the development of new chemotherapeutics, NSCLC prognosis remains unsatisfactory with a 5year overall survival of less than $15 \%$. Preliminary results of randomized clinical trials conducted with these TKIs have shown that their use in patients with advanced disease is effective and significantly increasing the survival of these patients, especially if they harbour mutations in the EGFR which are more frequently found in a subgroup of non-smoking, female patients, of Asian ethnicity and with adenocarcinoma histological sub-type ${ }^{28}$.

\section{Conclusion}

Evaluating the profile of lung cancer was helpful in demonstrating the general pattern of distribution of NSCLC in the defined study group. IHC can be used as a rapid and effective tool for diagnosing the histologic type of NSCLC because of its high sensitivity and specificity. In adenocarcinoma, there is a significant number of EGFR positivity associated with non-smokers females.

Since there are supporting and contradicting reports on the relationship between EGFR protein expression by IHC and mutation status, the response to EGFR-TKI based on IHC status need to be evaluated further and correlated to mutation status for EGFR-TKI response. For this a large multicentered long term study is needed.

\section{References}

[1.] American Cancer Society. Cancer Facts and Figures 2011. Available at: http://www.cancer.org/Research/CancerFactsFigures/CancerFactsFigures/cancer-facts-figures-2011

[2.] Antonio Marchetti, Carla Martella, Lara Felicioni, Fabiobarassi, Simona Salvatore, Antonio Chella et al:EGFR Mutation In Non - Small Cell Lung Cancer: Analysis of a Large Series of Cases And 
South American Journal of Medicine

Volume 4, Issue 1, 2016

Development of a Rapid and Sensitive Method for Diagnostic Screening With Potential Implication on Pharmacologic Treatment. Journal of Clinical Oncology 2005;23(4):857-865.

[3.] Behera D, Epidemiology of lung cancer - Global and Indian perspective Review article JIACM 2012; 13(2): 131-7

[4.] Binukumar Bhaskarapillai, Saina Sunil Kumar, Satheesan Balasubramanian lung cancer in Malabar Cancer Centre in Kerala- A Descriptive Analysis. Asian Pacific Journal of Cancer Prevention, Vol 13, 2012.

[5.] Choong NW, Salgia R, Vokes EE. Key signaling pathways and targets in lung cancer therapy. Clin Lung Cancer 2007; 8 Suppl 2: S52-S60

[6.] Dhananjay Saranath and Aparna Khanna, Current Status Of Cancer Burden: Global And Indian Scenario. Biomedical Research Journal, 2014;1(1):1-5

[7.] Dunagan D, Chin R Jr, McCain T, Case L, Harkness B, Oaks T, et al. Staging by positron emission tomography predicts survival in patients with non-small cell lung cancer. Chest 2001; 119(2): 333-339

[8.] Edwards SL, Roberts C, McKean ME, et al. Preoperative histological classification of primary lung cancer: accuracy of diagnosis and use of the non-small cell category. J Clin Pathol 2000;53:537540.

[9.] GLOBCAN facts and figures 2012

[10.] Hiroshi Haneda, Hidefumi Sasaki, Osamu Kawano, et al. A Correlation Between EGFR Gene Mutation Status And Bronchoalveolar Carcinoma Features In Japanese Patients With Adenocarcinoma; Jpn J Clin Oncol2006;36(2)69-75

[11.] IARC. Monographs on the Evaluation of Carcinogenic Risks to Humans VOLUME 83 Tobacco Smoke and Involuntary Smoking. 2004.

[12.] Kerr K. M, Bubendorf L, Edelman M. J, Marchetti A, Mok5 T, Novello S, O’Byrne K, Stahel, S. Peters R, Felip E \& Panel Members. Second ESMO consensus conference on lung cancer: pathology and molecular biomarkers for non-small-cell lung cancer ;Annals of Oncology 25: 1681-1690, 2014.

[13.] Murrey and nadal's trxt book of respiratory medicine. Fifth edition.

[14.] NCCN Guidelines for Patients. Lung Cancer Screening, Version 1.2014

[15.] Ordóñez NG: Value of thyroid transcription factor-1, E-c adherin, BG8, WT1, and CD44S immunostaining in distinguishing epithelial pleural mesothelioma from pulmonary and nonpulmonary adenocarcinoma. Am J Surg Pathol 24:598-606, 2000

[16.] Ou SH, Zell JA. Carcinoma NOS is a common histologic diagnosis and is increasing in proportion among non-small cell lung cancer histologies. J Thorac Oncol 2009;4:1202-1211

[17.] Pham DK, Kris MG, Riely GJ. Use of cigarette-smoking history to estimate the likelihood of mutations in epidermal growth factor receptor gene exons 19 and 21 in lung adenocarcinomas. J Clin Oncol 2006; 24: 1700-1704.

[18.] Rossi G, Pelosi G, Graziano P, Barbareschi M, Papotti M. A reevaluation of the clinical significance of histological subtyping of non-small-cell lung carcinoma: diagnostic algorithms in the era of personalized treatments. Int J Surg Pathol 2009;17:206-218

[19.] Sequist LV, Joshi VA, Janne PA, Muzikansky A, Fidias P, Meyerson M, Haber DA, Kucherlapati $\mathrm{R}$, Johnson BE, Lynch TJ: Response to treatment and survival of patients with non-small cell lung cancer undergoing somatic EGFR mutation testing. Oncologist 2007, 12:90-98

[20.] Shanmugapriya Shankar, Vijayalakshmi Thanasekaran1, Dhanasekar1 T, Prathiba Duvooru, Clinicopathological and immunohistochemical profile of non-small cell lung carcinoma in a tertiary care medical centre in South India. Lung India • Vol 31 • Issue 1 • Jan - Mar 2014

[21.] Sheikh HA, Fuhrer K, Cieply K, Yousem S. p63 expression in assessment of bronchioloalveolar proliferations of the lung. Mod Pathol 2004;17:1134-40.

[22.] Sheppard MN: Specific markers for pulmonary tumours. Histopathology 36:273-276, 2000

[23.] Stenhouse G, Fyfe N, King G, Chapman A, Kerr K M. Thyroid transcription factor 1 in Pulmonary adenocarcinoma; J Clini Pathol 2004; 57:383-387.

[24.] Swerdlow AJ, Peto R, Doll R. Epidemiology of cancer. In: Oxford Textbook of Medicine. Oxford, UK: Oxford University Press; 2010:299-332.

[25.] Travis WD, Rekhtman N, Riley GJ, et al. Pathologic diagnosis of advanced lung cancer based on small biopsies and cytology: a paradigm shift. J Thorac Oncol 2010;5:411-414. 
[26.] Tsao AS, Tang XM, Sabloff B. Clinicopathologic characteristics of the EGFR gene mutation in non-small cell lung cancer. J Thorac Oncol 2006; 1: 231-239.

[27.] Valsamo K. Anagnostou, Konstantinos N. Syrigos, Gerold Bepler, Robert J. Homer, and David L. Rimm. Thyroid Transcription Factor 1 Is an Independent Prognostic Factor for Patients With Stage I Lung Adenocarcinoma; JOURNAL OF CLINICAL ONCOLOGY:VOLUME 27:NUMBER 2:JANUARY 102009.

[28.] Zhou C, Wu YL, Chen G. Erlotinib versus chemotherapy as first-line treatment for patients with advanced EGFR mutation-positive non small-cell lung cancer (OPTIMAL, CTONG-0802): a multicentre, open-label randomized phase 3 study. Lancet Oncol 2011; 12: 735-742 


\title{
Acute Left Ventricular Failure in Cocaine Abused Young Patient: Case Report
}

\author{
Article by Naresh Sen ${ }^{1}$, Dr. Sonal Tanwar ${ }^{2}$ \\ ${ }^{1 .}$ Narayana Hrudayalaya Institute of Cardiac Sciences, Bangalore (India) \\ Email id:drnaresh.sen@gmail.com \\ 2. Anand Multispeciality Hospital, Beawar, Rajasthan (India) \\ Email id:drtanwarsonal@gmail.com
}

\begin{abstract}
Background: Cocaine is responsible for LV systolic dysfunction in patients (long-term users or with acute intoxication). The mechanism leading to develop cocaine-induced cardiomyopathy is not completely understood, however development of a coronary thrombus, increased oxidative stress, calcium flux sympathomimetic effects are contributing factors in its pathophysiologic formation.

Case Report: A 23 year old B.Tech third year student from top of north India was admitted in cardiac emergency department with complaint of severe breathlessness and pink frothy sputum. ECG showed sinus tachycardia, hyperacute T waves without any ST elevation and depression or $T$ wave inversion. He denied previous history of hypertension, diabetes, thyroid, asthma or tuberculosis and trauma or surgery. He stated us his personal history about cocaine abuser almost 7 years 6 to 8 times per month. On examination he was hypertensive and tachycardic with low Oxygen saturation (70\%). Lab data showed an elevated Brain natriuretic peptide; urine toxicology was positive for cocaine. 2Dechocardiography showed dilated left ventricle with poor LV systolic function LVEF-30\%. Coronary angiography revealed LAD spasm without any obstructive lesions, subsequently NTG infusion was given and final result was TIMI 3 flow in coronaries. He was managed medically and subsequently discharged with drug rehabilitation. On follow-up diagnostic evaluation after 6 months of cocaine cessation, his ejection function improved significantly.

Conclusion: Cocaine is a potent sympathomimetic agent associated with the development of possible fatal cardiovascular complications. Hypertension, Dilated cardiomyopathy, Dysrhythmias and Acute myocardial infarction are just some of many cardiovascular effects related to the abuse of cocaine. The management is like other forms of cardiomyopathy; however $\beta$-blockers should be avoided. Non-invasive testing should be performed after several months to re-evaluate the treatment response.
\end{abstract}

Keywords: Cocaine, Left Ventricle Systolic dysfunction, Heart Failure

\section{Introduction}

More than 14 million people worldwide, mostly within the age range of 15 to 64 years, consume cocaine. Men of 15-35 years represent the majority. Dose-dependent tachycardia, hypertension along with increased arousal is the first physiological response to cocaine use. Performance improvement, attentiveness, sense of positive self-image and euphoria often accompany the cumulative use of cocaine. End-organ-damage associated with cocaine can affect almost every organ system. Cocaine results in a gradual addiction due to its vigorous sympathomimetic features with possible destructive cardiovascular effects. Dysrhythmias, acute myocardial infarction, myocarditis, hypertension, endocarditis, hypotensive shock, cerebral vascular accidents and dilated cardiomyopathy are several cardiovascular complications due to cocaine abuse [1]. Cocaine blocks the presynaptic dopamine and catecholamine uptake, resulting in post-synaptic sympathetic stimulation and dopaminergic receptor activation [2]. Peripheral vasoconstriction results in hypertension, tachycardia and an increase in afterload. Arrhythmias are likely to occur due to the altered autonomic action and 
South American Journal of Medicine

Volume 4, Issue 1, 2016

cardiovascular resistance results in a decreased myocardial blood supply [3]. Negative inotropic events can also occur from cocaine abuse. Hypertrophy of the left ventricle and cardiomyopathy with significant reduction of the ejection fraction has been described in the setting of chronic cocaine consumption. Myocardial hypertrophy is likely to occur secondary to the temporary blood pressure elevation after cocaine use [4]. Smoking and alcohol use exacerbate the cardiotoxic impact of cocaine [5].

\section{Case report}

A 23 year old B.Tech third year student from top of north India was admitted in cardiac emergency department with complaint of severe breathlessness and pink frothy sputum last 6 hrs. ECG showed normal sinus rhythm, hyperacute T waves without any ST elevation and depression or $\mathrm{T}$ wave inversion. He denied previous history of hypertension, diabetes, thyroid, asthma or tuberculosis, trauma or surgery. He stated us about his personal history, about cocaine abuser almost 7 years 6 to 8 times per month. He denied for alcohol taking and any iv drugs or smoking.

On examination, Initial vital signs revealed a tachycardia (heart rate: 123 beats per minute) and hypertension (blood pressure: 180/110 $\mathrm{mmHg}$ ) patient, with peripheral oxygen saturation of $70 \%$, Respiratory rate was $33 / \mathrm{min}$ and body temperature was 98.2 degree F. On General physical examination, no pallor, no icterus, no cyanosis, no clubbing, no lymphadenopathy but jugular venous pressure was raised. Cardiovascular system revealed S1 slightly loud due to tachycardia and S2 was normal and LV S3 sound was there due to LV dysfunction with 2/6 systolic murmur at mitral valve area with radiation to the left axilla and on lung examination there were significant bilateral diffuse crepts found. Electrocardiogram on admission showed sinus tachycardia, left ventricular hypertrophy and hyperacute $\mathrm{T}$ wave in V1, V2 with nonspecific ST abnormalities over the anterior wall leads. Chest X-ray (Figure 1A) showed bilateral patchy opacities representing pulmonary edema. 2D Echocardiography (Figure 1B) revealed moderate left ventricle dilation (left ventricular end diastolic dimension LVEDD of $5.9 \mathrm{~cm}$ and LVESD of $4.8 \mathrm{~cm}$, Figure 3A) without signs of apical ballooning; moderate global hypokinesis of the left ventricle with an ejection fraction of 30\% (Figure 3A), Grade III diastolic dysfunction and mild to moderate mitral regurgitation [1-6].

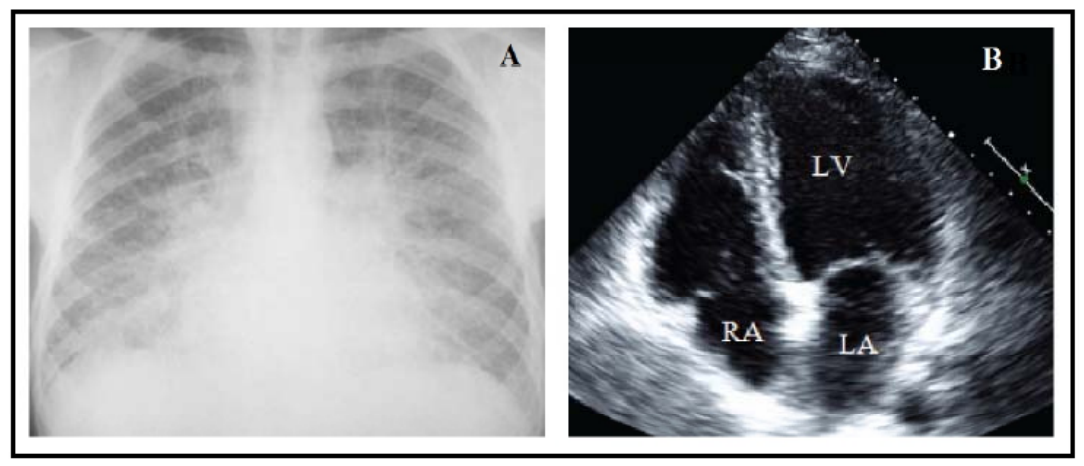

Figure-1 A. Chest X-Ray showed Cardiomegaly with Acute Pulmonary Edema, B. 2D Echo revealed dilated Left Ventricle with systolic dysfunction

Immediately he was treated aggressively for acute pulmonary edema, he was kept on high $\mathrm{O} 2$ and BiPap (non invasive ventilator). Initially we started iv diuretic and iv NTG infusion with small dose of morphine for high blood pressure and pulmonary edema. Initial laboratory workup at admission was insignificant except for elevated brain nautriuretic peptide of 894 $\mathrm{ng} / \mathrm{L}$ and positive urine toxicology screen for cocaine. Due to his recent use of cocaine $\beta$ blockers were not used to control the hypertension however we opted to use amlodipine 10 mg daily instead. Pulmonary team was consulted; the impression was consistent with pulmonary edema from questionable congestive heart failure (CHF), which could have been from the history of cocaine use rather than a primary pulmonary cause. The recommendations 
included initiating a treatment with a diuretic agent, vasodilators and obtaining 2D Echocardiography. The cardiology team has decided for further recommendations, cardiac catheterization and the possibility of implantable cardioverter defibrillator (ICD) placement. The patient was taken for cardiac catheterization on hospital day 2 to rule out ischemic cardiomyopathy which revealed $\mathrm{LAD}$ (left anterior descending coronary spasm without any obstructive lesions( Figure 4A). Subsequently NTG infusion was given and final result was normal TIMI 3 flow was there in LAD. (Figure 4B )

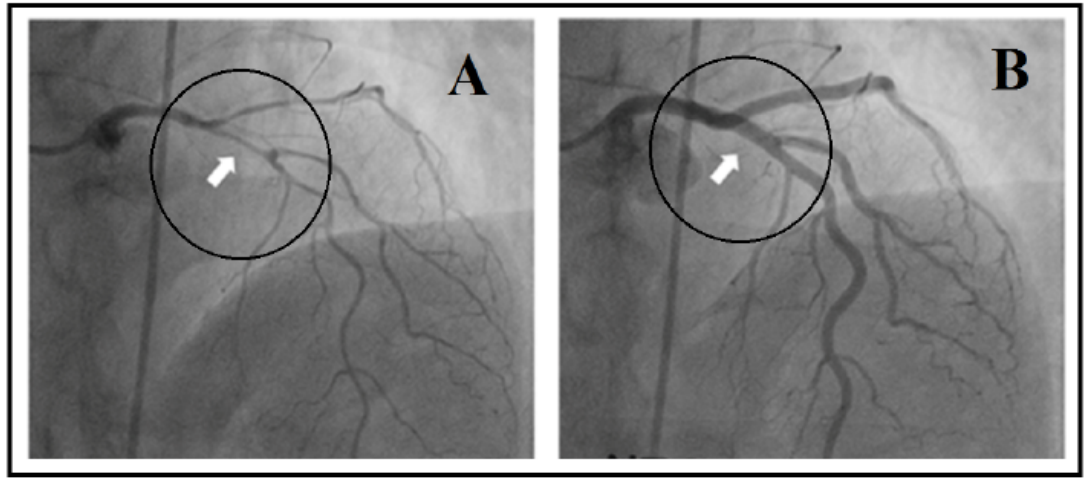

Figure-2 A. Coronary Angiography revealed Left Anterior Descending Coronary Spasm. B. Coronary Angiography revealed became normal TIMI flow after NTG IV infusion.

Management consisted of Amlodipine $10 \mathrm{mg}$ daily, Furosemide $40 \mathrm{mg}$ twice daily, Spironlectone $50 \mathrm{mg}$ once daily, Hydralazine $10 \mathrm{mg}$ daily and Ramipril $10 \mathrm{mg}$ daily. By the 4th day he was clinically asymptomatic and the pulmonary examination was unremarkable. Repeat chest $\mathrm{x}$-ray showed almost complete resolution of bilateral patchy airspace consolidation phenomena however with some bibasilar persistence. An association between his symptoms and the binge consuming of cocaine was established. Cardiac biopsy was not recommended at this time. Re-evaluation of all the above findings including reconsidering a cardiac biopsy 6 months after the discharge was arranged. On the 5th day, the psychiatry service counseled the patient; he agreed to undergo a rehabilitation course in an inpatient institution. On the following day he was transferred to the rehabilitation center on his CHF medications.

Six months later and after successful completing of the treatment course at the rehabilitation center the patient was re-evaluated. Chest Xray showed no cardiomegaly and clear lungs(Figure 2A). Repeat 2D echocardiography was performed and showed normal LV size(Figure 2B), an improved ejection fraction from 30\% to 59\%, improvement of the previously dilated size of the left ventricle (LVEDD from $6.3 \mathrm{~cm}$ to $5.3 \mathrm{~cm}$ and LVESD from $4.8 \mathrm{~cm}$ to $3.7 \mathrm{~cm}$ ) Figure $3 \mathrm{~A}, 3 \mathrm{~B}$. The clinical condition was remarkably better, echocardiographic geometric changes partially resolved. Beta-blocker was added; cardiac biopsy was not done. Evidences for the strong association between previous cocaine abuse and newly diagnosed CHF were clinically confirmed. 


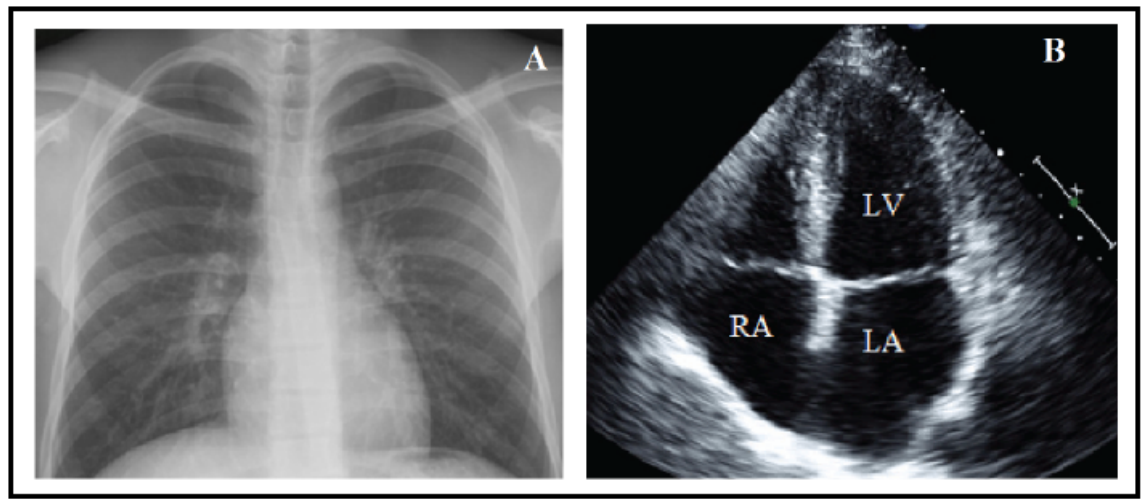

Figure-3 A. Chest X-Ray showed No Cardiomegaly with clear lungs B. 2D Echo revealed Normal Left Ventricle with good systolic function

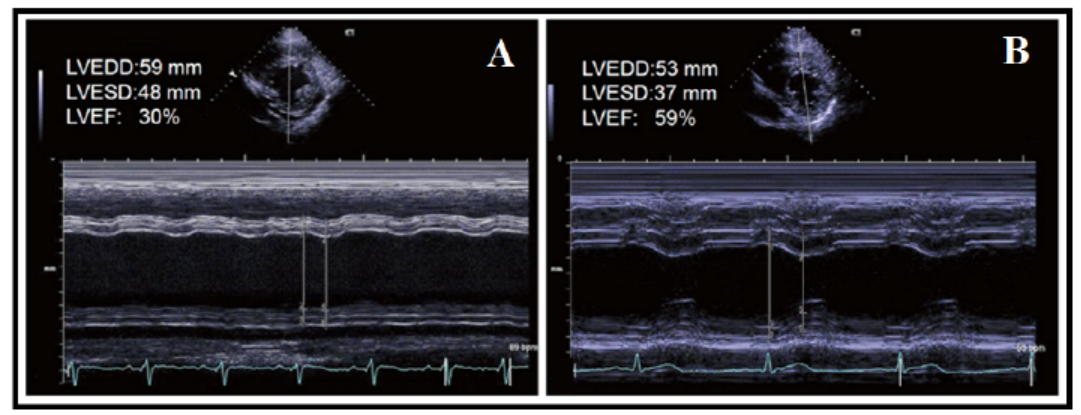

Figure-4 A. 2D Echo M Mode revealed Dilated Left Ventricle with systolic dysfunction(LVEF-30\%) B. 2D Echo M Mode revealed Normal Left Ventricle with systolic function(LVEF-59\%)

\section{Discussion}

Cocaine stimulates the sympathetic nervous system by inhibiting catecholamine reuptake at sympathetic nerve terminals, stimulating central sympathetic outflow, and increasing the sensitivity of adrenergic nerve endings to norepinephrine [7-8]. Cocaine also acts like a class I antiarrhythmic agent (local anesthetic) by blocking sodium and potassium channels, which depresses cardiovascular parameters. [9] Of these 2 primary, opposing actions, enhanced sympathetic activity predominates at low cocaine doses, whereas the local anesthetic actions are more prominent at higher doses. [8] In addition, cocaine stimulates the release of endothelin-1, a potent vasoconstrictor, from endothelial cells[10] and inhibits nitric oxide production, the principal vasodilator produced by endothelial cells. [11] Cocaine promotes thrombosis by activating platelets, [12-13] increasing platelet aggregation, [12, 14] increasing platelet $\alpha$-granule release, $[12,15]$ increasing plasminogen activator inhibitor activity. [16]

Cocaine increases myocardial oxygen demand by increasing both heart rate and blood pressure. $[17,18]$ The influence of cocaine on heart rate and blood pressure is dose dependent and is mediated through $\alpha$-adrenergic stimulation. [17, 18] At the same time, cocaine decreases oxygen supply via coronary vasoconstriction. Cocaine-induced coronary vasoconstriction occurs in normal (nondiseased) coronary artery segments but is more pronounced in atherosclerotic segments. [19] Combining cocaine use with cigarette smoking has additive effects on coronary vasoconstriction while markedly increasing the rate-pressure product. Long-term cocaine users demonstrate coronary endothelial dysfunction. [20, 21]. Because endothelial dysfunction increases the sensitivity of a vessel to the constrictor effects of catecholamines, [22] it may be particularly detrimental for cocaine users. Even in the absence of epicardial coronary disease, cocaine causes microvascular disease[23, 24] and is associated with thrombosis. [25, 26]

Cocaine causes systolic and diastolic dysfunction, arrhythmias, and atherosclerosis. Cocaine decreases myocardial contractility and ejection fraction by blocking sodium and 
potassium channels within the myocardium. [27] Intracoronary infusion of cocaine decreases left ventricular ejection fraction and increases left ventricular end-diastolic pressure and endsystolic volume.[28] Long-term cocaine use is associated with left ventricular hypertrophy and prolonged deceleration time. [29, 30] Cocaine prolongs the PR, QRS, and QT intervals. $[31,32]$ Cocaine is associated with coronary atherosclerosis even in young users with relatively few cardiac risk factors. [33, 34] Cocaine causes systolic dysfunction in long-term users and with acute intoxication. In a dog model, acute cocaine intoxication caused left ventricular dilation, decreased contractility, and increased end-diastolic pressure. [35] Rabbits demonstrated regional wall motion abnormalities (mostly anteroseptal) associated with decreased left ventricular fractional shortening and increased systolic dimension in response to acute cocaine intoxication. [36] After 2 weeks of abstinence from cocaine, 6 of 84 (7\%) asymptomatic cocaine users (mean age, 36 years) had an ejection fraction $<55 \%$.[37] In 33 cocaine-using patients undergoing coronary angiography (indication: chest pain, 28; congestive heart failure, 4$)$, ejection fraction was abnormal in 18 patients $(55 \%)$ and $\leq 30 \%$ in 6 patients (18\%).[33] Moreover, 4 patients had an ejection fraction $<30 \%$ with global hypokinesis. Dilated cardiomyopathy is more common among cocaine users, [34] but a case of left ventricular apical ballooning (Takotsubo cardiomyopathy) has also been described. [38] In a registry including 83 hospitals nationally, stimulant drug use (96\% cocaine, $5 \%$ methamphetamine) was self-reported in 594 of 11258 patients (5.3\%) who presented to the emergency department with acute decompensated heart failure. [39] Patients with stimulant drug use were more likely to have $\geq 3$ hospitalizations within 6 months ( $28 \%$ versus $11 \%$ ) and had lower ejection fractions (median, $23 \%$ versus $40 \%$ ).

Acute cocaine intoxication decreases myocardial contractility and ejection fraction[27, 28] and increases left ventricular end-diastolic pressure and end-systolic volume. [28] Long-term cocaine use is associated with left ventricular hypertrophy and prolonged deceleration time. [30] The pathophysiology of cocaine-associated cardiomyopathy, however, remains unclear. Of 18 cocaine users undergoing coronary angiography with an ejection fraction $<55 \%, 12$ had coronary artery disease and regional wall motion abnormalities suggesting recent or remote MI; however, 6 did not have coronary artery disease and demonstrated global hypokinesis (4 of 6 with an ejection fraction $<30 \%$ ). [33] Thus, a manifestation of coronary artery disease can explain cocaine-induced ventricular dysfunction in some patients, but cocaine also has a direct toxic effect on cardiac myocytes. Factors contributing to cocaine-induced cardiomyopathy may include the blocking of sodium and potassium channels within the myocardium, alterations in calcium ion handling, [28] myocardial inflammation with necrosis and fibrosis, left ventricular hypertrophy, [29, 30] alterations in gene expression, [39] and concomitant alcohol consumption. [33]

Cessation of cocaine is the primary therapeutic goal in cocaine-induced cardiomyopathy. Cocaine-induced heart failure improved dramatically with cessation of cocaine and recurred with resumption of cocaine. [34] As with CACP, medical therapy for cocaine-induced heart failure and cardiomyopathy should follow published guidelines, except all $\beta$-blockers should be avoided in the acute setting. Thereafter, $\beta$-blockers should be considered for each patient individually, after careful risk-benefit assessment, and maybe after cocaine cessation has been documented. Continued cocaine use precludes eligibility for cardiac transplantation.

\section{Learning path}

Cocaine use should be considered if young patients presented with heart failure, mainly without other underlying risk factors. It is important to counsel these patients regarding the deleterious effects of cocaine abuse and the potential reversal of cardiac dysfunction with abstaining from the cocaine use. The unfavorable economic impact and awareness of the possible cardiovascular effects should be considered during the initial evaluation when young adults with heart failure for medical assessment. 
South American Journal of Medicine

Volume 4, Issue 1, 2016

\section{Conclusion}

Cocaine is a potent sympathomimetic agent associated with the development of possible fatal cardiovascular complications. Hypertension, Dilated cardiomyopathy, Dysrhythmias and Acute myocardial infarction are just some of many cardiovascular effects related to the abuse of cocaine. The therapy of cocaine-induced cardiomyopathy is similar to the way that other types of cardiomyopathy are managed. Beta-blockers should not be considered initially; benzodiazepine is preferred to counteract the adrenergic effect. In the acute setting the addition of beta-blockers will adversely result in the alpha-adrenergic receptors being unopposed, therefore leading to coronary vasoconstriction, left ventricle wall stress and a hypertensive crisis. As recommended in other types of cardiomyopathy, pharmacological agents such as, diuretics, Angiotensin-Converting-Enzyme Inhibitors, Angiotensin-Receptor Blocker, vasodilators, or digoxin should be initially included. Cessation of cocaine is the primary goal of postdischarge therapy. The use of cocaine should be investigated in patients with cardiovascular disease, especially young patients, because its presence may influence disease diagnosis, management, and therapy. Non-invasive testing should be performed after several months to re-evaluate the treatment response.

\section{Acknowledgements}

I would like to thank to Prof. George cherian HOD in Cardiology at Narayana Hrudayalaya, Bangalore who gave support and concern about learning and also I thank to Editor of Texila American University or Academic department for continous learning.

\section{References}

[1.] Abraham JR, Butany J, Leong S, Luk A, Phillips K, Soor GS. Cocaine cardiotoxicity a review of the pathophysiology, pathology, and treatment options. Am J Cardiovasc Drugs. 2009;9(3):177-196. doi: 10.1007/BF03256574.

[2.] Afonso L, Mohammad T, Thatai D. Crack whips the heart: a review of the cardiovascular toxicity of cocaine. Am J Cardiol. 2007;100:1040-1043. doi: 10.1016/j.amjcard.2007.04.049.

[3.] Arora S, Alfayoumi F, Srinivasan V. Transient left ventricular apical ballooning after cocaine use: is catecholamine cardiotoxicity the pathologic link? Mayo Clin Proc. 2006; 81: 829- 832.

[4.] Aslibekyan S, Levitan EB, Mittleman M. Prevalent cocaine use and myocardial infarction. Am J Cardiol. 2008; 102: 966-969.

[5.] Bertolet BD, Freund G, Martin CA, Perchalski DL, Williams CM, Pepine CJ. Unrecognized left ventricular dysfunction in an apparently healthy cocaine abuse population. Clin Cardiol. 1990; 13: $323-328$.

[6.] Brickner ME, Willard JE, Eichhorn EJ, Black J, Grayburn PA. Left ventricular hypertrophy associated with chronic cocaine abuse. Circulation. 1991; 84: 1130-1135.

[7.] Carrillo J, Marmol-Velez A, Martinez S, Restrepo CS, Riascos R, Rojas CA, Vargas D. Cardiovascular complications of cocaine: imaging findings. Emerg Radiol. 2009;16:11-19. doi: 10.1007/s10140-008-0762-X.

[8.] Diercks DB, Fonarow GC, Kirk JD. Illicit stimulant use in a United States heart failure population presenting to the emergency department (from the Acute Decompensated Heart Failure National Registry Emergency Module). Am J Cardiol.2008; 102: 1216- 1219.

[9.] Egashira K, Morgan KG, Morgan JP. Effects of cocaine on excitation-contraction coupling of aortic smooth muscle from the ferret. J Clin Invest. 1991;87: 1322- 1328.

[10.] Figueredo VM. Chemical cardiomyopathies: the negative effects of medications and nonprescribed drugs on the heart. Am J Med. 2011;124:480-488. doi: 10.1016/j.amjmed.2010.11.031.

[11.] Figueredo VM, Maraj S, Morris DL. Cocaine and the heart. Clin Cardiol. 2010;33(5):264-269. doi: 10.1002/clc.20746.

[12.] Fischman MW, Schuster CR, Resnekov L, Shick JF, Krasnegor NA, Fennell W, Freedman DX. Cardiovascular and subjective effects of intravenous cocaine administration in humans. Arch Gen Psychiatry. 1976; 33: 983- 989. 
[13.] Flores ED, Lange RA, Cigarroa RG, Hillis L. Effect of cocaine on coronary artery dimensions in atherosclerotic coronary artery disease: enhanced vasoconstriction at sites of significant stenoses. J Am Coll Cardiol. 1990; 16: 74-79.

[14.] Fraker TD Jr, Madu EC, Mouhaffel AH, Satmary WA. Cardiovascular complications of cocaine. Chest. 1995;107(5):1426-1434. doi: 10.1378/chest.107.5.1426.

[15.] Gardin JM, Wong N, Alker K, Hale SL, Paynter J, Knoll M, Jamison B, PattersonM, Kloner R. Acute cocaine administration induces ventricular regional wall motion and ultrastructural abnormalities in an anesthetized rabbit model. Am Heart J. 1994; 128: 1117- 1129.

[16.] Hale SL, Alker KJ, Rezkalla S, Figures G, Kloner RA. Adverse effects of cocaine on cardiovascular dynamics, myocardial blood flow, and coronary artery diameter in an experimental model. Am Heart J. 1989; 118: 927-933.

[17.] Hale SL, Alker KJ, Rezkalla SH, Eisenhauer AC, Kloner RA. Nifedipine protects the heart from the acute deleterious effects of cocaine if administered before but not after cocaine. Circulation. 1991; 83: $1437-1443$.

[18.] Hale SL, Lehmann MH, Kloner RA. Electrocardiographic abnormalities after acute administration of cocaine in the rat. Am J Cardiol. 1989; 63: 1529- 1530.

[19.] Havranek EP, Nademanee K, Grayburn PA, Eichhorn EJ. Endothelium-dependent vasorelaxation is impaired in cocaine arteriopathy. J Am Coll Cardiol.1996; 28: 1168- 1174.

[20.] Heesch CM, Wilhelm CR, Ristich J, Adnane J, Bontempo FA, Wagner WR. Cocaine activates platelets and increases the formation of circulating platelet containing microaggregates in humans. Heart. 2000; 83: 688- 695.

[21.] Kelly RF, Sompalli V, Sattar P, Khankari K. Increased TIMI frame counts in cocaine users: a case for increased microvascular resistance in the absence of epicardial coronary disease or spasm. Clin Cardiol. 2003; 26: 319- 22.

[22.] Kugelmass AD, Oda A, Monahan K, Cabral C, Ware JA. Activation of human platelets by cocaine. Circulation. 1993; 88: 876-883.

[23.] Lange RA, Cigarroa RG, Yancy CW Jr., Willard JE, Popma JJ, Sills MN, McBrideW, Kim AS, Hillis LD. Cocaine-induced coronary-artery vasoconstriction. N Engl J Med. 1989; 321: 1557- 1562.

[24.] Mo W, Singh AK, Arruda JA, Dunea G. Role of nitric oxide in cocaine-induced acute hypertension. Am J Hypertens. 1998; 11: 708- 714.

[25.] Moliterno DJ, Willard JE, Lange RA, Negus BH, Boehrer JD, Glamann DB, Landau C, Rossen JD, Winniford MD, Hillis LD. Coronary-artery vasoconstriction induced by cocaine, cigarette smoking, or both. N Engl J Med. 1994; 330: 454-459.

[26.] Moliterno DJ, Lange RA, Gerard RD, Willard JE, Lackner C, Hillis LD. Influence of intranasal cocaine on plasma constituents associated with endogenous thrombosis and thrombolysis. Am J Med. 1994; 96: 492- 496.

[27.] Om A, Warner M, Sabri N, Cecich L, Vetrovec G. Frequency of coronary artery disease and left ventricle dysfunction in cocaine users. Am J Cardiol. 1992; 69:1549- 1552.

[28.] Pitts WR, Vongpatanasin W, Cigarroa JE, Hillis LD, Lange RA. Effects of the intracoronary infusion of cocaine on left ventricular systolic and diastolic function in humans. Circulation. 1998; 97: $1270-1273$.

[29.] Przywara DA, Dambach GE. Direct actions of cocaine on cardiac cellular electrical activity. Circ Res. 1989; 65: 185- 192.

[30.] Rezkalla SH, Mazza JJ, Kloner RA, Tillema V, Chang SH. Effects of cocaine on human platelets in healthy subjects. Am J Cardiol. 1993; 72: 243- 246.

[31.] Rinder HM, Ault KA, Jatlow PI, Kosten TR, Smith BR. Platelet alpha-granule release in cocaine users. Circulation. 1994; 90: 1162-1167.

[32.] Tazelaar HD, Karch SB, Stephens BG, Billingham ME. Cocaine and the heart. Hum Pathol. 1987; 18: 195- 199 .

[33.] Tong W, Lima JA, Meng Q, Flynn E, Lai S. Long-term cocaine use is related to cardiac diastolic dysfunction in an African-American population in Baltimore, Maryland. Int J Cardiol. 2004; 97: 2528. 
South American Journal of Medicine

Volume 4, Issue 1, 2016

[34.] Vita JA, Treasure CB, Fish D, Yeung AC, Vekshtein VI, Ganz P Selwyn AP Endothelial dysfunction leads to increased coronary constriction to catecholamines in patients with early atherosclerosis. J Am Coll Cardiol. 1990; 15: 158A.

[35.] Virmani R, Robinowitz M, Smialek JE, Smyth DF. Cardiovascular effects of cocaine: an autopsy study of 40 patients. Am Heart J. 1988; 115: 1068- 1076.

[36.] Vongpatanasin W, Mansour Y, Chavoshan B, Arbique D, Victor RG. Cocaine stimulates the human cardiovascular system via a central mechanism action. Circulation. 1999; 100: 497- 502.

[37.] Wilbert-Lampen U, Seliger C, Zilker T, Arendt RM. Cocaine increases the endothelial release of immunoreactive endothelin and its concentrations in human plasma and urine: reversal by coincubation with sigma-receptor antagonists. Circulation. 1998; 98: 385-390.

[38.] Weber JE, Hollander JE, Murphy SA, Braunwald E, Gibson CM. Quantitative comparison of coronary artery flow and myocardial perfusion in patients with acute myocardial infarction in the presence and absence of recent cocaine use. J Thromb Thrombolysis. 2002; 14: 239- 245.

[39.] Willens HJ, Chakko SC, Kessler KM. Cardiovascular manifestations of cocaine abuse: a case of recurrent dilated cardiomyopathy. Chest. 1994; 106: 594- 600. 


\title{
Literacy of Autism Spectrum Disorder (ASD) among Clinical Year Medical Students in Malaysia
}

\author{
Article by Roy Rillera Marzo ${ }^{1}$, Samantha Wong LiySyen², Sylvia Sutharsana ${ }^{2}$ \\ ${ }^{1}$ Deputy Dean, Master in Public Health, Fellow in Public Health \\ ${ }^{2}$ Faculty of Medicine, Masterskill University College of Health Sciences \\ Email: rrmtexas@yahoo.com
}

\begin{abstract}
Objective: This study was carried out to assess the literacy of Autism Spectrum Disorder among clinical year medical student in Malaysia.

Methodology: This was a quantitative approach study in which the data was assessed cross-sectional and descriptively. The target population of this study was clinical year medical students from private and public universities. The data was collected through the method of multi-stage sampling which includes cluster and simple random sampling.

Results: Of the 210 clinical year medical students that responded to our study, 70(33.3\%) were males and 140(66.7\%) were females. There were more students from private universities 179(85.2\%) compared to public universities 31(14.8\%). The total mean score on belief about autism was $3.84 \pm 1.36$ out of the maximum 7. There were only 6 (2.9\%) out of 210 students who considered to have no misconception on ASD. The total mean score on knowledge was $12.93 \pm 3.56$ out of 19 . It was reported that only 3 (1.4\%) students out of 210 considered to have adequate knowledge. The findings in this study showed that there was lack of appropriate attitude of the clinical year medical students towards autistic individuals.

Conclusion: The recognition of the clinical year medical students in Malaysia regarding ASD is low as we can see that there are only $2.9 \%$ of the students have accurate belief and $1.4 \%$ of students have adequate knowledge about ASD. There are $85.7 \%$ of the students who see the autistic individual as normal individual, which to say that there are still presence of $14.3 \%$ who see them as abnormal. Thus, this shows that there are still certain level of stigmatization or discrimination which occurred. Belief and attitudes toward autistics can be improved in such a way that medical students would be exemplary to the public on the way autistics should be treated. Ignorance is due to the lack of knowledge thus, medical students should be equipped to educate the public regarding autism to eliminate the existing ignorance that can be seen in the public's attitude towards autism.
\end{abstract}

Keywords: Autism Spectrum Disorder, Medical Students, Knowledge, Belief, Attitude.

\section{Introduction}

The word autism originated from the Greek word "autos" which means "self". The term describes status in which a specific person is removed from social interaction hence, an isolated self. Eugen Bleular, a Swiss psychiatrist, first produced the word to define the symptoms of schizophrenia back in 1911. Eventually the term "autism" was used to describe children with emotional or social problems in the 1940s. A doctor, Leo Kanner from Johns Hopkins University described autism as developmental disease which is present from birth and withdrawn behaviour of several children he studied. Meanwhile, a scientist in Germany, Hans Asperger identified a similar condition that is now called Asperger's Syndrome.

So what is Autism anyways? Autism is more suitable to be known as Autism Spectrum Disorder (ASD) as it describes a range of complex neurodevelopmental conditions. This disorder is characterized by impaired social interaction, verbal and non-verbal communication, restricted interest and repetitive behaviour. In the 2013 fifth edition of the Diagnostic and Statistical Manual of Mental Disorder (DSM-5), the diagnosis of ASD which several disorders were previously diagnosed distinctly were combined into one umbrella 
South American Journal of Medicine

Volume 4, Issue 1, 2016

diagnosis of ASD. The disorders are comprised of autistic disorder, pervasive developmental disorder-not otherwise specified (PDD-NOS), childhood disintegrative disorder and Asperger syndrome.

To date, there is no known cause of ASD. There are scientists suggested that mutations or rare gene changes are associated with ASD, over the past few years. Rarely, these conditions can cause autism by themselves. However, ASD is more commonly caused by a conjunction of autism risk genes and environmental factors that may influenced the early brain development.

On the other hand, there are presence of non-genetic factors that can elevate an individual's risk such as events before and during birth. These comprise gestational diseases, advanced parental age during time of conception and certain labour and delivery complications, especially in circumstances that may cause baby's brain oxygen deprivation. These conditions are not sufficiently to cause ASD by themselves. In contrast, the risk can be increased moderately if these non-genetic conditions present in addition with the genetic risk factors.

In addition, there are debates about linkage of vaccination and ASD in which some people have the belief that vaccines provided to children may causes ASD. Therefore, there are several studies that involved the evaluation of vaccine ingredients and the amount of antigen in the vaccines received among the autistic and non-autistic children. However, these studies have shown to overturn the belief as vaccines does not cause in developing ASD.

Besides, each autistic individual is affected differently. Some of them are able to live independently and some may have learning disabilities which require a lifetime support from specialists. They may also experience some form of sensory sensitivity or under-sensitivity, for instance to sound, touch, taste, smell, lights or colour. Autism is also considered an unseen condition as some may not show obvious characteristics. Hence none of us can always accurately tell whether someone is autistic. Moreover, it is essential to for the public to understand that ASD will not only influence the children, as autistic children can grow up as autistic adult.

In a nutshell, there is a need to achieve an apprehension of ASD among the medical professions, in order to plan a suitable and proper management of the disorder. This research is designed to study the extent of literacy among clinical year medical students towards individual with ASD. There is an importance of the need of them to understand about ASD as they are the doctor-to-be who may encounter autistic patients during their practice. The literacy about ASD can help them to get early diagnosis of ASD and in providing early intervention towards those who are affected. This study may help to improve their awareness and knowledge about ASD.

\section{Incidence and prevalence}

According to studies in Asia, Europe and North America, the average prevalence of individuals diagnosed with ASD are about $1 \%$ of the world population, while study in South Korea reported a prevalence of $2.6 \%$. It should also be noted males show higher risks for having ASD than females. In Malaysia, there is no official registry for the number of children with autism. However, it is estimated that in every 600 children in Malaysia, one out of them is autistic. Recent statistics show that some 47,000 of the people in this country are autistic. This figures are raising by three percent each year (Yayasan Sime Darby, 2014).

\section{Significant of study}

The purpose of the study is to discover the level of knowledge about ASD among the clinical year medical students. Even though early intervention is important, autism is usually diagnosed only when the child reaches school going age in Malaysia. Due to the lack of awareness and knowledge, there may be delay in providing intervention to those affected as this may worsen their condition. Hence, there is a need of raising the understanding and knowledge of medical students about ASD before they start their practice in hospital or clinic settings. 


\section{Objectives}

General Objective:

To assess the literacy of Autism Spectrum Disorder (ASD) among clinical year medical students in Malaysia

Specific Objectives:

1. To identify the beliefs of clinical year medical students regarding ASD

2. To explore the level of knowledge about ASD among clinical year medical students

3. To discover the attitudes of clinical year medical students towards autistic individual

\section{Literature review}

In recent years, the prevalence rates of autism have increased. A California statistics identified a $17.6 \%$ per year increase in the prevalence rates of autism between the birth cohorts of 1990-1992. According to the study of Durand-Zaleski et al., although 95\% respondents recognized the names of each disorder fewer than $70 \%$ could report specific characteristics and only 33\% considered that publically available information was adequate. The study also showed that most public behaviours and attitudes towards different disorders appear to be based on assumptions, sadly, rather than knowledge or evidence. The study highlighted that the stigmatization of public with mental disorders can be changed eventually with certain alterations in knowledge of mental health.

Although research and literacy on ASDs are increasing worldwide, most studies across the world have reported wide variation of awareness among the public on autism. Studies have found that parents of children with autism noticing and then expressing their worries to health professionals, when their children were between the ages of fifteen to nineteen months. In a study done in Karachi, Pakistan, General Practitioners who were lesser than 30 years of age and five or fewer years after acquisition of their medical degrees were found to be more informed and accurate in their understanding of Autism.

Meanwhile in London, studies were done among medical students to assess their level of awareness about childhood autism. Medical students, who are the future healthcare professionals, are responsible for the diagnosis and management of children with autism. It was observed that fourth year medical students were more likely to correctly respond to questions related to diagnostic criteria and core symptoms .The findings suggest that more emphasis should be placed on teaching medical students about childhood autism to enhance early diagnosis and intervention .

Whereas in a study conducted in Karachi, Pakistan to assess the level of awareness among fourth year medical students, it was found that majority of the student could define autism correctly which is deduced to be due to the increment in the exposure of these disorders through relations with peers, television and social medias. Higher mean scores were obtained by public medical students which can be contributed by the accessibility of heterogeneous patients from all socioeconomic classes. The availability and exposure of patients in the public institute give the medical students a possibility to interact with patients from various departments and aggrandize their clinical knowledge.

When it came down to the community, according to a study done in Harbin, China, participants who lived in urban areas and who had contact with ASD cases were more likely to recognize ASD compared to others . Among the participants, 2470 (68.2\%) reported that they would consult a psychotherapist for diagnostic evaluation if they find out that their children cannot speak and make eye contact by two years old.

On the other hand, another study was conducted on the same topic of interest in Alabama, Unites States of America. It appears that recent media attention has successfully raised the level of awareness of the populace. Meanwhile, most of the respondents felt that the government was not spending enough on services for autistic people. Respondents were then asked to rate the level of importance of service areas that represent the need for lifelong necessities and supports to assist individuals and their families. 
Education wise, the public felt that schools should accommodate the facilities needed by students with autism and that the benefits should begin as early in the life of the child as possible. Regarding the arrangement of educational services in inclusive classrooms, the responses were nearly equally divided. This outcome emulates an ongoing debate among special education professionals referring to the right to involve as a full member of the school community and the conceivable need for separation for some forms of comprehensive instructions. In addition to that, our educational system must prepare students with autism and other developmental disabilities to be productive citizens within their communities. As autism is a spectrum disorder, a sequence of career and vocational training, and job opportunities must be made obtainable with the eventual goal being full time ambitious employment.

As a wrap up, in some parts of the world awareness has been raised and attitudes and behaviours towards autism is changing for the betterment of the public. However, studies done worldwide have proven that autism awareness is still in bleak, hence, researches and studies should be done further on the ways to tackle this ignorance among public and show a little more compassion towards autistic people. Schools and employers should make way and special arrangements rather than alienating them instead of accepting them the way they are. Medical students must add on to their knowledge about autism so that in future they would be able to diagnose correctly and provide insights to their future generations. Doctors should provide consultations and better understanding to parents with autistics children or even the public in order to change the negative attitude towards autistic people. Government plays a vital role in that matter and changes are hoped to be seen in the upcoming years.

\section{Methodology}

\section{Study design}

This was a quantitative approach study in which the data was assessed cross-sectional and descriptively. The target population of this study was clinical year medical students from private and public universities. The data was collected through the method of multi-stage sampling which includes cluster and simple random sampling.

\section{Sample population}

The sample size of this study was 210 students. All medical students in Malaysia were encouraged to participate in this study provided that they are currently studying in year 3 and above.

\section{Survey instrument}

A questionnaire was distributed in public and private universities for the purpose of data collection in this study. The answered questionnaire was collected after completion on the spot itself. Before the distribution of the questionnaire to the respective universities, a pre-test was conducted. The pre-test was distributed among 20 clinical year medical students studying in Master skill University College of Health Sciences (MUCH). A reliability test was conducted on the results of the pre-test, which the Cronbach's alpha value obtained was 0.753. This test was analysed by PASW Statistics Student Version 18. The questionnaire was then considered validated.

\section{Questionnaire design}

The components of the questionnaire was adapted and modified from few different sources. The questionnaire consisted of four parts. Part 1 explored the socio-demographic details about the respondents such as the gender, ethnicity, types of institution and education level. Next, Part 2 identified the belief of the respondents about autism which was partly adapted from the study done by Stone. Part 3 was adapted from KCAHW questionnaire created by Bakare et al. to determine the extent of knowledge of the respondents. Last part of the questionnaire, Part 4, assessed the attitudes of the respondents toward autistic individuals. Some item of this part was taken from the study done by Edyvean. 
There were overall of 35 questions in this questionnaire. Part 1 consisted of 4 questions, Part 2 with 7 questions, Part 3 with 19 questions and lastly Part 4 with 5 questions. Part 2 and Part 3 were analysed according to the total scores achieved where the respondents could achieved the maximum score of 7 in Part 2 and 19 in Part 3 or a minimum score of zero in each part.

\section{Data analysis}

The primary data analysis was coded and analysed by PASW Statistics Student Version 18. Descriptive statistics were used to describe the demographic features of the participants and tables, charts, mean and percentages were used to interpret the results.

\section{Ethical consideration}

The protocol was required to be reviewed by Medical Research Ethical Committee (MREC) of MUCH to insure full protection of the rights of study subjects. NMRR (National Malaysian Research Register) registration was carried out after the approval by MREC. Following the acquisition of NMRR registration number, the questionnaires were distributed to the study subjects. To assure the confidentiality of all the information provided, a cover letter was attached with the questionnaire.

\section{Results \& discussion}

Table 1. Socio-demographic of the Clinical Medical Students

\begin{tabular}{|l|l|c|c|}
\hline \multicolumn{2}{|l|}{ Variables } & Frequency (n) & Percentage (\%) \\
\hline \multirow{2}{*}{ Gender } & Male & 70 & 33.3 \\
\cline { 2 - 4 } & Female & 140 & 66.7 \\
\hline Ethnicity & Malay & 45 & 21.4 \\
\cline { 2 - 4 } & Chinese & 70 & 33.3 \\
\cline { 2 - 4 } & Indian & 81 & 38.6 \\
\cline { 2 - 4 } & Others & 14 & 6.7 \\
\hline \multirow{4}{*}{ University } & Public & 31 & 14.8 \\
\cline { 2 - 4 } & Private & 179 & 85.2 \\
\hline \multirow{2}{*}{\begin{tabular}{l} 
Lducation \\
\cline { 2 - 4 }
\end{tabular}} & $3^{\text {rd }}$ Year & 112 & 53.3 \\
\cline { 2 - 4 } & $4^{\text {th }}$ Year & 64 & 30.5 \\
\cline { 2 - 4 } & $5^{\text {th }}$ Year & 34 & 16.2 \\
\hline
\end{tabular}

Data from 210 clinical year medical students in Malaysia was analysed. Table 1 shows the pattern of distribution of socio-demographic variables of the study: gender, ethnicity, type of university and education level. In this study, there were 70 (33.3\%) males and 140 (66.7\%) females. Most of the students were Indians (38.6\%), followed by Chinese (33.3\%), Malays (21.4\%), and others (6.7\%). As shown in the table, there were more students from private universities (85.2\%) compare to the public universities (14.8\%). According to the education level of the respondent, the $3^{\text {rd }}$ year medical students had highest percentage of participation (53.3\%), while the $5^{\text {th }}$ year medical students had the lowest percentage (16.2\%). 
South American Journal of Medicine

Volume 4, Issue 1, 2016

Table 2a.Score Distribution on Belief about Autism

\begin{tabular}{|l|l|l|l|l|}
\hline Scores & Frequency (n) & Percentage (\%) & Total Mean Score & Std. Dev. \\
\hline 0 & 2 & 1.0 & & \\
\cline { 1 - 2 } 1 & 5 & 2.4 & & \\
\hline 2 & 24 & 11.4 & \multirow{3}{*}{3.84} & \multirow{2}{*}{1.36} \\
\hline 3 & 54 & 25.7 & & \\
\cline { 1 - 2 } 4 & 63 & 30.0 & & \\
\hline 5 & 38 & 18.1 & & \\
\hline 6 & 18 & 8.6 & & \\
\hline 7 & 6 & 2.9 & & \\
\hline
\end{tabular}

*Std. Dev.: Standard deviation

Table 3 portrays the numbers and percentages of the scores that the clinical year medical students have achieved on the questionnaire. The total scores ranged from 0 to 7 . An achievement of maximum score of was required to indicate the students to have an accurate belief about autism. However, there were only 6 (2.9\%) out of 210 students who obtained the maximum score. The total mean score on belief about autism was $3.84 \pm 1.36$ out of 7 . The scores are slightly deviated away from the total mean scores by standard deviation of 1.36 . These findings suggest that most of the clinical year medical students had misconception about ASD. This indicates that majority of the population is not familiar with the basic facts about autism as there is lack of exposure on autism and hence lead to limited attention on autism in Malaysia.

Table 2b. Number and Percentage of Correct Responses for Each Item on Belief about Autism

\begin{tabular}{|l|l|l|}
\hline \multirow{2}{*}{ Item } & \multicolumn{2}{|l|}{ Correct Responses } \\
\cline { 2 - 3 } & Frequency (n) & Percentage (\%) \\
\hline 1. Autism is an emotional disorder. (D) & 119 & 56.7 \\
\hline $\begin{array}{l}\text { 2. Vaccines can cause autism in children. } \\
\text { (D) }\end{array}$ & 141 & 67.1 \\
\hline $\begin{array}{l}\text { 3. Males is more frequently diagnosed with } \\
\text { autism compare to females. (A) }\end{array}$ & 125 & 59.5 \\
\hline $\begin{array}{l}\text { 4. Children with autism can grow up to live } \\
\text { independently. (A) }\end{array}$ & 126 & 60.0 \\
\hline $\begin{array}{l}\text { 5. Autism can be cured. (D) } \\
\text { 6. With the proper treatment, most children } \\
\text { with autism will eventually outgrow it. (D) }\end{array}$ & 30 & 37.1 \\
\hline $\begin{array}{l}\text { 7. It is essential for autistic children to } \\
\text { receive special education services. (A) }\end{array}$ & 188 & 14.3 \\
\hline
\end{tabular}

*D: Disagree

*A: Agree

Based on Table 2b, we can observed that majority of the students (89.5\%) were able to answer item 7 ("It is essential for autistic children to receive special education services.") correctly. This finding is in agreement with a study assessing the autism awareness based on the view of campus community by Leigh Ann Tipton et al. In this study, minority of the 
students (14.3\%) were able to response correctly that with proper treatment, most children with autism actually will not eventually outgrow it (Item 6). This is similar to results reported by Stone et al. On the other hand, most of the students believe that autism can be cured (Item 5), in fact, actually autism are non-curable. Although it is non-curable, interventions could be tailored to autistics which may varies among one another. The percentage of the correct responses for this item is stated to be $37.1 \%$. Meanwhile, in the previous study of Leigh and colleagues shows $58.1 \%$ where we noticed that the percentage was approximately decreased to half in our study. The responses for the other items $(1,2,3, \& 4)$ support the findings of their study.

Table 3a. Score Distribution on Knowledge about ASD

\begin{tabular}{|c|c|c|c|c|}
\hline Scores & Frequency (n) & Percentage (\%) & Total Mean Score & Std. Dev. \\
\hline 0 & 1 & 0.5 & \multirow{20}{*}{12.93} & \multirow{20}{*}{3.56} \\
\hline 1 & 2 & 1.0 & & \\
\hline 2 & 1 & 0.5 & & \\
\hline 3 & 2 & 1.0 & & \\
\hline 4 & 2 & 1.0 & & \\
\hline 5 & 2 & 1.0 & & \\
\hline 6 & 1 & 0.5 & & \\
\hline 7 & 2 & 1.0 & & \\
\hline 8 & 8 & 3.8 & & \\
\hline 9 & 8 & 3.8 & & \\
\hline 10 & 10 & 4.8 & & \\
\hline 11 & 20 & 9.5 & & \\
\hline 12 & 26 & 12.4 & & \\
\hline 13 & 20 & 9.5 & & \\
\hline 14 & 31 & 14.8 & & \\
\hline 15 & 26 & 12.4 & & \\
\hline 16 & 21 & 10.0 & & \\
\hline 17 & 10 & 4.8 & & \\
\hline 18 & 14 & 6.7 & & \\
\hline 19 & 3 & 1.4 & & \\
\hline
\end{tabular}

Table 3a depicts the pattern of distribution of the scores on the knowledge about ASD. A total score of 19 was the maximum score possible on questionnaire where the knowledge about ASD is assessed. Besides, the knowledge about ASD is considered to be adequate if only the maximum score is achieved. Therefore, in this study, it was reported that only 3 (1.4\%) students out of 210 considered to have adequate knowledge. The standard deviation of 3.56 indicates that the scores of the students were slightly polarized. The total mean score on the knowledge was $12.93 \pm 3.56$ out of 19 . This value is found out to be closely similar with a study assessing the knowledge about childhood autism among paediatric and psychiatric nurses in Ebonyi state, Nigeria by Monday N Igwe et al. which observed a total mean score of $12.56 \pm 3.23$ out of a total of 19 possible. According to their studies, the total mean score of $12.93 \pm 3.56$ out of 19 is low and is a reflection of deficits in knowledge about autism.

On the basis of the total mean score of $12.93 \pm 3.56$, data was dichotomized into above average and below average. Thus, 85 (40.8\%) students had knowledge below the mean score and 125 (59.2\%) students had higher scores.

Furthermore, the score of 14 out 19 had the highest number of achievers which is 31 (14.8\%). The median score for total knowledge score was 10. It is interesting to note that 171 (81.5\%) students which considered as the majority of the population scored higher than the median score.

However, these findings suggest that the knowledge of the students regarding ASD was considered low according to Monday N Igwe et al. as a maximum score of 19 should be 
South American Journal of Medicine

Volume 4, Issue 1, 2016

achieved in order to be claimed to have adequate knowledge. The strict scoring system can be due to the increasing incidence and prevalence of autism and also the increasing of childhood neuro-developmental disorders being recognized with high demands for earlier diagnosis and intervention.

Table 3b. Scores Distribution on Knowledge about ASD According to Each Domain

\begin{tabular}{|c|c|c|c|}
\hline Domain & Scores & Frequency (n) & Percentage (\%) \\
\hline \multirow{9}{*}{$\begin{array}{l}\text { Domain 1: Impairment in Social } \\
\text { Interaction }\end{array}$} & 0 & 6 & 2.9 \\
\hline & 1 & 6 & 2.9 \\
\hline & 2 & 2 & 1.0 \\
\hline & 3 & 12 & 5.7 \\
\hline & 4 & 16 & 7.6 \\
\hline & 5 & 36 & 17.1 \\
\hline & 6 & 36 & 17.1 \\
\hline & 7 & 44 & 21.0 \\
\hline & 8 & 52 & 24.8 \\
\hline \multirow{2}{*}{$\begin{array}{l}\text { Domain 2: Impairment in } \\
\text { Communication and Language } \\
\text { Development }\end{array}$} & 0 & 66 & 31.4 \\
\hline & 1 & 144 & 68.6 \\
\hline \multirow{5}{*}{$\begin{array}{l}\text { Domain 3: Obsession and } \\
\text { Compulsive Pattern of Behaviour }\end{array}$} & 0 & 16 & 7.6 \\
\hline & 1 & 19 & 9.0 \\
\hline & 2 & 43 & 20.5 \\
\hline & 3 & 68 & 32.4 \\
\hline & 4 & 64 & 30.5 \\
\hline \multirow{7}{*}{$\begin{array}{l}\text { Domain 4: Co-morbid Conditions } \\
\text { and Onset of Autism }\end{array}$} & 0 & 3 & 1.4 \\
\hline & 1 & 4 & 1.9 \\
\hline & 2 & 21 & 10.0 \\
\hline & 3 & 64 & 30.5 \\
\hline & 4 & 62 & 29.5 \\
\hline & 5 & 46 & 21.9 \\
\hline & 6 & 10 & 4.8 \\
\hline
\end{tabular}

Table 3b displays the distribution of the scores based on domains. A maximum score in each domain should be achieved in order to indicate the adequacy of knowledge about ASD (Domain $1=8$, Domain $2=1$, Domain $3=4$ \& Domain $4=6$ ). It is observed that in Domain 1 , there were only $52(24.8 \%)$ students, Domain 2 with $144(68.6 \%)$ students, the next is Domain 3 with 64 (30.5\%) and lastly in Domain 4 with only 10 (4.8\%) students who were able to achieve a maximum score in each respective domain. Therefore, we could suggest that students were more knowledgeable in Domain 2 which is related to impairment in communication and language development. Meanwhile, the least knowledgeable domain was Domain 4 which is related to co-morbid conditions and onset of autism.

Table 4. Numbers and Percentages of the Positive Responses on Attitudes towards Autistic Individual

\begin{tabular}{|l|l|l|}
\hline \multirow{2}{*}{\multicolumn{1}{|c|}{ Item }} & \multicolumn{2}{c|}{ Positive Responses } \\
\cline { 2 - 3 } & Frequency (n) & Percentage (\%) \\
\hline $\begin{array}{l}\text { 1. Are you willing to move next door to an } \\
\text { individual with ASD? }\end{array}$ & 189 & 90.0 \\
\hline $\begin{array}{l}\text { 2. If an autistic person sits next to you in the bus, } \\
\text { will you change your seat? }\end{array}$ & 200 & 95.2 \\
\hline $\begin{array}{l}\text { 3. Do you see autistic individuals as normal } \\
\text { individuals? }\end{array}$ & 180 & 85.7 \\
\hline
\end{tabular}




\begin{tabular}{|l|l|l|}
\hline $\begin{array}{l}\text { 4. Do you feel frightened if an autistic person shares } \\
\text { the same classroom with you? }\end{array}$ & 201 & 95.7 \\
\hline $\begin{array}{l}\text { 5. Do you think autism is the fault of the person who } \\
\text { has it? }\end{array}$ & 204 & 97.1 \\
\hline
\end{tabular}

In Table 4, it can be noticed that on item 5 ("Do you thinks autism is not the fault of the person who has it"), the positive responses was the highest percentage (97.1\%) when compare to the other items. When the students are being asked whether they see autistic individuals as normal individuals, $85.7 \%$ of them see autistic individual as normal individuals. This item show the least number of positive responses when compare to the others which achieved $90 \%$ or higher positive responses. However, the findings in this study depicts that there was lack of appropriate attitude of the clinical year medical students, unless a maximum percentage of $100 \%$ is achieved in each item. This can proved that there is still presence of stigmatization or discrimination. Low level of knowledge about ASD can lead to stigmatization or discrimination towards autistic individuals as well as their families in the society. They may experience avoidance and negative reaction from the public.

\section{Socio-demographic related to literacy of ASD}

The significance difference between the socio-demographic variables with the belief, knowledge and attitudes towards ASD individual were examined. An independent samples ttest was conducted to examine whether there was a significant difference between the variables of gender (Male or Female) and type of institution (Public or Private) in relation to their beliefs and knowledge about ASD. The test revealed that there are no significant differences between those gender with the total mean score related to beliefs $(\mathrm{t}=0.00, \mathrm{df}=$ 208, $\mathrm{p}=1.00)$ and knowledge $(\mathrm{t}=0.16, \mathrm{df}=208, \mathrm{p}=0.870)$.

Next, there was insignificant differences found in between the type of institution and the total mean score related to belief about ASD. On the other hand, the type of institution and the total mean score related to knowledge about ASD revealed a statistically significant difference $(\mathrm{t}=1.99, \mathrm{df}=208, \mathrm{p}=0.048)$. Public students (Mean $\pm \mathrm{SD}=14.10 \pm 3.00)$ reported significantly higher levels of knowledge about ASD than private students (Mean \pm $\mathrm{SD}=12.73 \pm 3.62$ ). This finding is supported by the previous studies of Farah Shaukat et al. which assessed the knowledge about childhood autism among medical students from private and public universities in Karachi.

In addition, the statistical significant difference among the students with different ethnicity and education level relation to their beliefs and knowledge was examined by a one-way ANOVA. The comparisons of the ethnicity of the students with the total mean score regarding the belief and knowledge revealed no significant relationship.

In contrast, total belief mean score by education showed a significant relationship as an ANOVA test between means yielded $\mathrm{F}=9.252$ at $\mathrm{p}=0.000$, for $\mathrm{p}<0.05$. In conjunction with that, a Games-Howell post hoc test was conducted for the comparisons between different education level groups. The results indicated that $4^{\text {th }}$ year medical students had more accurate beliefs about ASD in comparison with $3^{\text {rd }}$ year students (Mean difference $=-0.47$ at $\mathrm{p}=$ 0.043 ), and finally, $5^{\text {th }}$ year students had more accurate beliefs about ASD in comparison with $3^{\text {rd }}$ year students (Mean difference $=-1.06$ at $\mathrm{p}=0.001$ ).

In relation to the differences between the students' knowledge about ASD with respect to their education level, differences in mean scores were found. $3^{\text {rd }}$ year medical students had a mean score \pm standard deviation $=12.36 \pm 3.37,4^{\text {th }}$ year students had a mean score \pm standard deviation $=13.19 \pm 4.11$ and $5^{\text {th }}$ year students had a mean score \pm standard deviation $=14.32$ \pm 2.59 . An ANOVA test mean yielded $(\mathrm{F}=4.349$ at $\mathrm{p}=0.014$ for $\mathrm{p}<0.05$. These results revealed a significant difference between the mean of knowledge about ASD with students' education level. In addition, a Games-Howell post hoc test was conducted for the comparisons between these two variables. Finding shows that $5^{\text {th }}$ year medical students had 
South American Journal of Medicine

Volume 4, Issue 1, 2016

higher level of knowledge regarding ASD compared to $3^{\text {rd }}$ year students (Mean difference $=$ 1.97 at $\mathrm{p}=0.002$ ).

Moreover, the association of the socio-demographic variables with the attitudes were examined by Chi-square tests. We have found out that there was insignificant association found between the gender, ethnicity and types of institution with the attitudes of the students towards autistic person. But, regarding the education levels and the attitudes were found out to have a significant relationship on the item of "Do you feel frightened if an autistic person shares the same classroom with you?" $\left({ }^{2}=10.06, p=0.007\right)$ and "Do you think autism is the fault of the person who has it?" $\left({ }^{2}=14.67, \mathrm{p}=0.001\right)$. The other items show no significant differences.

\section{Conclusion}

Our data described that $97.1 \%$ of the students have misconception about ASD and only $14.3 \%$ aware that with proper treatment, only minority of the children with autism can outgrow it. $89.5 \%$ of the students agree with the fact that it is essential for autistic children to receive special education services.

Next, only 3 (1.4\%) of 210 students reported to have adequate knowledge regarding ASD. In overall, the students were most knowledgeable about the impairment in communication and language. The students were least aware of the co-morbid conditions and onset of autism.

Besides, our study portrays the lack of appropriate attitudes of the students. For example, as from what we observed, there are $85.7 \%$ of the students who see the autistic individual as normal individual, mean to say that there are still presence of $14.3 \%$ of the students who see them as abnormal. Thus, this shows that there are still certain level of stigmatization or discrimination which occurred, unless the maximum percentage (100\%) of positive responses are achieved by all the participants.

The belief, knowledge and attitudes are expected to be high and good among the medical students as they have higher opportunity to learn more about ASD as compare to the public. They should be more understanding towards the autistics because they will soon become the future healers to the public regardless of their specialization. However, we still see a need of improvement about ASD in terms of belief, knowledge and attitudes among the clinical year medical students in Malaysia.

Belief and attitudes toward autistics can be improved in such a way that medical students would be exemplary to the public on the way autistics should be treated. Ignorance is due to lack of knowledge thus, medical students should be equipped to educate the public regarding autism to eliminate the existing ignorance that can be seen in the public's attitude towards autism.

As what we have learned, autistics should not be isolated but must be given special attention instead as they require sophisticated methods of teaching. This would enable them the opportunity to enhance their talents and skills. Teaching is not only specific for teachers but to even those who come across an autistic child albeit in their family or even friends. It takes time and patience to identify what the child is really keen on and to explore more about it with the child. Self-esteem can be boosted by letting the autistic child to do what he or she seems to be good at. This would open up an array of opportunities for the child to venture on in the future.

According to the recommendations that we have listed previously, efforts should be taken for the betterment of the current situation. Instead of relying fully on the government, nongovernment organizations (NGOs) can give a hand in raising awareness among the public and any special target group of their choice. By doing so, they will be helping our nation rise in an aspect that we all would have least expected; the mental health field. It is a known fact that ASD comes under Psychiatry, thus knowledge on this field would be better and it would gradually reduce a specific taboo which is all Psychiatry patients should be sent to an asylum and treated as people who have gone insane. 
With that said, we hope to see changes among medical students and the citizens of Malaysia regarding ASD gradually. Patience and teamwork is what needed to achieve our goals and together we shall rise to gain some knowledge, educate and treat autistics like how they are supposed to be treated.

To conclude our research, lack of literacy of ASD was obvious among clinical year medical students according to our data.

\section{Recommendations}

There are obvious loopholes that could be rectified using certain methods that can be applied and carried out either in the short term or in the long run. First of all, medical students should take the initiative and have self-directed learning sessions about autism to equip themselves the knowledge that is required for them to identify and diagnose autism in their career. It has come to our attention that the criteria to diagnose an autistic child, which is the stepping stone to the management of such as cases are not being taught to medical students. Not forgetting the fact that the curriculum is standardized worldwide thus the probability to alter the curriculum seems low as it requires more time and work. However, students ought to be enthusiastic and build the curiosity to learn more about autism.

Moving on, various articles should be available for medical students in online continuing medical education (CME) so that when they read the articles and attempt the questions provided, it will boost their understanding towards autism and the ways to manage it. Health care professionals from various medical institutions as well as health care settings should organise CMEs and enable medical students to attend and gain more knowledge regarding autism. Psychiatrist could give talks and explain thoroughly as autism is a spectrum disorder and one autistic child always varies from the other. This could greatly benefit medical students in the future.

Furthermore, Ministry of Health should realise the current situation which is lack of knowledge and understanding of autism among medical students and they should organise campaigns, camps or workshops in which medical students would gain more knowledge and maybe come across autistic children and learn the ways to handle and manage them. Exposure to a certain matter is so vital in understanding of its kind and same goes to this issue that we are trying to tackle now. Visits to care homes that shelter autistics and special education schools should be organised for medical students in order for them mingle around the children and this matter would be alien to them no more.

Besides that, non-governmental organizations (NGOs) should organize events for medical students in which activities would be carried out which would help the students to learn the more about the ways to diagnose and autistic child. Field trips to KIWANIS Home which is the special care home for the autistics can also be conducted so that the exposure could aid in medical students' learning and understanding of autism.

In a nutshell, there are so many ways to curb the lack of literacy of autism among medical students. All parties need to come hand-in-hand in order to produce a quality bunch of future doctors who would be better equipped with adequate knowledge and skills to treat and manage any type of patients.

\section{Acknowledgements}

This study was made complete by the close monitoring of our Research Advisor, Dr. Roy Rillera Marzo, without whose advice and suggestions this research would not have been made possible. We would also like to express our utmost gratitude to all medical students who responded to our study for their cooperation. 
South American Journal of Medicine

Volume 4, Issue 1, 2016

\section{References}

[1.] Arif, M. M., Ayesha Niazy, Bilal Hassan, \& Farah Ahmed. (2013). Awareness of Autism in Primary School Teachers. (M. V. Pletnikov, Ed.) Autism Research and Treatment, 1-5.

[2.] Autism Speaks Inc. (n.d.). What is Autism? Retrieved from Autism Speaks: https://www.autismspeaks.org/what-autism

[3.] Autism Speaks Organization. (n.d.). What is Autism? Retrieved from Autism Speaks: https://www.autismspeaks.org/what-autism

[4.] Bakare, M. O., M. F. TundeAyinmode, A. O. Adewuya, M. A. BelloMojeed, S. Sale, B. O. James, . . . A. O. Orovwigho. (2015). Recognition of Autism Spectrum Disorder (ASD) symptoms and knowledge about some other aspects of ASD among final year medical students in Nigeria, SubSaharan Africa. BMC Research Notes, 1-8.

[5.] Bakare, M. O., Peter O Ebigbo, Ahamefule O Agomoh, \& Nkem C Menkiti. (2008). Knowledge about childhood autism among health workers (KCAHW) questionnaire: description, reliability and internal consistency. Clinical Practice and Epidemiology in Mental Health, 1-8.

[6.] BERNAMA. (2014, March 28). With support, autistic children can move on. Retrieved from The Malaysian Times: http://www.themalaysiantimes.com.my/with-support-autistic-children-can-move-on/

[7.] Broder-Fingert, S., Christine F. Ferrone, Ann Giauque, \& Susan L. Connors. (2014). Residents' Knowledge and Comfort With Caring for Children With Autism Spectrum Disorder. Clinical Pediatrics, 1390-1392.

[8.] Campbell, D. J., David N. Ellis, Abigail Baxter, \& Keith Ni. (2007). Alabama Autism Awareness Assessment.

[9.] Campbell, L. (2008). An Assessment of Autism Knowledge in the Medical Field. 1-90.

[10.] Centers for Disease Control and Prevention. (2015, August 12). Facts About ASD. Retrieved from Centers for Disease Control and Prevention: http://www.cdc.gov/ncbddd/autism/facts.html

[11.] Croen, A., Grether, J.K. , Hoogstrate, J. , \& Selvin, S. (2002). Descriptive Epidemiology of autism in California population: Who is at risk?. Journal of Autism and Developmental Disorders, 32, $217-224$

[12.] Daley TC, S. M. (2002). Diagnostic Conceptualization of Autism among Indian Psychiatrist, Psychologist and Pediatrician. J Autism Developmental Disorder, 13-23.

[13.] Daugherty, C. (2012). The Knowledge and Awareness of Autism Spectrum Disorders within the Hispanic Community. 1-17.

[14.] DeStefano, F., Cristofer S. Price, \& Eric S. Weintraub. (2013). Increasing Exposure to AntibodyStimulating Proteins and Polysaccharides in Vaccines Is Not Associated with Risk of Autism. The Journal of Paediatrics, 561-567. Retrieved from Vaccines Do Not Cause Autism: http://www.jpeds.com/article/S0022-3476(13)00144-3/pdf?ext=.pdf

[15.] DeVilbiss, E. A., \& Brian K. Lee. (2014). Brief Report: Trends in U.S. National Autism Awareness from 2004 to 2014: The Impact of National Autism Awareness Month. Journal of Autism \& Developmental Disorders, 3271-3273.

[16.] Diagnostic and Statistical Manual of Mental Disorder Fifth Edition DSM-5. (2013). Washington, DC: American Psychiatric Publishing.

[17.] Dillenburger, K., Julie-Ann Jordan, \& Lyn McKerr. (2013). Autism Spectrum Disorder:Public awareness and attitudes. Research Update.

[18.] Dillenburger, K., Lynne McKerr, \& Julie-Ann Jordan. (2015). Children and young people's awareness, knowledge, and attitudes towards autism in Northern Ireland. Research Update.

[19.] Durand-Zaleski, Jan Scott, Frédéric Rouillon, \& Marion Leboyer. (2012). A first national survey of knowledge, attitudes and behaviours towards schizophrenia, bipolar disorders and autism in France. BMC Psychiatry 2012, 8.

[20.] Edyvean, C. (n.d.). Attitudes Toward Autism: Reducing Discrimination with Contact. 1-22.

[21.] Haimour, A. I., \& Yahia F. Obaidat. (2013). School Teachers' Knowledge about Autism in Saudi Arabia. World Journal of Education, 45-56.

[22.] Hansen, L. K. (2015). Development and Validation of a Survey of Knowledge of Autism Spectrum Disorder. 1-75.

[23.] Harrison, A. J., B. L. Cochran, \& K. K. Blane. (2015). ASD Knowledge and Stigmas in Tanzania. 
[24.] Heidgerken, A. D., Gary Geffken, Avani Modi, \& Laura Frakey. (2005). A Survey of Autism Knowledge in a Health Care Setting. Journal of Autism and Developmental Disorders, 323-330.

[25.] Igwe, M. N., Muideen O Bakare, Anthony C Ahanotu, Justin U Achor, \& Chinonyerem Igwe. (2011). Assessment of knowledge about childhood autism among paediatric and psychiatric nurses in Ebonyi state, Nigeria. Child and Adolescent Psychiatry and Mental Health, 1-8.

[26.] Imran, N., Mansoor R Chaudry, Muhammad W Azeem, Muhammad R Bhatti, Zaidan I Choudhary, \& Mohsin A Cheema. (2011). A survey of Autism knowledge and attitudes among the healthcare professionals in Lahore, Pakistan. BMC Pediatrics, 1-6.

[27.] K., S. (2001). Research in brief: what do medical students know about autism? Autism, 127-133.

[28.] Khemlani, A. (2015, December 14). Autism Awareness. Spotlight Health Care, p. 17 \& 25.

[29.] Laura Simmons. (2008). Think differently-act positively. London: The National Autistic Society.

[30.] Ministry of Education. (2012, September). The Ministry of Education Malaysia Preliminary Report of National Education Blueprint 2013-2025. Retrieved from Kementerian Pendidikan Malaysia: http://www.moe.gov.my/userfiles/file/PPP/Preliminary-Blueprint-Eng.pdf

[31.] Ministry of Health. (2014). Management Of Autism Spectrum Disorder In Children and Adolescents. Putrajaya: Malaysia Health Technology Assessment Section (MaHTAS).

[32.] Nair, R. (2015). Challenges, Strategies and Success Gained By a Teacher in Teaching Autism Students in a Private Centre. International Journal of Social Science and Humanities Research, 419425.

[33.] National Institute of Mental Health. (n.d.). Autism Spectrum Disorder. Retrieved from National Institute of Mental Health: http://www.nimh.nih.gov/health/topics/autism-spectrum-disordersasd/index.shtml

[34.] O'Leary, M. B. (2014, February 27). Study reveals why autism is more common in males. Retrieved from ELSEVIER: https://www.elsevier.com/connect/study-reveals-why-autism-is-morecommon-in-males

[35.] Pipkin, L. M. (2011). Physician assistants' knowledge and attitudes regarding Autism. 1-43.

[36.] Rahbar MH, I. K. (2011). Knowledge and attitudes of general practitioners regarding Autism in Karachi, Pakistan. Journal of Autism and Developmental Disorder, 465-474.

[37.] Rhoades, R. A., Angela Scarpa, \& Brenda Salley. (2007). The importance of physician knowledge of autism spectrum disorder: results of a parent survey. BMC Pediatrics, 7-37.

[38.] See, C. M. (2012). The Use of Music and Movement Therapy to Modify Behaviour of Children with Autism. 1103-1116.

[39.] Shaukat, F., Fatima, A., Zehra, N., Hussein, M. A., \& Ismail, O. (2014). Assessment of knowledge about childhood autism among medical students from private and public universities in Karachi. Journal of the Pakistan Medical Association, 1331-1334.

[40.] Small, S. H. (2012). Autism Spectrum Disorders (ASD): Knowledge, Training, Roles and Responsibilities of School Psychologists. 1-220.

[41.] Stone, W. (1987). Cross-disciplinary perspectives on autism. Journal of Pediatric, 615-630.

[42.] Suhaily, b., \& Siti Syuhada, b. (2014). A PRELIMINARY STUDY: AWARENESS, KNOWLEDGE AND ATTITUDE OF PEOPLE TOWARDS CHILDREN WITH AUTISM. Proceeding of the Social Sciences Research ICSSR 2014, 322-332.

[43.] Surmen, A., Seyhan Hidiroglu, Hamide Hande Usta, Muhammed Awiwi, Ahmet Saki Oguz, Melda Karavus, \& Ahmet Karavus. (2015). A study exploring knowledge, attitudes and behaviours towards autism among adults applying to a Family Health Center in Istanbul. North Clin Istanbul, 1318.

[44.] The National Autism Society of Malaysia. (n.d.). What Is Autism? Retrieved from NASOM The National Autism Society of Malaysia: http://www.perkobp.org/Image/What\%20is\%20Autism1.pdf

[45.] Tipton, L. A., \& Jan Blacher. (2014). Brief Report: Autism Awareness: Views from a Campus Community. Journal of Autism \& Developmental Disorders, 477-483.

[46.] Wang, J., Zhou, X., Xia, W., Sun, C., Wu, L., \& JianLi. (2011). Autism awareness and attitudes towards treatment in caregivers of children aged 3-6 years in Harbin, China. Social Psychiatry \& Psychiatric Epidemiology, 1301-1308.

[47.] Yasar, P., \& Kathleen A. Cronin. (2014). Perspectives of College of Education Students in Turkey 
South American Journal of Medicine

Volume 4, Issue 1, 2016

on Autism Spctrum Disorders. INTERNATIONAL JOURNAL OF SPECIAL EDUCATION, 1-15.

[48.] Yayasan Sime Darby. (2014, April 30). Yayasan Sime Darby Wraps Up Autism Awareness Month with Grant to Assist Autistic Children from Poor Families. Retrieved from Yayasan Sime Darby: http://www.yayasansimedarby.com/1405210849\%C2\%BBYayasan_Sime_Darby_Wraps_Up_Autism_ Awareness_Month_with_Grant_to_Assist_Autistic_Children_from_Poor_Families.aspx

[49.] York, A., N. von Fraunhofer, J. Turk, \& P. Sedgwick. (1999). Fragile-X syndrome, Down's syndrome and autism: awareness and knowledge amongst special educators. Journal of Intellectual Disability Research, 314-324.

[50.] YS, K., BL, L., YJ, K., E, F., E, L., \& EC, L. (2011). Prevalence of autism spectrum disorders in a total population sample. 


\title{
Management of Aortic Dissection in Marfanoid young patient with Ebstein anomaly: Rare Case Report
}

\author{
Article by Naresh $\operatorname{Sen}^{1}$ and Sonal Tanwar ${ }^{2}$ \\ ${ }^{1}$ Narayana Hrudayalaya Institute of Cardiac Sciences, Bangalore (India) \\ Email id: drnaresh.sen@gmail.com \\ ${ }^{2}$ Anand Multispeciality Hospital, Beawar, Rajasthan (India) \\ Email id: drtanwarsonal@gmail.com
}

\begin{abstract}
Background: Marfan syndrome is an autosomal dominant connective tissue disorder characterized by a combination of clinical manifestations in different organ systems. Patients with Marfan syndrome (MFS) whose lifetimes are extended may be encountered as acute abdomen cases (Aortic dissection) apart from the obligatory reasons and emergencies arising naturally out of their disease, as in the case reported. Ebstein's anomaly is a rare congenital heart disease; in which there is a downward displacement of the tricuspid valve into the right ventricle.

Case Report: 25-year-old Indian male shopkeeper, $47 \mathrm{~kg}$ in weight and $176 \mathrm{~cm}$ tall was admitted in emergency department with acute abdominal pain associated with dyspnea. Long arms and legs, arachnodactyly, kyphoscoliosis, pectus excavatum were found to be present in the physical examination. According to chest radiography, density increase in the left apical field (hyperluscency) (thought to be secondary to bullous structure), transpiring in the ascendent aorta, a rightward shift of the heart (due to the effect of the kyphoscoliosis and pectus excavatum), and thoracolumbar scoliosis (kyphoscoliosis) with a rightward aperture were detected. In addition, according to the echocardiographic examination, Ebstein's anomaly, Aortic Dissection, Tricuspid Regurgitaion, pulmonary hypertension, and inferior deficiency of mitral, aorta, and tricuspid valves were present. Moreover, a right bundle block (secondary to Ebstein's anomaly) was observed in the electrocardiographic examination. Finally he was shifted to cardiothoracic surgery unit for surgical repair of aortic dissection and ebstein anomaly.

Conclusion: For cases of Marfan Syndrome (MFS), the risks of which have been detected through a detailed cardiac examination including echocardiography, we believe that they can be operated as emergency cases with close anesthesia management. Mostly ascending aorta is involved with marfan syndrome but in this case evidence of ebstein anomaly is an interesting point towards cardiovascular surgery and learning about management and post op care.
\end{abstract}

Keywords: Aortic dissection, marfan syndrome, ebstein anomaly.

\section{Introduction}

Marfan syndrome is an autosomal dominant connective tissue disorder characterized by a combination of clinical manifestations in different organ systems. Patients with Marfan syndrome (MFS) whose lifetimes are extended may be encountered as acute abdomen cases (Aortic dissection) apart from the obligatory reasons and emergencies arising naturally out of their disease, as in the case reported. The gene that causes MFS, FBN1, is located on chromosome 15 and encodes fibrillin-1. The condition affects the skeletal, skin/integumentary, ocular, pulmonary, and cardiovascular systems. (1) Although MFS is a multisystem disorder, the most clinically significant manifestation is cardiovascular disease. Because of the abnormal supporting tissues of the aorta and cardiac valves, individuals with MFS are predisposed to the development of aortic dilatation and valvular insufficiency. Mitral valve prolapse with regurgitation is common and can lead to the development of endocarditis 
South American Journal of Medicine

Volume 4, Issue 1, 2016

or congestive heart failure. The natural history of the disease includes a substantial risk of sudden and premature death from aortic dissection. Life expectancy is almost halved in patients with MFS, cardiovascular complications being responsible for $95 \%$ of deaths. However, with rapid advances in medical and surgical treatments, together with reduction of physical and hemodynamic stress, effective management of patients has improved life expectancy. Serial imaging of the aorta is suggested, with MRI being the preferred imaging technique. In an acute dissection treatment choice depends on its location. For Stanford type A (ascending aortic) dissection, surgical management is superior to medical management. For uncomplicated Stanford type B (distal aortic) dissections (including abdominal aortic dissections), medical management is preferred over surgical. $(2,5)$

Ebstein's anomaly is a rare congenital heart disease; in which there is a downward displacement of the tricuspid valve into the right ventricle. It has a distal effective portion and an atrialized proximal portion(3). It is frequently associated with intracardiac shunting, pulmonary hypertension, cardiac dysrhythmias and cyanosis. Clinically, there is a wide spectrum of severity of disease with patients ranging from those who are asymptomatic to those who are debilitated ${ }^{1}$. Congestive heart failure and sudden collapse are the most common causes of death. The incidence in general population is $1: 110,000$ and there is no sex difference. $(3,4)$

\section{Case report}

The case was 25 -year-old Indian male shopkeeper, $47 \mathrm{~kg}$ in weight and $176 \mathrm{~cm}$ tall. He has admitted in emergency department with acute abdominal pain associated with dyspnea and chest heaviness. Tall and slender build, Disproportionately fingers (Figure-1), long arms and legs, arachnodactyly, kyphoscoliosis, pectus excavatum were found to be present in the physical examination.

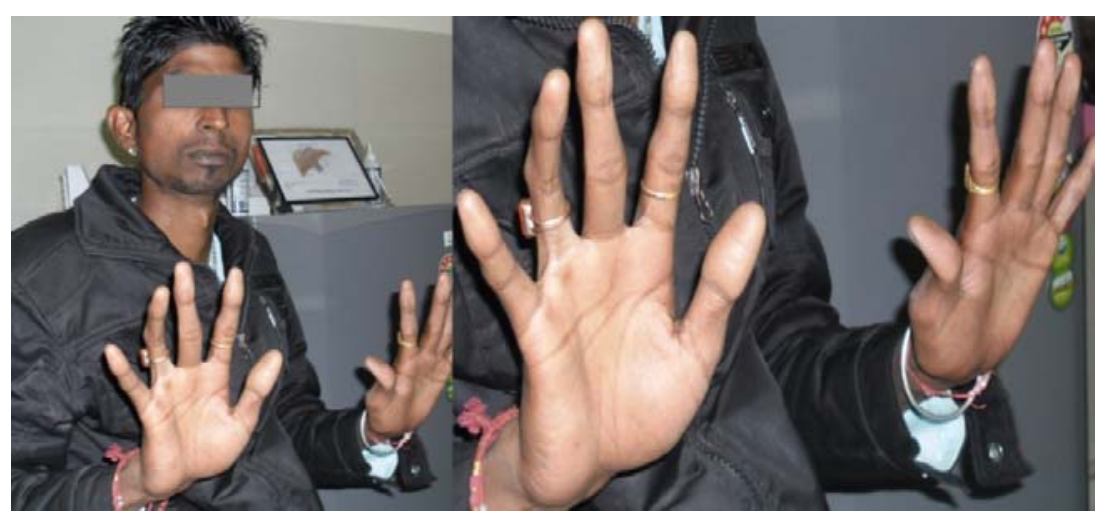

Figure-1 (Disproportionately fingers)

His Vital Sign revealed Blood pressure was $134 / 86 \mathrm{mmHg}$, temperature $-98.2^{\circ} \mathrm{F}\left(36.8^{\circ} \mathrm{C}\right)$; heart rate $-68 \mathrm{bpm}$ and respiratory rate was 26 breaths/min. Raised JVP, regular heart rhythm with no extra sounds, soft S1, grade 4/6 systolic murmur in the lower parasternal area and the absence of thrill. The lungs auscultation revealed bilaterally fine basal crepts. with an oxygen saturation of $94 \%$. The abdomen is nondistended, soft, and tender in epigastric region, with no palpable masses. There is no pedal edema of the extremities. The neurologic examination reveals normal mentation, intact cranial nerves, intact motor strength and sensation, and normal reflexes. No tremor is noted. Moreover, a right bundle block (secondary to Ebstein's anomaly) was observed in the electrocardiographic examination(Figure-2). In addition, according to the echocardiographic examination, Ebstein's anomaly, Aortic Dissection, Tricuspid Regurgitaion, pulmonary hypertension, and inferior deficiency of mitral, aorta, and tricuspid valves were present(Figure-3). According to chest radiography, density increase in the left apical field (hyperluscency) (thought to be secondary to bullous structure), transpiring in the ascending aorta, a rightward shift of the heart (due to the effect of the kyphoscoliosis 
and pectus excavatum), and thoracolumbar scoliosis (kyphoscoliosis) with a rightward aperture were detected (Figure-4).

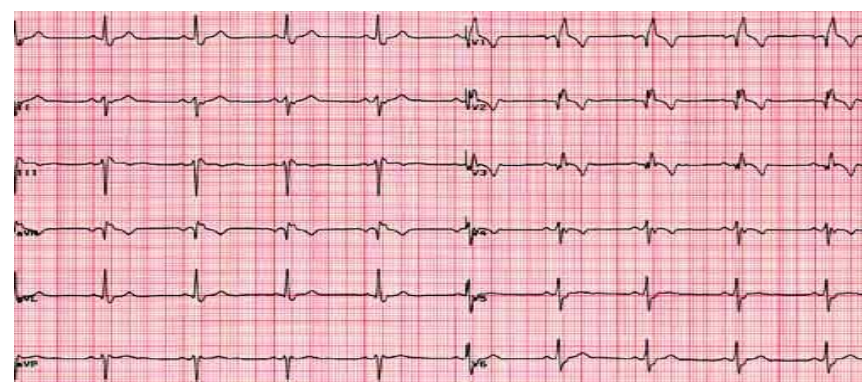

Figure-2 (ECG- Right Bundle Branch Block.)
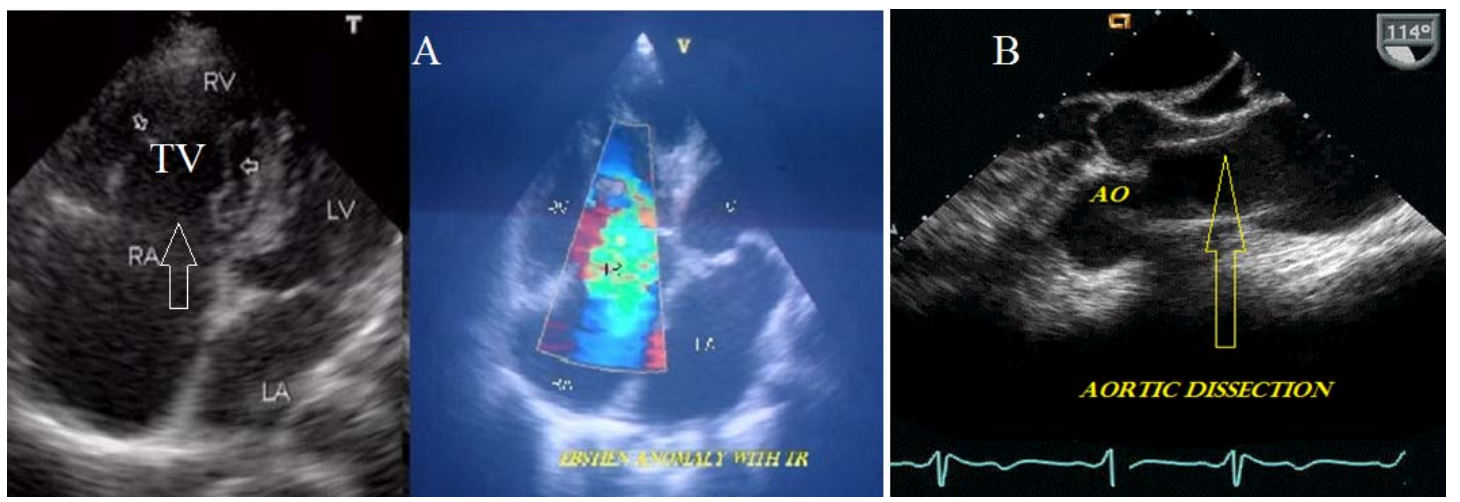

Figure-3 (A. 2D Transthorasic Echo- Ebstein Anomaly with TR, B. 2D Trans Esophageal Echo- Aortic Dissection

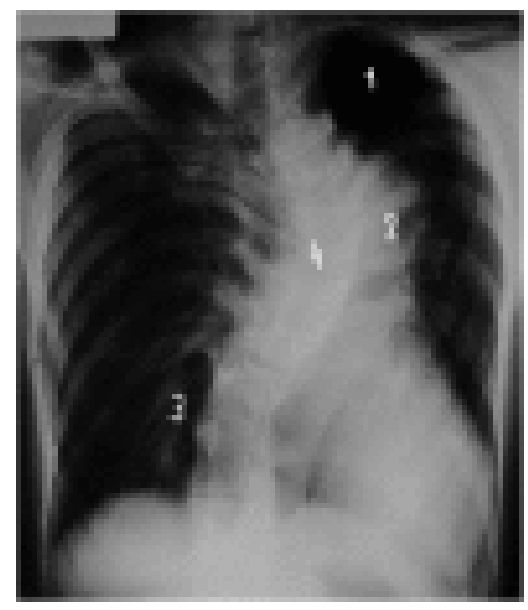

Figure-4 (X-ray during preoperative preparation. 1, density increase in the left apical area; 2, transpiring in ascendent aorta; 3 , a rightward shift of the heart; 4 , scoliosis)

During the preoperative laboratory examination no other pathology was detected besides leucocytosis $\left(17 \times 10^{9} / \mathrm{L}\right)$, CRP elevation $(16.2 \mathrm{mg} / \mathrm{dL})$, and albumin decrease $(31 \mathrm{~g} / \mathrm{L})$. Preoperative blood gas values were in the normal range. A moving and soft tissue structure (connection with decreasing aortic dissection) disturbing phleb of the aorta lumen inside the composition of thoracic descending aorta and abdominal aorta was observed in the abdominal ultrasonography with confirmation support the presence of acute aorta dissection were found in tomographic examination. (Figure-5) 
South American Journal of Medicine

Volume 4, Issue 1, 2016

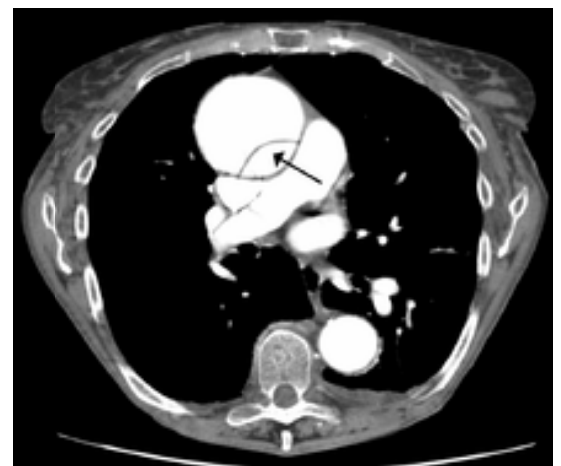

Figure-5 (Aortic dissection, Type A II - Originates in ascending aorta and is confined to the ascending aorta)

The patient was being monitored by the cardiology outpatient clinic due to MFS and Ebstein's anomaly. The prescribed drugs were metoprolol, digoxin, and alprazolam. More importantly, previous detailed genetic research on the patient showed that there was a mutation in the FBN1 gene on the 15th chromosome. Finally he was shifted to cardiothorasic sugery unit for surgical repair of aortic dissection and ebstein anomaly.

\section{Short comments on treatment part.}

\subsubsection{Repairing type a dissections of aorta.}

Patients with type A dissections are treated with immediate surgical correction. This involves transfer to the operating room, where median sternotomy is performed. Profound hypothermia is initiated after the patient is placed on cardiopulmonary bypass. Cardiopulmonary bypass is performed by femoral-femoral cannulation and through the superior vena cava for retrograde cerebral perfusion. In an acute dissection treatment choice depends on its location. For Stanford type A (ascending aortic) dissection, surgical management is superior to medical management. For uncomplicated Stanford type B (distal aortic) dissections (including abdominal aortic dissections), medical management is preferred over surgical. (7)

\subsubsection{Medication for aortic dissections}

Aortic dissection generally presents as a hypertensive emergency, and the prime consideration of medical management is strict blood pressure control. The target blood pressure should be a mean arterial pressure (MAP) of 60 to $75 \mathrm{mmHg}$, or the lowest blood pressure tolerated by the patient. Another factor is to reduce the shear-force $\mathrm{dP} / \mathrm{dt}$ (force of ejection of blood from the left ventricle). Beta blockers are first line treatment for patients with acute and chronic aortic dissection. In acute dissection, rapidly acting, titratable parenteral agents (such as esmolol, propranolol, or labetalol) are preferred. Vasodilators such as sodium nitroprusside can be considered for patients with ongoing hypertension, but they should never be used alone, as they generally cause reflex tachycardia. Calcium can be used in the treatment of aortic dissection, particularly if there is a contraindication to the use of beta blockers. The calcium channel blockers typically used are verapamil and diltiazem, because of their combined vasodilator and negative inotropic effects. $(\mathbf{7 , 8})$

\subsection{Surgery for ebstein anomaly}

Surgical care includes correction of the underlying tricuspid valve and right ventricular abnormalities, correction of any associated intracardiac defects, palliative procedures in early days of life as a bridge to more definitive surgical treatment later, and surgical treatment of associated arrhythmias. Complete repair of Ebstein anomaly in symptomatic neonates has been shown to be feasible, with good early and late survival and excellent functional status. In patients $\geq 50$ years of age with Ebstein anomaly, surgery is associated with good long-term 
survival and improved functional status, although long-term survival might be improved by performing surgery earlier. (13)

The trend is to perform surgery earlier rather later in the course of heart failure. Indications for surgery are generally as follows: New York Heart Association (NYHA) class I-II heart failure with worsening symptoms or with a cardiothoracic ratio of 0.65 or greater. (14) NYHA class III-IV heart failure, History of paradoxical embolism, Significant cyanosis with arterial $\mathrm{O}_{2}$ saturation of $80 \%$ or less and/or polycythemia with hemoglobin of $16 \mathrm{~g} / \mathrm{dL}$ or more and Arrhythmias refractory to medical and radiofrequency ablation

Various approaches are available to treat structural abnormalities. Tricuspid valve repair is preferred over valve replacement, and bioprosthetic valves are preferred over mechanical prosthetic valves. The atrialized portion of the right ventricle can be resected surgically, and the markedly dilated, thin-walled right atrium can be resected. Associated septal defects may be closed. Palliative procedures include creation of atrial septal defect, closure of tricuspid valve with plication of the right atrium, and maintenance of pulmonary blood flow through aortopulmonary shunt. Palliative procedures usually are reserved for severely ill infants with otherwise dire prognosis.

Left ventricular dysfunction should not be considered a contraindication to tricuspid valve surgery. In these patients, although early mortality is greater with tricuspid valve surgery, the late results are favorable and left ventricular function seems to improve postoperatively. $(\mathbf{1 5 , 1 6 )}$ Functional status improves after surgery. Surgical treatments of arrhythmias include the following: Ablation of the accessory pathways and Maze procedure for atrial arrhythmias. Cardiac transplantation is appropriate in selected patients.

\section{Discussion}

MFS primarily affects cardiovascular, skeletal, ocular, integumentary and pulmonary systems. Cardiovascular complications are of special importance as they constitute the primary cause of mortality. The most serious medical complication of MFS is dilation and dissection of the ascending aorta, which can lead to aortic rupture and premature death if untreated. But management routinely includes use of beta-adrenergic blockers, which have been shown to slow the progressive widening of the aorta in many patients with MFS. Other cardiovascular complications include mitral valve prolapse, aortic regurgitation, tricuspid valve prolapse, and dilation of the main pulmonary artery. (1)

The skeletal manifestations of the condition include tall stature; thin habitus with increased arm span-to-height ratio; long, slender fingers (arachnodactyly); elongated face; high arched palate; pes planus; joint laxity; scoliosis; and pectus deformity. Ectopia lentis (lens dislocation) is a hallmark ocular feature present in approximately $60 \%$ of patients. Other ocular findings include corneal flatness, increased axial globe length leading to nearsightedness, and hypoplastic irides. Spontaneous pneumothorax or apical blebs are the most common pulmonary abnormalities. Other cardinal features involve skin, integument, and dura, and include striae atrophicae (i.e., stretch marks), recurrent hernias, and lumbosacral ectasia. (2)

The progressive and potentially fatal clinical features of MFS make early diagnosis very important. Due to the lack of a molecular diagnostic test, diagnosis depends on the revised (Ghent) clinical criteria. The most prominent major criteria are: a constellation of skeletal manifestations including pectus carinatum or excavatum, reduced upper- to-lower-segment ratio, or arm-span-to-height ratio $>1.05$, scoliosis, and reduced elbow extension; ectopia lentis; dilatation or dissection of the ascending aorta; lumbosacral dural ectasia; and inheritance of a genotype previously associated with classic MFS or an unequivocal family history. Spontaneous pneumothorax, striae atrophicae, and recurrent hernias are also useful signs for diagnosis. Diagnostic dilemmas arise due to considerable inter- and intrafamilial variability. (5)

Cardiovascular assessment is mandatory before embarking on surgery due to the threat to life from mitral valve prolapse and aortic dilatation. Blood pressure may be maintained below 
South American Journal of Medicine

Volume 4, Issue 1, 2016

normal with antihypertensive agents. Individuals are at risk from spontaneous pneumothorax, usually arising out of an apical bulla, which may complicate a present compromise. The major objectives of surgery for aortic dissection are to alleviate the symptoms, decrease the frequency of complications, and prevent aortic rupture and death. The affected layers of the aorta are sutured together, and the aorta is reinforced with a Dacron graft. Improved cardiopulmonary bypass circuits have decreased the prevalence of injury to blood elements. Morbidity and mortality rates associated with this highly invasive surgery have decreased with the introduction of profound hypothermic circulatory arrest and retrograde cerebral perfusion. (7)

Dissections involving the arch are more complicated than those involving only the ascending aorta because the innominate, carotid, and subclavian vessels branch from the arch. Deep hypothermic arrest is usually required. If the arrest time is less than 45 minutes, the rate of CNS complications is less than $10 \%$. Retrograde cerebral perfusion may improve the protection of the CNS during the arrest period. The mortality rate associated with aortic arch dissections is approximately $10-15 \%$. Significant neurologic complications occur in an additional $10 \%$ of patients.

Postoperative complications for extensive disease involving the thoracoabdominal aorta include myocardial infarction, respiratory failure, renal failure, stroke, and paraparesis or paraplegia. The use of adjunct procedures has decreased the frequency of procedure-related spinal cord injury during descending aorta and thoracoabdominal surgeries. The long term follow-up in individuals who survive aortic dissection involves strict blood pressure control. The relative risk of late rupture of an aortic aneurysm is 10 times higher in individuals who have uncontrolled hypertension, compared to individuals with a systolic pressure below 130 mmHg. (9) Management of anesthesia for MFS has specific precautions for valvular diseases, thoracic aortic aneurysm, and skeletal joint laxity. Patients with MFS must be carefully assessed preoperatively for specific complications. Antibiotic prophylaxis should be given before dental and other surgical procedures. The anesthesiologist should be prepared for a potentially difficult intubation. (9)

No single intraoperative anesthetic agent or technique has demonstrated superiority. But the anesthetic technique chosen should not decrease myocardial contractility and should avoid sudden increases in contractility, in order to minimize the risk of aortic dissection or rupture. Perioperative hypertension or hypotension must be avoided. The presence of significant aortic insufficiency warrants that the blood pressure be high enough to provide adequate coronary blood flow but should not be so high as to risk dissection of the aorta. Preoperative echocardiography should be considered so as to exclude cardiac or aortic pathology. A patient has been reported who had acute, intraoperative coronary artery obstruction (presumably not a coronary air embolus). (10)

Patients may have significant pulmonary problems including restriction of lung function due to pectus excavatum, kyphoscoliosis, or intrinsic pulmonary involvement with emphysema. Bronchogenic cysts and "honeycomb lung" that lead to spontaneous pneumothorax must also be kept in mind when using positive pressure ventilation. Midtracheal obstruction has been reported after Harrington rod placement and secondary to unexpected tracheomalacia after the induction of general anesthesia. Patients must be carefully positioned to avoid joint dislocations secondary to joint laxity. Although there is a possibility of temporomandibular joint dysfunction, this has not been reported to cause difficulty with laryngoscopy. At extubation, care should be taken to avoid sudden increases in blood pressure or heart rate. Adequate postoperative pain management is vitally important to avoid detrimental hypertension and tachycardia. (8-11)

Ebstein's anomaly includes an abnormal tricuspid valve and "atrialized" right ventricle, that is, the septal leaflets and often the posterior leaflets of the tricuspid valve are displaced into the right ventricle. But the anterior leaflet is usually malformed, excessively large, and abnormally attached or adherent to the right ventricular free wall. Thus, a portion of the right ventricle is "atrialized" in that it is located on the atrial side of the tricuspid valve, and the 
remaining functional right ventricle is small. Eighty percent of patients with Ebstein's anomaly have an interatrial communication (atrial septal defect or patent foramen ovale) through which right-to-left shunting of blood may occur. (3) The clinical presentatation of Ebstein's anomaly varies greatly. As in our case if the tricuspid valve is minimally displaced, tricuspid regurgitation may actually be mild enough to go unrecognized until adulthood. In fact, the diagnosis may be made by accident with few, if any symptoms. The electrocardiogram will show evidence of right bundle block or right atrial enlargement in over $50 \%$ of the cases. $(3,4)$

Anesthesia on patients with Ebstein's anomaly depends to a large degree on the clinical manifestations. The right ventricular dysfunction which puts these patients especially at a high risk for anesthesia is worsened by the tricuspid regurgitation. Similarly, poor left ventricular function is an especially ominous feature before anesthesia. One must be very observant in Ebstein's anomaly patients during the perioperative period for the occurrence of arrhythmias (especially supraventricular arrhythmias such as Wolff- Parkinson-White syndrome). It is important to review the chronic antiarrhythmic medications that the patient may be receiving. (4)

Prior monitoring and treatment of the case by the cardiology clinic positively affected cardiac performance. Moreover, careful preoperative evaluation, a good preparation, close anesthesia management, and postoperative care prevented fatal complications from developing in the patient. (13-15)

\section{Problem faced and lesion learnt}

At the end of the operation, the patient, in whom cutaneous and subcutaneous local anesthetic infiltrations were applied, was extubated to reverse the neuromusculer blocking effect while nitroglycerine infusion continued. While the patient was recovering consciousness, he was taken to the intensive care unit (ICU) for monitoring and intravenously patient-controlled analgesia and nitroglycerine infusion continued. The patient was observed in the ICU for 2 days after the operation and was transferred to the surgical clinic without any complications. The case was discharged from the hospital on the sixth postoperative day. $(8,9)$

\section{Conclusion}

For cases of Marfan Syndrome (MFS), the risks of which have been detected through a detailed cardiac examination including echocardiography, we believe that they can be operated as emergency cases with close anesthesia management. Mostly ascending aorta is involved with marfan syndrome but in this case evidence of ebstein anomaly is an interesting point towards cardiovascular surgery and learning about management and post op care. The major objectives of surgery for aortic dissection are to alleviate the symptoms, decrease the frequency of complications, and prevent aortic rupture and death. The affected layers of the aorta are sutured together, and the aorta is reinforced with a Dacron graft. In case of ebstein anomaly, surgical care includes correction of the underlying tricuspid valve and right ventricular abnormalities, correction of any associated intracardiac defects, palliative procedures in early days of life as a bridge to more definitive surgical treatment later, and surgical treatment of associated arrhythmias.

\section{Consent}

We have taken consent from the patient for the pictures provided.

\section{Acknowledgements}

I would like to thank to Prof. George cherian HOD in Cardiology at Narayana Hrudayalaya, Bangalore who gave support and concern about learning and also I thank to Texila American University or Academic department for continuous learning. 
South American Journal of Medicine

Volume 4, Issue 1, 2016

\section{References}

[1.] Ades L. Guidelines for the diagnosis and management of Marfan syndrome. Heart Lung Circ. 2007;16:28-30.

[2.] Attenhofer Jost CH, Connolly HM, Scott CG, Burkhart HM, Warnes CA, Dearani JA. Outcome of cardiac surgery in patients 50 years of age or older with Ebstein anomaly: survival and functional improvement. J Am Coll Cardiol. 2012 Jun 5. 59(23):2101-6.

[3.] Attie F, Casanova JM, Zabal C, Buendía A, Miranda I, Rijlaarsdam M. Ebstein's anomaly. Clinical profile in 174 patients. Arch Inst Cardiol Mex. 1999 Jan-Feb. 69(1):17-25..

[4.] Brickner ME, Hillis LD, Lange RA. Congenital heart disease in adults: second of two parts. N Engl J Med. 2000;342:334-342.

[5.] Brown ML, Dearani JA, Danielson GK, Cetta F, Connolly HM, Warnes CA, et al. Effect of operation for Ebstein anomaly on left ventricular function. Am J Cardiol. 2008 Dec 15. 102(12):17247.

[6.] Brown ML, Dearani JA, Danielson GK, Cetta F, Connolly HM, Warnes CA, et al. Functional status after operation for Ebstein anomaly: the Mayo Clinic experience. J Am Coll Cardiol. 2008 Aug 5. 52(6):460-6.

[7.] Dean JCS. Management of Marfan syndrome. Heart. 2002;88:97-103.

[8.] Groves ER. Epidural analgesia for labour in a patient with Ebstein's anomaly. Can J Anaesth 1995;42(1):77-79.

[9.] McGoldrick KE. Eye, ear, nose, and throat diseases. In: Fleisher LA, editor. Anesthesia and Uncommon Disease. 5th ed. Philadelphia: Saunders Elsevier; 2006. pp. 6-7.

[10.] Meijboom LJ, Nolle GJ, Mulder BJM. Prevention of cardiovascular complications in the Marfan syndrome. Vas Disc Prevent. 2004;1:79-86.

[11.] Mesrobian RB, Epps JL. Midtracheal obstruction after Harrington rod placement in a patient with Marfan's syndrome. Anesth Analg. 1986;65:411-413.

[12.] Misa VS, Pan PH. Evidence based case report for analgesic and anaesthetic management of parturient with Ebstein's anomly and Wolff-Parkinson- White syndrome. Int J Obstet Anesth 2007;16:77-81.

[13.] Oh AY, Kim YH, Kim BK, et al. Unexpected tracheomalacia in Marfan syndrome during general anesthesia for correction of scoliosis. Anesth Analg. 2002;95:331-332.

[14.] Oliver WC, Lynch JJ. Congenital heart disease. In: Fleisher LA, editor. Anesthesia and Uncommon Disease. 5th ed. Philadelphia: Saunders Elsevier; 2006. pp. 115-118.

[15.] Robinson PN, Godfrey M. The molecular genetics of Marfan syndrome and related microfibrillopathies. J Med Genet. 2000;37:9-25.

[16.] Shores J, Berger KR, Murphy EA, Pyeritz RE. Progression of aortic dilatation and the benefit of long-term beta-adrenergic blockade in Marfan's syndrome. N Engl J Med. 1994;330:1335-1341. 


\title{
A Rare Case of Pregnancy with Nephritic Syndrome which can be Misdiagnosed as Preeclampsia
}

\author{
Article by Archana Kumbhar ${ }^{1}$ and Shailendra Kumbhar ${ }^{2}$ \\ ${ }^{1}$ MS OBGY, DNB OBGY. (Assistant Professor in Dept of OBGY at Prakash Institue \\ of Medical Sciences, Islampur.) \\ Email id: meetarchu007@gmail.com \\ ${ }^{2}$ MD Medicine (Senior resident in Dept of Medicine at Prakash Institue of Medical \\ Sciences, Islampur.) \\ Email id: skumbhar22@gmail.com
}

\begin{abstract}
Pregnancy with hypertension, proteinuria, edema detected in third trimester is always preeclampsia unless proven otherwise 1 . We had a similar case with acute onset of hypertension, proteinuia, oedema, mild breathlessness along with frank hematuria at 32 weeks of gestation in a primigravida. She was initially diagnosed as preeclampsia with its complication either HELLP syndrome or DIC. Investigations showed sever anaemia, mild thrombocytopenia normal liver \& kidney function normal coagulation studies without any evidence of sepsis. Surprisingly fetal parameters were absolulety normal. There was no evidence of Intrauterine Growth restriction, fetal, and uterine Doppler studies were normal. Renal Doppler showing paranchymal renal disease. Patient was stabilized in ICU with nasal Oxygen, diuretics, antihypertensive, antibiotics, steroids for fetal pulmonary maturity. In view of deteriorating maternal condition uncontrolled hypertension increasing hematuria urgent delivery by caesarian section done as bishops was very poor. Surgery went uneventful with outcome of male child of $1.7 \mathrm{kgs}$. Post surgery patient was hemodynamically stable hypertension well controlled but hematuria was persistent and fluctuant. Urine culture report was negative. Suspecting some renal pathology with nephritic syndrome like presentation, she was found to be ASO titer positive. Detailed history revealed pharyngitis 4-5 days before with altered voice since then. Repeat renal uitrasonography 15 days postdelivery showed same findings of altered corticomedullary differentiation, raised cortical echogenicity suggestive of medical renal disease with normal renal artery Doppler. Final diagnosis of nephritic syndrome was made and patient was discharged on day 16 with fluctuant hematuria. Hematuria completely cured over 3 months period.
\end{abstract}

Keywords: hematuria, nephritic syndrome, renal Doppler.

\section{Case report}

26 years primigravida with 32 weeks of gestation presented to emergency department with sudden increasing edema over lower extrimities and vulval edema with hematuria and slight breathing difficulty. She was not a diagnosed case of hypertension or any other systemic disease. There was a history of fever with sore throat 4- 5days back. On examination she was found to have tachycardia (pulse rate-139/min), severe hypertension $(160 / 110 \mathrm{~mm}$ of $\mathrm{hg}$ ) with tachypnea (RR $30 / \mathrm{min})$, pallor, cardiovascular system was normal. On respiratory system examination fine basal crepts were noted. Obstetrics findings were corresponding to weeks of gestation. There was evidence of pitting type lower abdominal wall oedema, pedal oedema upto lower thighs, severe vulval oedema and frank hematuria. Considering provisional diagnosis of severe preeclampsia with its complications, she was treated with antihypertensives diuretics and steroids. As there were no premonitory signs or symptoms of eclampsia Inj. MgSO4 was withhold. Patient was kept in intensive care unit under strict monitoring. 
South American Journal of Medicine

Volume 4, Issue 1, 2016

On investigations found to have anaemia (Hb $7.2 \mathrm{gms} \%$ ), mild thrombocytopenia (plt count 82000/cmm), hypoalbuminemia with normal total and differential leukocyte count. Urine examination showed plenty of RBCS, protein 4+, with 4-5 pus cells with rbc casts . Renal function tests were slightly deranged with Sr. creatinine level of $1.4 \mathrm{mg} / \mathrm{dl}$, 24 hours urinary protein of 1.2 gms. Liver function tests, coagulation studies were in normal range. Urine culture no growth noted. Obstetrics ultrasound showed single live intrauterine pregnancy with 32wks of gestation no evidence of intrauterine growth restriction with fetal wt of $1.68 \mathrm{kgs}$. Umbilical, uterine artery and middle cerebral artery Doppler studies were normal. Renal ultrasound was suggestive of raised cortical echogenicity with accentuated corticomedullary differentiation in both kidneys indicating renal medical paranchymal disease. Renal artery Doppler studies were normal. Even after receiving blood and platelet transfusion her hematuria and anaemia was persistent so decision of termination of pregnancy was taken. She was delivered by caesarian section with outcome of male child 1.7 kgs. There were no intra or post operative complications. Postdelivery her blood pressure responded well to antihypertensives but hematuria was persistent. Renal function returned to normal over period of 7 days. Anaemia and thrombocytopenia also reveresd. Only positive finding remaining was hematuria. Further investigations like Sr LDH, Lipid profile, CRP were normal. Sr ASO (antistreptolysin O) titre were slightly raised. Repeat renal ultrasound on day 15 post delivery suggestive of same findings of medical renal disease.

So final diagnosis was made as nephritic syndrome, patient was discharged after explained about self limiting and gradual course of disease and close follow up. On weekly follow up urine examinations showed gradual reduction in hematuria. It took almost 3 months for complete recovery.

\section{Discussion}

Hypertensive disorders complicate 5 to 10 percent of all pregnancies, and together they form one member of the deadly triad, along with hemorrhage and infection, that contribute greatly to maternal morbidity and mortality rates. The World Health Organization systematically reviews maternal mortality worldwide. In developed countries, 16 percent of maternal deaths were due to hypertensive disorders. This percentage is greater than three other leading causes: hemorrhage-13 percent, abortion-8 percent, and sepsis-2 percent $^{1}$.

Preeclampsia : new onset of hypertension after 20 weeks of gestation with significant proteinuria(more than $300 \mathrm{mg}$ over 24 hours). ${ }^{1}$

Severe preeclampsia - preeclampsia with severe hypertension $>160 / 110$ and/ or with symptoms and /or biochemical and/ or hematological impairment. ${ }^{1}$

Acute nephritic syndrome (glomerulonephritis) - hematuria, hypertension, fluid retention, sustained proteinuria (1-2 grams over 24 hours) with red blood cell casts. Dysmorphic RBCs, raised sr. creatinine redued GFR and oliguria may be seen ${ }^{2}$. Thin glomerular basement membrane with pores in podocytes large enough to permit protein \& RBCs ${ }^{3}$. There are varying degrees of renal insufficiency and salt and water retention, which causes edema, hypertension, and circulatory congestion.

Proteinuria in most adults with glomerular disease is non selective containing albumin and mixture of other proteins ${ }^{2}$.

Etiological factors for nephritic syndrome are $e^{4}$

1. Poststreptococcal infection

2. Subacute bacterial endocarditis

3. Systemic lupus erythematosus

4. Antiglomerular basement membrane disease

5. IgA nephropathy

6. ANCA small vessel vasculitis

7. Henoch-Schonlein purpura

Poststreptococcal glomerular nephritis is common in adults than other types. Following skin infection i.e post impetigo $M$ type streptococci with subtype 47,49,55,2,60,57 are 
observed. After pharyngitis $M$ type streptococci with subtypeb 1,2,4,3,25,49,12 are observed. Symptoms are headache, malaise, anorexia, flank pain. $20 \%$ of adults have proteinuria of nephritic range. ASO titres are raised in only $30 \%$ of cases. Diagnosis rarely requires renal biopsy. Treatment is supportive with control of hypertension ,oedema. Dialysis may be needed. No role of immunosuppressive therapy. Overall prognosis is good. Complete resolution of hematuria and proteinuria occurs within 3-6 weeks of onset ${ }^{5}$.

Acute poststreptococcal glomerulonephritis is prototypical of these syndromes. Although it rarely develops during pregnancy. Diagnosis is confirmed by history of streptococcal infection within previous weeks and/ or raised ASO titres. Fetal loss is almost invariable renal function returns to normal after delivery ${ }^{6}$.

\section{References}

[1.] http:// www.merck.com/mmpe/sec17/ch235b.html

[2.] Julia B. Lewis, Eric G, Neilson: Glomerular diseases; Harrison Principles of Internal Medicine $17^{\text {th }}$ edition, chp 277 page1784, editor: Anthony S. Fauci.

[3.] Julia B. Lewis, Eric G, Neilson: Glomerular diseases; Harrison Principles of Internal Medicine $17^{\text {th }}$ edition, chp 277 page1785-87, editor: Anthony S. Fauci.

[4.] McGraw - Hill, Williams Obstetrics, 23 ed, Chapt 34, Pregnancy Hypertension.

[5.] McGraw - Hill, Williams Obstetrics, 23 ed, Chapt 48. Renal and Urinary Tract Disorders.

[6.] Sibai M, Renal Diseases \& Pregnancy B, Glob.libr.womens med, Glowm.10157, 2008.

\section{Author's profile}

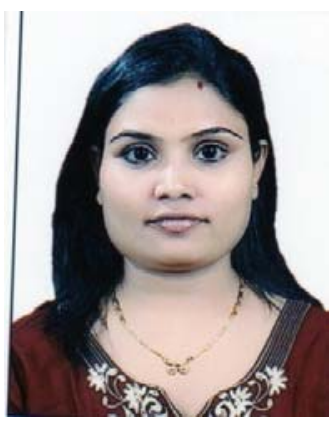

DR ARCHANA KUMBHAR

M..B.B.S., M.S.- OBGY, DNBE-OBGY. ASSISTANT PROFESSOR IN DEPT OF OBGY AT PRAKASH INSTITUTE OF MEDICAL SCIENCES ISLAMPUR.

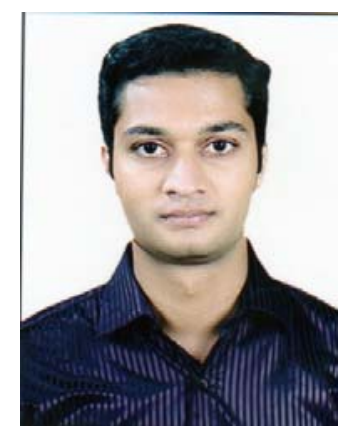

DR SHAILENDRA KUMBHAR

M.B.B.S., M.D.MEDICINE

SENIOR RESIDENT IN DEPT OF MEDICINE

AT PRAKASH INSTITUTE OF MEDICAL SCIENCES

ISLAMPUR. 


\title{
Male osteoporosis - the problem statement among South India men
}

\author{
Article by Anil Gowtham Manivannan ${ }^{1}$, Sakthivel Annamalai ${ }^{2}$ and Alphonse \\ Mariadoss Joseph ${ }^{3}$ \\ ${ }^{1}$ Resident Orthopaedics, K.G. Hospital and post graduate research institute, \\ Coimbatore, Tamil Nadu, India. \\ ${ }^{2}$ M.S.ortho, D.ortho, Head department of orthopaedics, \\ ${ }^{3}$ M.ch ortho, D.ortho, Professor of orthopaedics, K.G. Hospital and post graduate \\ research institute, Coimbatore, Tamil Nadu, India. \\ Email: anilthambu91@yahoo.com
}

\begin{abstract}
Two points worth noting about osteoporosis in India - high incidence among men and lower age of peak incidence compared to Western countries. 1 out of 8 males and 1 out of 3 females in India suffers from osteoporosis. The incidence of hip fracture is 1 woman to 1 man. In Western countries, the peak incidence of osteoporosis occurs at 70-80 years of age, in India it afflicts at age 50-60. But there is a worrying trend of increasing prevalence of osteoporosis among the younger men in India that has been under studied. This crosssectional study was conducted in a tertiary care centre. With informed consent, male subjects were evaluated clinically including anthropometry and history, biochemically with 25-OH Vitamin D and radiologically with DEXA scan. Calculation of T score and categorization as osteoporosis, osteopenia, and normal BMD was done as per WHO classification and data was analyzed. The male population having decreased bone mass was more than expected. Osteoporosis and osteopenia are prevalent in younger male population too contrary to the popular belief. A significantly large proportion of south Indian men had osteoporosis and vitamin $D$ deficiency. Further interventional studies are needed to look at reduction in end points like fractures and morbidity in these subjects.
\end{abstract}

Keywords: male osteoporosis, DEXA scan ,vitamin D deficiency.

\section{Introduction}

Osteoporosis is "a systemic skeletal disease characterized by low bone mass and microarchitectural deterioration of bone tissue with a consequent increase in bone fragility and susceptibility to fracture" (WHO, 1994).Osteoporosis in men is now recognized as a major underestimated public health problem. With the gradual increase in life expectancy, advancing age related illnesses are increasing [1]. After the age of fifty, one out of three osteoporotic fractures are seen in men. Furthermore, an in depth understanding of this subject has revealed that about fifty percent of these causes are potentially treatable. Studies have shown that men with osteoporotic fractures have a much higher mortality and morbidity when compared to women [2]. This may add on to the economic burden in a developing country like India, where men may be the only earning members in many families.

The mortality after osteoporosis-related fracture is higher in men than women; mortality ratio after hip fracture was found to be 3.2 for men and 2.2 for women [3]. Similar to west, osteoporotic fractures are a major cause of morbidity and mortality in elderly Indians. The osteoporosis and osteopenia may occur at a relatively younger age in Indian population [4]. In addition to genetic determinants, several life-style related factors like physical activity, calcium intake, smoking, alcohol consumption, and vitamin D status may influence the bone mass in men[5]. However, the prevalence and influence of these factors may vary according to ethnicity.

Screening for osteoporosis in men is usually recommended above the age of 70 years [1,5]. However, its relevance in relation to the variability in ethnicity requires validation through 
South American Journal of Medicine

Volume 4, Issue 1, 2016

prospective studies. There are differences in peak bone mass, body frame, and nutrition and life style factors among various populations [1]. There are no clear guidelines available for screening men with osteoporosis among ethnic groups other than the Caucasian population. In this study, we have attempted to look at the prevalence of osteoporosis and vitamin D status in healthy South Indian men and to study the influence of various life style factors on bone mineral density.

\section{Materials and methods}

The study was a cross sectional one conducted in a tertiary care centre in Coimbatore.

Inclusion criteria

- The study included healthy males at or above 50 year of age who were free from apparent illness studied.

Exclusion criteria

- Men with a history of chronic liver or renal disease, hyperthyroidism, hyperparathyroidism, hypogonadism, rheumatoid arthritis, ankylosing spondylitis, primary hyperparathyroidism, chronic obstructive pulmonary disease, chronic smokers, chronic alcoholism and malabsorption.

- Men on medications such as bisphosponates, thyroxine, steroids, immunosuppressive therapy, anti-epileptics, calcitonin, anti-retroviral, and anti-tuberculous therapy

- Patients with previous history of fractures, hip replacement, kyphosis or scoliosis

The data included age, sex, height, weight, BMI, a past history of fragility fracture, parental history of hip fracture, history of smoking or alcohol intake ( 3 or more units/day), the presence of rheumatoid arthritis, and any other history suggestive of secondary osteoporosis were studied.

BMD was assessed using the Hologic Discovery WI bone densitometer machine at the right hip by the same technician. The WHO classification was used for categorization of BMD. Osteoporosis was defined as $\mathrm{T}$ score $\leq-2.5$, osteopenia or low bone mass -1 to -2.5 and normal as $>-1[6,7]$. Blood work to assess serum $(25-\mathrm{OH})$ cholecalciferol was done for the same subjects to evaluate vitamin D deficiency.

\section{Results}

The study population consists of 200 males $>50$ years in various age groups (Fig 1). The BMI insignificantly decreased with advancing age (Fig 2).The mean BMD at total hip was normal in age groups 50-60 and 61-70 years, osteopenic in age 71-80 years, while osteoporotic in age above 80 years. Since there were only three subjects in the fourth group (>80 years age), results cannot be generalized. Only $13.5 \%$ men had sufficient vitamin D levels, the rest $86.5 \%$ had deficiency $(28.5 \%$ had insufficient levels and $58 \%$ had low deficit values). Surprisingly, young men in the fifth decade were found to have compromised bone health in both vitamin D levels and BMD. The trend of bone health in men in the study group in both fifth and sixth decade of life is almost the same. Middle aged men in their 50's and 60 's were found to have insufficient vitamin D levels of $19.41 \mathrm{ng} / \mathrm{ml}$ and $20.56 \mathrm{ng} / \mathrm{ml}$ respectively and demonstrated low bone mineral density in DEXA scan (Fig 3, 4). Overall in the study group, BMD results shows compromised bone health in 101 men (17 osteoporotic and 84 osteopenic), nearly $50 \%$ of the study group and the rest 99 men had normal bone density (Fig 5). 


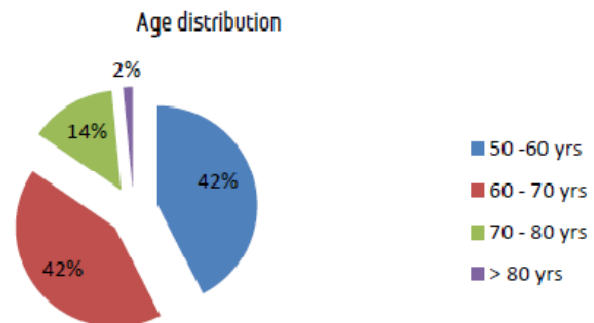

Figure 1

Table 1

\begin{tabular}{|l|l|}
\hline Mean distribution (n=200) \\
\hline Age & $62.17 \pm 7.64 \mathrm{yrs}$ \\
\hline Height & $163.79 \pm 6.93 \mathrm{~cm}$ \\
\hline weight & $64.20 \pm 11.30 \mathrm{~kg}$ \\
\hline BMI & $23.90 \pm 3.73 \mathrm{~kg} / \mathrm{m}^{2}$ \\
\hline S.25-OH cholecalciferol & $18.96 \pm 10.23 \mathrm{ng} / \mathrm{ml}$ \\
\hline
\end{tabular}

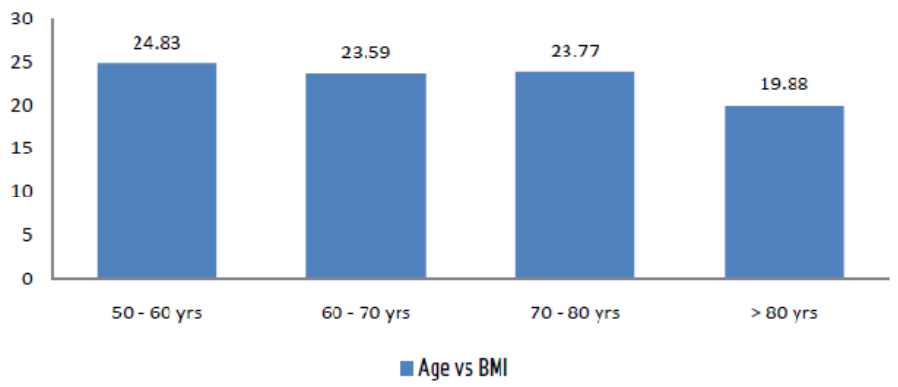

Figure 2

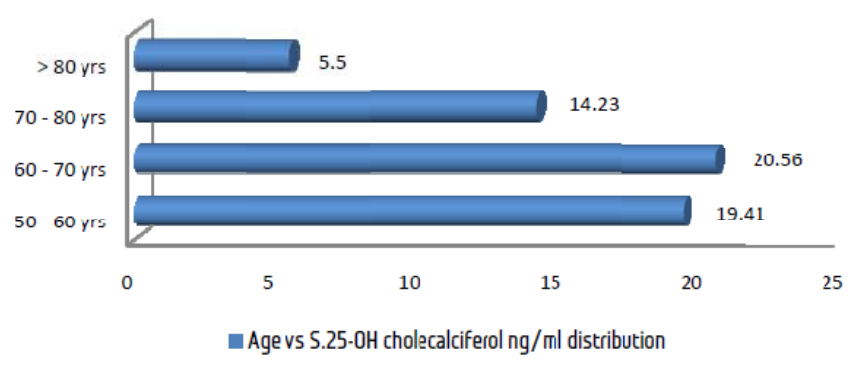

Figure 3

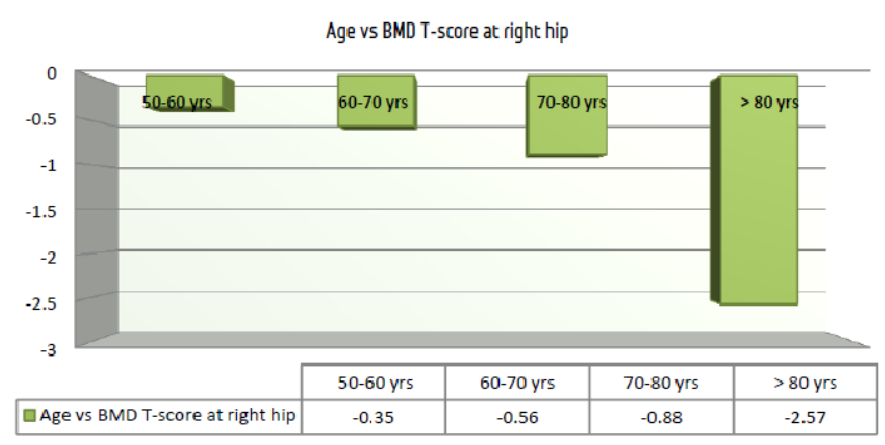

Figure 4 
South American Journal of Medicine

Volume 4, Issue 1, 2016

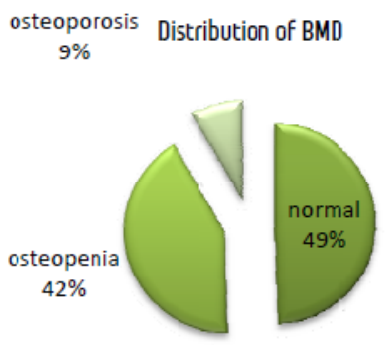

Figure 5

\section{Discussion}

Male osteoporosis is an underreported public health problem. In our study, we attempted to look at the prevalence of osteoporosis and the various risk factors in South Indian healthy men above the age of 50 years. In previously published literature, a $9 \%$ prevalence of osteoporosis has been reported in Northern India[8]. However, in another study at Rochester [9], a 19\% prevalence of osteoporosis has been reported, which bears similarity to our study. The differences in the prevalence that was seen between south Indian and north Indian subjects would have been due to many factors like genetic, nutritional, and other environmental factors. They need to be looked at in further prospective studies.

BMD begins to decline after the third decade and is influenced by genetic and environmental factors. Prepubertal BMD is similar in both sexes. However, the pubertal increase in BMD is more in men when compared to women due to a greater cross sectional area in view of increased periosteal apposition under the influence of androgens. Bone remodeling with aging leads to trabecular thinning in men, whereas loss of trabecular connectivity in women. Decline in BMD in men may begin as early as 30-40 years. However, the accelerated menopausal bone loss may not be seen. The estimated rate of bone loss with aging in men is about $1 \%$ per year[10].

\section{Osteoporosis and Risk of Fracture: Morbidity, Mortality, and Economic Burden Associated with Fracture}

The most dreaded complication of osteoporosis is hip fracture, which has been reported to be more in men when compared to women. Osteoporosis in men accounts for more than 30 $40 \%$ of overall fracture. Fracture in men follows a bimodal presentation with peaks at adolescence and after 60 years. The morbidity and mortality associated with hip fractures in men has been reported as high as $33 \%$ [11]. Moreover, a three to four time's higher mortality rate has been described in men with hip fracture when compared to females. The economic burden of osteoporotic fractures is not only borne by the patient but by the country as a whole. The major costs may not only include that of investigations, surgery, or long term management of these patients but also the large number of man hours that is lost by these men after they sustain a fracture. This is particularly relevant in developing countries like India where there is an increase in the aging population[12].

\section{Vitamin D deficiency and BMD}

A high prevalence of vitamin D deficiency has been reported in various cohorts of Indian population. Vitamin D deficiency can either decrease mineralization or cause secondary hyperparathyroidism or both resulting in a low bone mineral density [13]. A low vitamin D may also cause proximal myopathy predisposing these patients to a fall and subsequent fracture.

However looking closely, only $13.5 \%$ subjects had sufficient $25(\mathrm{OH})$ vitamin D levels, while out of rest, $58 \%$ had either low or deficient level. Vitamin D deficiency is quite prevalent in India. Goswami et al. [14], in a study from Delhi, reported that up to $90 \%$ of apparently healthy urban office workers and hospital staff had moderate to severe vitamin D deficiency. Tandon et al.[15] evaluated young healthy men $(n=40)$ and women $(n=50)$ between 
20 and 30 years of age from the Indian paramilitary forces and found a mean vitamin D level $18.4 \mathrm{ng} / \mathrm{ml}$ in men. Arya et al. [16]reported that $78.3 \%$ subjects were diagnosed to be vitamin D deficient/insufficient from study done at Lucknow (North India). Zargar et al. [17]from Kashmir valley studied 92 healthy natives; out of them, 64 were men. They observed that 49 of the 64 males (76.56\%) were vitamin D deficient. Vupputuri et al. [18]reported 25-OH D levels below $20 \mathrm{ng} / \mathrm{ml}$ in $94.3 \%$ of study subjects from north India.

In the present study, with advancing age, fewer subjects had sufficient vitamin D level (more than $30 \mathrm{~g} / \mathrm{ml}$ ) and more subjects had low (less than $10 \mathrm{ng} / \mathrm{ml}$ ) or deficient level. This can be due to decreased formation of vitamin $\mathrm{D}$ in skin and poor absorption in gastrointestinal tract with age[19].In our observation, BMD was positively correlated with 25-OH vitamin D level. The subjects with normal mean BMD at total hip had mean 25-OH vitamin D level above $22 \mathrm{ng} / \mathrm{ml}$ while subjects with osteopenia at total hip had mean $25-\mathrm{OH}$ vitamin D level just above $15 \mathrm{ng} / \mathrm{ml}$.

Arya et al. [16]also reported that low serum 25-OH D level is possibly one of the reasons for lower BMD among Indians. Several investigators from west had reported significantly lower hip BMD in subjects with low serum 25-OH D concentrations. Besides, vitamin D supplementation led to beneficial effect on hip BMD[20]. In recent Indian study by Marwaha et al. [21], prevalence of osteoporosis ranged from 2.6 to18.0 \% in males. Their study subjects also included those with past history of fractures, while our study excluded any subject with past or present osteoporotic fracture. All these studies suggest that osteoporosis in men is not uncommon as previously believed, and the prevalence rates might be different because of various DXA machines used, or difference in selection criteria. Marwaha et al. [21] reported reduced mean BMI with advancing age in Indian men and women and also observed that prevalence of osteoporosis increased with age in females, but not in males. Lekamwasam et al. [22] reported $5.8 \%$ prevalence of osteoporosis among men older than 50 years in Sri Lanka, and it increased with advancing age.

\section{Conclusion}

A significantly larger proportion of otherwise normal healthy men in our community had osteoporosis and vitamin D deficiency. This study indicates that osteoporosis and osteopenia are prevalent in younger male population too contrary to the popular belief. Large scale prospective studies with interventions are needed to look at the reduction in the end points like number of incident fractures and morbidity associated with them.

\section{References}

[1.] Agrawal N. K and. Sharma B, "Prevalence of osteoporosis in otherwise healthy Indian males aged 50 years and above," Archives of Osteoporosis, vol. 8, no. 1-2, article no. 116, 2013.

[2.] Arya V, Bhambri R and Godbole MM(2004) Vitamin D status and its relationship with bone mineral density in healthy Asian Indians. Osteoporosis Int 15:56-61.

[3.] Bliuc D,. Nguyen N. D,. Milch V. E,. Nguyen T. V,. Eisman J. A, and. Center J. R, "Mortality risk associated with low-trauma osteoporotic fracture and subsequent fracture in men and women," JAMA-Journal of the American Medical Association, vol. 301, no. 5, pp. 513-521, 2009.

[4.] Center JR, Nguyen TV, Schneider D et al (1999) Mortality after all major types of osteoporotic fractures in men and women: an observational study. Lancet 353:878-882.

[5.] Center J. R.,. Nguyen T. V,. Schneider D,. Sambrook P. N, and. Eisman J. A, "Mortality after all major types of osteoporotic fracture in men and women: an observational study," The Lancet, vol. 353, no. 9156, pp. 878-882, 1999.

[6.] Chapuy MC, Arlot ME, Duboeuf F, Brun J, Crouzet B and Arnaud S (1992) Vitamin D3 and calcium to prevent hip fractures in the elderly women. N Engl J Med 327:1637-1642.

[7.] Ebelin P. R, "Osteoporosis in men," The New England Journal of Medicine, vol. 358, pp. 1474$1482,2008$.

[8.] Goswami R, Gupta N and Goswami D (2000) Prevalence and significance of low 25hydroxyvitamin D concentrations in healthy subjects in Delhi. Am J ClinNutr 72:472-475. 
South American Journal of Medicine

Volume 4, Issue 1, 2016

[9.] Harinarayan C. V and. Joshi S. R, "Vitamin D status in India-its implications and remedial measures, "Journal of Association of Physicians of India, vol. 57, pp. 40-48, 2009.

[10.] Heaney R. P,. Abrams S,. Dawson-Hughes B et al., "Peak bone mass," Osteoporosis International, vol. 11, no. 12, pp. 985-1009, 2000.

[11.] Holick MF (2007) Vitamin D, deficiency. N Engl J Med 357:266 - 281.

[12.] Kanis J. A,. Johnell O,. Oden A,. Johansson H, and. McCloskey E, "FRAX and the assessment of fracture probability in men and women from the UK," Osteoporosis International, vol. 19, no. 4, pp. 385-397, 2008.

[13.] Khanna P, Bhargav S (1971) Roentgen assessment of bone density in north Indian Population. Indian J Med Res 59:1599-1609

[14.] Lekamwasam S, Wijayaratne L and Rodrigo M (2009) Prevalence and determinants of osteoporosis among men aged 50 years or more in Sri Lanka: a community-based cross-sectional study. Arch Osteoporos 4:79-84.

[15.] Malhotra N and. Mithal A, "Osteoporosis in Indians," Indian Journal of Medical Research, vol. 127 , no. 3, pp. 263-268, 2008.

[16.] Marwaha RK, Tandon N and Garg MK (2011) Bone health in healthy Indian population aged 50 years and above. Osteoporos Int 22:2829-2836.

[17.] Melton L. J III,. Atkinson E. J,. O'Connor M. K,. O'Fallon W. M, and. Riggs B. L, "Bone density and fracture risk in men," Journal of Bone and Mineral Research, vol. 13, no. 12, pp. 1915-1923, 1998. [18.] Rao S. S, Budhwar N., and Ashfaque A., "Osteoporosis in men," American Family Physician, vol. 82, no. 5, pp. 503-508, 2010.

[19.] Tandon N, Marwaha RK and Kalra S(2003) Bone mineral parameters in healthy young Indian adults with optimal vitamin D availability. Natl Med J India 16:298-302.

[20.] Vupputuri MR, Goswami R and Gupta N(2006) Prevalence and functional significance of 25hydroxyvitamin $\mathrm{D}$ deficiency and vitamin $\mathrm{D}$ receptor gene.

[21.] World Health Organization (WHO), "Assessment of fracture risk and its application to screening for postmenopausal osteoporosis: report of a WHO study group,” WHO Technical Report 843, WHO, Geneva, Switzerland, 1994.

[22.] Zargar AH, Ahmad S and Masoodi SR (2007) Vitamin D status in apparently healthy adults in Kashmir Valley of Indian subcontinent. Postgrad Med J 83:713-716.

\section{Author profile}

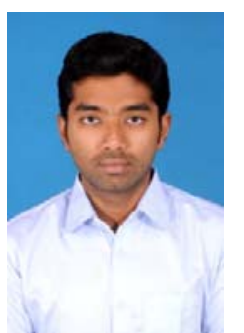

Author's Name: Dr. Anil Gowtham Manivannan

Designation: Resident Orthopaedics,

Department of orthopaedics.

Institution: K.G.Hospital and post graduate research institute, Coimbatore, Tamil Nadu, India.

Email:anilthambu91@yahoo.com

Mobile no: +91 9487570968. 


\title{
Maternal Autonomy and Young Child Nutritional Status
}

\author{
Article by Nadia Sultana ${ }^{1}$, Afroza Begum ${ }^{2}$, Abdus Samad $^{3}$, M.M. Aktaruzzaman ${ }^{4}$ and \\ Irin Hossain ${ }^{5}$ \\ National Institute of Preventive and Social Medicine, Mohakhali, Dhaka ${ }^{125}$ \\ National Heart foundation Dhaka ${ }^{3}$ \\ VBDC, DGHS, Mohakhali, Dhaka ${ }^{4}$ \\ Email: irin.hossain@gmail.com
}

\begin{abstract}
The maternal autonomy was measured by the level of participation in household decisions according to the BDHS 2011 scale. The nutritional status of the children was evaluated through measuring height and weight of the children and plotting it in CDC growth reference chart. The study was a cross sectional study which took place in Manikganj district of Bangladesh, on 260 married mothers who have at least one child aged between 1 to 3 years. Our estimation results show that, mother's level of participation in household decisions found to have significant impact on child's nutritional outcome, especially in terms of height. Other factors such as, age gap with the husband more than 5 years, early marriage and adolescent pregnancy found to decrease the maternal autonomy condition significantly. On the other hand mother's living in the single family, with better education and who have their personal income are significantly more autonomous. They also found to be less prone to have stunted children.
\end{abstract}

Keywords: Maternal autonomy, child nutritional status, rural

\section{Introduction}

In Bangladesh, malnutrition is one of the most critical components for child health that affects almost $56.5 \%$ children. We are still facing challenges to keep malnutrition levels below the World Health Organization's (WHO) public health critical thresholds. According to UNICEF Nutrition database 2012, the stunting prevalence among under five children in our country is $41 \%$. This malnutrition starts early in the life cycle of a child. The period from birth to 36 months of age is a critical period in early childhood development. Quality and quantity of food available to a household are not the only factors explaining the determinants of malnutrition in infants and young children. Care and feeding practices of the caregiver are key factors that lead to undernourishment. [1] As UNICEF report states, 'Eliminating gender discrimination and empowering women will have a profound and positive impact on the survival and well-being of children (UNICEF 2007). Furthermore there are studies where it was found that, maternal autonomy positively impacts child's nutritional outcome, which was found more specifically in children under the age of 3 years. The relation was not the same for children aged more than 3 years [2]. Much concern has been showed in the past decade, about the need to empower women, so they can make their own decisions about childbearing and about other aspects of their lives. Lack of power over their own decision-making starting from the home to outside has long been recognized as the major obstacle to improve women's sexual and reproductive health. As the primary caregiver of a child is the mother, disempowerment of mother has contribution to high rates of this malnutrition among developing countries including ours. Low female status can result in compromised health outcomes for women, which in turn are related to lower infant birth weight and may affect the quality of infant care and nutrition. A mother influence child nutrition directly through improved childcare practices and indirectly through improvements in their own nutrition. This whole concept is more observable in a rural setting, where women are in more disadvantageous position. We conducted the study in Garpara union of Manikganj Sadar 
South American Journal of Medicine

Volume 4, Issue 1, 2016

Upazilla to get a detail for studying the linkages between maternal autonomy and child nutritional outcome in a disadvantaged setting.

\section{Background}

The majority of women has limited access to and control over resources and restriction in their mobility and are often under threat of violence from male partners. Women in Bangladesh have a lower social status than men. Their low status is deeply rooted in a culture and traditions, which place greater value on sons and men. Women's status remains low from one generation to the next. In such circumstance, autonomy is an intangible factor which expresses itself in a number of ways, as for example, having decision making power, mobility, command and control over resources, and intolerance and unwillingness to put up with violence. The facilitating factors in exercising autonomy are education, position in the household, economic status of the household and of the woman, access and availability of properties, and norms and attitudes of the community. Autonomy has basic relevance with women's own well-being. It determines to a large extent her ability to make effective choices and exercise control over her life. Women's autonomy contributes in large measure to enhancing quality of life for the family and for the community. There are a number of ways by which mother's decision making power might come to be associated with improved child health outcomes. Particularly in countries such as Bangladesh, where mothers play a vital role in child care. While men tend to make investments in themselves and/or the overall worth of their households, women are more likely to invest in the basic food and health care needs of their children and to prioritize these needs above all other needs. In families where mother play an important role in decision making, the proportion of family resources devoted to children is greater than in families in which mother play a less decisive role [3]. Constraints are there on women's household decision making power, physical mobility, restrict their ability to make these independent decisions. Women are governed by social norms that restrict their physical mobility. Thus, even in instances where women wish to make decisions regarding household consumption, expenditures, or health care, they may need help and agreement from other family members, particularly the husband or mother-in-law, in actually carrying out these dealings. On the other hand a woman who lives in a high-income household may be able to afford more food or medicines for sick children, but she does not necessarily make the decisions about household expenditures or whether to take the child to the doctor. It has often been argued that child health and investments in children are determined by intra-household resource allocation decisions.

\section{Methods}

\subsection{Study design and sample}

The study design was cross sectional study. A concurrent mixed method approach was commenced for data collection. Face to face interview of the respondents was done for quantitative data. The interviews were conducted by house to house visit. One focus group discussions (FGDs) for qualitative data were done. Before the data collection, the detail of the study was explicitly explained to each eligible respondent and informed consents were taken from them. Approach to explore the association between maternal autonomy and young child nutritional status in rural Bangladesh through both quantitative and qualitative approach. A sample of married women who are also a mother of at least one children aged between 1 to 3 years, were inspected. Autonomy of rural mothers and nutritional status of their children were attempted to describe within the study period to create an image of the relationship between those two.

The respondents were selected through purposive sampling from the study population. Door to door visit was carried out for desired sample.

Sample size was determined statistically through the formula of Daniel (Daniel, 1991; Kothair, 1985). Prevalence of stunting was taken into account as an indicator of child malnutrition status, which was $41 \%$ for under 5 years children in Bangladesh. (UNICEF, 
2011). The calculated number of sample size was 373 if simple random sampling technique would be used. But as in this study purposive sampling technique was used and the non responsive rate was $10 \%$, we got 260 respondents who met our desired criteria.

\subsection{Variables and measurements}

3.2.1 Measuring the maternal autonomy: Maternal autonomy was evaluated on the basis of household decision making status of the respondent. This household decision making is measured by an additive index of participation on decision-making. To develop this, we used 5 decision-making variables as used in BDHS, 2007 and assigned scores for each response. The initial score was converted into 0 to 4 according to the direction from no autonomy to well autonomy. Level of autonomy was increased with the increased number of score. After calculating the total score, perception was categorized through using cut off points for three equal groups and the scoring was done on the scale of 20 .

3.2.2 Measuring the nutritional status of children: Child anthropometric measurements were taken including height and weight using height scale, weighing machine. As indicator of malnutrition, stunting and underweight were taken into account. CDC growth chart references for height and weight were used to scheme if the child was stunted or underweight. According to CDC growth chart for boys and girls, from fifth to ninety-fifth percentile was said to be have normal growth. Plotting the child's growth below fifth percentile or above ninety-fifth percentile are regarded as abnormal.

\subsection{Analysis}

The focus of this analysis is on the pathways linking maternal autonomy and child nutritional status. Based on height, weight and age data, the dependent variables are dichotomous variables indicating whether or not the child is too short or too underweight for his/her age. Data processing and analysis was done using SPSS (Statistical Package for Social Sciences) version 20 . The test statistics was used to analyze the data are descriptive statistics and inferential statistic according to the demand of the study with $95 \%$ confidence interval. Level of significance was set at 0.05 . Qualitative data were analyzed on the basis of themes.

\section{Result}

\subsection{Socio-demographic status of rural mothers}

Socio-demographic statistics are presented in Table 1. Most mothers of the sample belongs from the age group 20-29 years, the average monthly family income was 17303.85 with the $\mathrm{SD} \pm 11726.78$ taka. Only $25 \%$ mothers have some kind of personal income. Majority of the family have 5 to 6 members. The percentage of joint families is higher, than that of the single families, around $36 \%$ and $63 \%$ consequently. Respondents without having any formal education corresponds about $16 \%$ of the population, whereas the literate group consists about $29 \%$ who finished study up to primary and more than half of the respondents were studied higher than primary. Among the husbands the literate group was about $77 \%$ and around one third of them did not have any sort formal education. Two large group among them were businessman about $45 \%$ and service holder about $31 \%$. Rests were farmers, day laborers and rickshaw pullers or drivers. Among the respondents almost $95 \%$ were Muslims and rests of them were Hindu.

Table 1. Distribution of age, age gap, monthly family income and family size

\begin{tabular}{|l|l|l|}
\hline Characteristics & Frequency & Percentage \\
\hline Age of the respondents (years) \\
\hline$\leq 19$ & 16 & 6.2 \\
\hline $20-29$ & 168 & 64.6 \\
\hline$\geq 30$ & 76 & 29.2 \\
\hline Monthly family income (Taka) \\
\hline$\leq 10000$ & 90 & 34.6 \\
\hline
\end{tabular}


South American Journal of Medicine

Volume 4, Issue 1, 2016

\begin{tabular}{|l|l|l|}
\hline $10001-20000$ & 107 & 41.2 \\
\hline$\geq 20001$ & 63 & 24.2 \\
\hline Mother's personal income & 25.39 \\
\hline Yes & 66 & 74.62 \\
\hline No & 194 & 32.7 \\
\hline Family size & 85 & 46.9 \\
\hline$\leq 4$ & 122 & 20.4 \\
\hline $5-6$ & 53 & 36.5 \\
\hline$\geq 7$ & 95 & 63.5 \\
\hline Family type & 165 & 16.9 \\
\hline Single & 44 & 30.0 \\
\hline Joint & 78 & 24.6 \\
\hline Educational level of respondents \\
\hline Illiterate & 21.5 \\
\hline Upton primary & 64 & 21.2 \\
\hline Upton secondary & 56 & 21.9 \\
\hline Above secondary & 56 & 21.9 \\
\hline Educational level of husbands & 35 \\
\hline Illiterate & 55 & 74.6 \\
\hline Upton primary & 57 & 13.1 \\
\hline Upton secondary & 57 & 6.5 \\
\hline Above secondary & 91 & 5.0 \\
\hline Occupational status of respondents \\
\hline Housewife & 194 & 0.8 \\
\hline Day laborer & 34 & 6.4 \\
\hline Service holder & 17 & 31.2 \\
\hline Business & 13 & 45.8 \\
\hline $\begin{array}{l}\text { Others } \\
\text { (handloom } \\
\text { worker) }\end{array}$ & 2 \\
\hline Occupational status of husbands \\
\hline Farmer & 23 & \\
\hline Day laborer & 19 & \\
\hline Rickshaw puller & 17 & \\
\hline Service holder & 81 & \\
\hline Businessman & 119 & \\
\hline Religion & 246 & \\
\hline Muslim & 14 & \\
\hline Hindu & \multicolumn{2}{|l|}{} \\
\hline
\end{tabular}

\subsection{Reproductive characteristics of rural mothers}

Reproductive measures showed in Table 2 indicate that almost $40 \%$ of the respondent got married before the legal age of marriage that is before 18 years. Rests of them got married above the age of 18 . Average age of marriage was at 19 years with the $\mathrm{SD} \pm 2.6$. The study records percentage of adolescent pregnancy 36.15 , where the mean age of first conceive was 20.61 years with the SD of \pm 2.9 . Almost $80 \%$ of the respondents have 2 children or less than that, others have more than 2 children. 
Table 2. Distribution of age at first marriage and first conception of the respondents

\begin{tabular}{|c|c|c|c|}
\hline Characteristics & Frequency & Percentage & Mean(SD) \\
\hline \multicolumn{4}{|c|}{ Age at first marriage of the respondents (years) } \\
\hline Early marriage & 80 & 30.8 & \multirow{2}{*}{$19.00 \pm 2.68$} \\
\hline Not early marriage & 180 & 69.2 & \\
\hline \multicolumn{4}{|c|}{ Age at first conception of the respondents (years) } \\
\hline Adolescent pregnancy & 94 & 36.2 & \multirow{2}{*}{$20.61 \pm 2.9$} \\
\hline Not adolescent pregnancy & 166 & 63.8 & \\
\hline \multicolumn{4}{|l|}{ Parity } \\
\hline 2 children or less & 203 & 78.1 & \multirow{2}{*}{$2.02 \pm 0.93$} \\
\hline More than 2 children & 57 & 21.9 & \\
\hline
\end{tabular}

\subsection{Maternal autonomy status}

Figure 1 showed the autonomy status of the rural mothers was studied as per the household decision making scale used in BDHS 2007, to measure the same. The household decision making was counted on the basis of 'last say' on deciding 5 dimensions, namely- decision about own healthcare, major household purchase, daily household purchase, visit to the relatives or health centers or other places and child healthcare.

On the basis of the 5 dimensions for measuring household decision making status, the cumulative empowerment was calculated and the score ranged from 0 to 20 with the mean score of 7.3 with SD of \pm 4.7 . After calculating the total score, the maternal autonomy was categorized through using cut off points for three equal groups. The cut off points were 5 and 9. As a result almost $47 \%$ were poorly autonomous and percentage of average and well autonomy was $24.2 \%$ and $28.5 \%$ accordingly. (Table 3 )

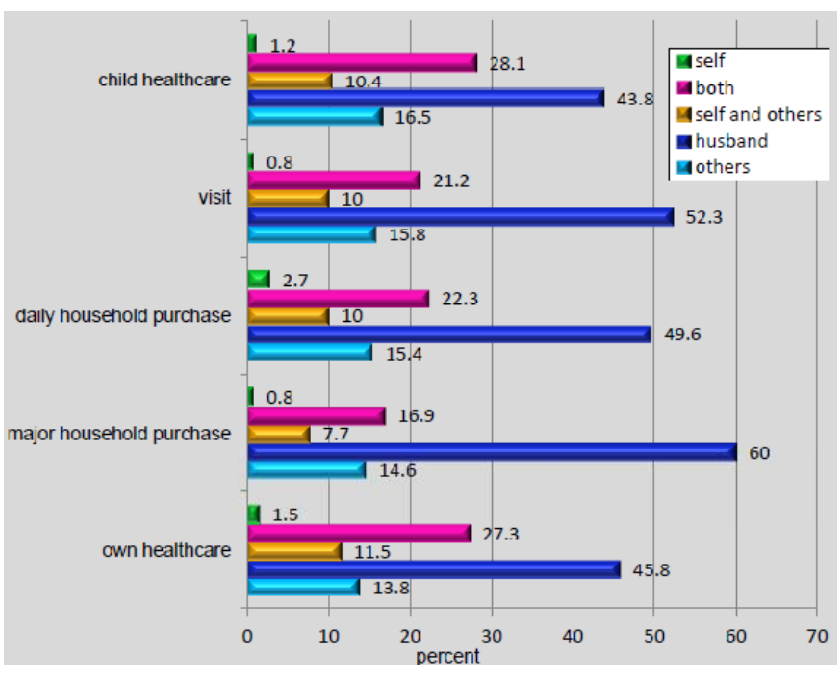

Figure 1. Household decision making status

Table 3. Maternal autonomy status

\begin{tabular}{|c|l|l|l|}
\hline Maternal & Poor & Average & Well \\
\cline { 2 - 4 } autonomy status & $47.30 \%$ & $47.30 \%$ & $28.50 \%$ \\
\hline
\end{tabular}

\subsection{Child nutritional status}

Anthropometric measurements of 124 male and 136 female children were recorded, as showed in Table 4 . The total percentage of stunted children was 38.08 and total percentage of underweight children was 34.23 . Stunting rate among girls were $21.15 \%$ where underweight rate was $17.69 \%$. Among boys, stunting and underweight percentages were $16.92 \%$ and $16.54 \%$ accordingly. 
South American Journal of Medicine

Volume 4, Issue 1, 2016

Table 4. Distribution of the height and weight percentile of the children

\begin{tabular}{|l|l|l|l|l|}
\hline & Girls (n=136) & Boys (n=124) \\
\hline Characteristics & Frequency & Percentage & Frequency & Percentage \\
\hline Height distribution & 55 & 40.44 & 44 & 35.48 \\
\hline Stunted & 81 & 59.56 & 80 & 64.52 \\
\hline Normal & \multicolumn{5}{|l|}{} \\
\hline Weight distribution & 33.82 & 43 & 34.68 \\
\hline Underweight & 46 & 66.18 & 81 & 65.32 \\
\hline Normal & 90 &
\end{tabular}

\subsection{Association of maternal autonomy and child nutritional status}

The height distribution of the children found to be dependent on maternal autonomy. The chi square statistic for this particular case was 6.13 with the $\mathrm{p}$ value $<0.05$ indicates a strong relationship. Among the poorly autonomous mothers about $44 \%$ children were stunted, where mothers with well autonomy were with only $27 \%$ stunted children. But the scenario didn't come out the same for weight distribution. Weight distribution of the children was not significantly associated with maternal autonomy (Table 5).

Table 5. Stunting of the children by maternal autonomy

\begin{tabular}{|c|c|c|c|c|}
\hline Characteristics & Stunted & Normal & $\chi^{2}$ & $\mathbf{p}$ \\
\hline Poor & $44.7 \%$ & $55.3 \%$ & \multirow{3}{*}{6.13} & \multirow{3}{*}{0.047} \\
\hline Average & $38.1 \%$ & $61.9 \%$ & & \\
\hline Well & $27 \%$ & $73 \%$ & & \\
\hline Characteristics & Underweight & Normal & $\chi^{2}$ & p \\
\hline Poor & $39.0 \%$ & $61.0 \%$ & \multirow{3}{*}{5.839} & \multirow{3}{*}{0.054} \\
\hline Average & $38.1 \%$ & $61.9 \%$ & & \\
\hline Well & $23.0 \%$ & $77.0 \%$ & & \\
\hline
\end{tabular}

\subsection{Multiple regression to predict the vulnerability to stunting of children}

Binary logistic regression model was constructed with all variables showed significant relationship by univairiate analysis to see the effect of independent variable after removing the effect of other variables. The full model was significant. The true association was found significant with two predictors which was educational qualification of the respondent and exclusive breast feeding. In comparison to illiterate group, up to primary, up to secondary and above secondary literate group have around 2, 7 and 4 times less likely to have stunted children respectively. As like that children who were exclusively breastfed were 2 times less likely to have stunted children than children who were not exclusively breastfed.

Table 6. Multiple regression to predict the vulnerability to stunting

\begin{tabular}{|l|l|l|l|l|}
\hline Variables & p value & Odds ratio & \multicolumn{2}{|c|}{ 95\% CI } \\
\cline { 3 - 5 } & & & Lower & Upper \\
\hline Education of the respondent \\
\hline Illiterate (ref) & 0.000 & & & \\
\hline Upton primary & 0.059 & 2.074 & 0.974 & 4.419 \\
\hline Upton secondary & 0.000 & 6.959 & 2.785 & 17.390 \\
\hline Above secondary & 0.003 & 4.671 & 1.683 & 12.966 \\
\hline Monthly family income & 0.997 & \\
\hline$\geq 10000$ taka (ref) & 0.953 & 1.021 & 0.514 & 2.028 \\
\hline 10001 - 20000 taka & 0.984 & 0.991 & 0.413 & 2.382 \\
\hline$\leq 20001$ taka & \multicolumn{5}{|l}{} \\
\hline Respondent's personal income \\
\hline Yes (ref) & 1 &
\end{tabular}




\begin{tabular}{|l|l|l|l|l|}
\hline No & 0.782 & 1.118 & 0.508 & 2.452 \\
\hline Exclusive breastfeeding & 1 & & \\
\hline Yes (ref) & 0.000 & 2.798 & 1.574 & 4.976 \\
\hline No & 0.461 & & \\
\hline Breastfeeding duration & & & \\
\hline $\begin{array}{l}\text { Before completing } \\
12 \text { months (ref) }\end{array}$ & 0.321 & 0.663 & 0.294 & 1.494 \\
\hline 12 to 23 months & 0.888 & 0.930 & 0.343 & 2.526 \\
\hline 24 months or more & 0.83 & \\
\hline Maternal autonomy & 0.463 & & & \\
\hline Poor (ref) & 0.434 & 1.325 & 0.655 & 2.683 \\
\hline Average & 0.242 & 1.564 & 0.739 & 3.309 \\
\hline Well
\end{tabular}

\subsection{Findings of qualitative data}

Qualitative data were needed to describe the real scenario of influence of maternal autonomy on child nutritional outcome. One focused group discussion with 10 married mothers who have at least one children aged between 1 to 3 years, was conducted to go in depth of the actual situation. The findings come out as following-

4.7.1 Status of maternal autonomy: Maternal autonomy was hard to describe in rural community both in the literate and illiterate group of mothers. Household decisions were mostly taken by their husbands. And it was generally accepted by the wives. As the major earning person of the family, the men are expected to have the final say on every minor or major decision of a household. In most cases women are thought to maintain only the family and they don't need to earn; the earning of the male head of the family should be regarded as sufficient. Health care of the mother's own or of their children, even if the mother feels an urgency she cannot go to the health center without the permission of her husband or parents in law. Even when a woman has personal income, she allows her husband to decide how to spend it. The participants were asked about all the five domains of household decisions, if they do participate. And the importance of taking part in this process.

4.7.2 Perception about child's health: Participants mostly expressed not having disease is the indicator of good well being. Some of them even expressed that, even if a child is visibly short in stature it's not a matter to be concerned about, childhood under nutrition that is height and weight gets better with age. Some of them specially from illiterate or low literate group they mentioned that costly food can ensure their children's good health. Educated mothers on the other hand have more clear perception that better health is ensured by balanced diet, proper hygiene etc. But this group also expressed that it's not possible all the time to get enough time to take special care for the food or better hygiene practice as they have to maintain all the household works.

4.7.3 Way to improve maternal autonomy: Participants were asked about how they can improve their maternal autonomy. They were not very clear about the idea as they have accepted the norm to listen and take decisions of others. Still education, employment and respect from the family members can improve their status they stated.

4.7.4 Husband's and other family member's role in maternal autonomy: Most of the respondents mentioned if they would be valued more, if their opinion would be appreciated more, they be more autonomous.

4.7.5 Importance of participation in household decisions for child's health outcome: The participants were in favor of the fact that better participation in household decision making will improve their child's health. They would be able maintain the time allocation as well as the resource allocation better for their child if they could have more say in the household decisions. Even when they understood what would be better for her child in some instance, they could not do accordingly as her husband would not give permission or the 
South American Journal of Medicine

Volume 4, Issue 1, 2016

process would delay as she have to wait for her husband or other members of the family to give a decision.

\section{Discussion}

The results of this study provide evidence for maternal autonomy to be a strong predictors of stunting of children under 3 years of age. The anthropometric index of height-for-age reflects shortfall in height-for-age show the "long-term, cumulative effects of inadequacies of nutrition and/or health" [3]. Stunting is the measure of chronic under nutrition of the children whereas underweight can be acquired acutely or it can be resulted from a chronic malnutrition. As similar to these study other studies have showed that, mother's power to affect purchasing decisions and resources allocated to food or child care has been identified as an important factor for child nutritional status, particularly in rural settings where resources are scarce. [2]. Level of participation of mothers in the household decision-making negatively affects child under nutrition, which implies that the mothers' participation in making decisions reduces the likelihood that their children will undergo under nutrition. There is a substantial literature that shows that when women have higher levels of autonomy at the household level for decision-making, access to resources, physical freedom, etc., they are more likely to have lower levels of infant mortality [6], and health seeking behaviors (Bloom et al., 2001). A cross-sectional survey from Chad [7] showed caregiver's decisions regarding

feeding/breasting feeding practices, sanitation and hygiene and treatment during illness of the child, had a positive association to child height-for-age indicator and was significant even when controlled for other household variables like household structure, income generating activities, social support, etc. The World Bank and United Nations emphasize the importance of empowerment of women with relation to child growth and development in their policy statements. Many women's empowerment programmes (such as those developed by Grameen Bank in Bangladesh and Self Employed Women's Association in India) include strategies to achieve improved health care-seeking behaviours of women and educational programmes for child care [8]. Well autonomous mothers shown to have less stunted children than the mothers with average and poor autonomy score.

\section{Acknowledgement}

I would like to thank Dr. Afroza Begum, Dr. Ashraful Alam, Dr. Irin Hossain, Dr. Abdus Samad, Dr. M M Aktaruzzaman for their invaluable support, concern and participation. I would especially like to thank for helping me write and design the report. A special thanks goes to Dr. Ayesha Siddiqua for hosting and supporting me while I was in Manikganj and my interview team there-Buri Apa, Nehar Sultana. I also wish to thank the women living in Garpara union of Manikganj, they allowed me to learn about their lives and what it means to be empowered. I would not be able to pull it all together without you.

\section{References}

[1.] Ahmed S,. Koenig M. A, \&. Stephenson R,. 'Effects of Domestic Violence on Perinatal and EarlyChildhood Mortality: Evidence From North India.'. American Journal of Public Health, (2006), Vol.96, No.8, pp.1423-1628.

[2.] Anjor Bhaskar, Does greater autonomy among women provide the key to better child nutrition? June 29(2012)

[3.] Begin F, Frongillo, Delisle, \& Habicht, 'Caregiver behaviors and resources influence child heightfor-age in rural Chad'. J Nutr (1999) Vol.129 No.3, pp.680-686

[4.] Bhuiya, M. Chowdhury, 'Beneficial effects of a woman-focused development programme on child survival: evidence from rural Bangladesh'. Social Science \& Medicine (2002), Vol.55 No.9, pp.15531560 .

[5.] Engle P. L, 'Maternal work and child-care strategies in peri-urban Guatemala: nutritional effect's' Child Dev (1991), Vol.62, No.7, pp.954-965 
South American Journal of Medicine

Volume 4, Issue 1, 2016

[6.] Gillespie S, \&. Haddad L, 'Attacking the double burden of malnutrition in Asia and the Pacific' (2001). Vol. ADB Nutrition and Development Series: Asian Development Bank.

[7.] Thomas D, 'Intra-household resource allocation: An inferential approach'. Journal of Human Resources (1990). Vol.25, pp.635-664. 


\title{
Gynaecomastia and pseudo gynaecomastia
}

\author{
Article by Sreelatha Murugappan \\ PhD in Medicine by Research in Cosmetology, Texila American University \\ Email: murugappan.spm@gmail.com
}

\begin{abstract}
The common male problem, Gyanecomastia, is truly Pseudo gynaecomastia with only fatty tissue and minimal glandular tissue. The condition is a part of the co existing Obesity disorder and is rarely, a standalone entity. The treatment options shall include an approach to answer the issue of obesity as a whole, not rest contented with surgical removal of the enlarged breasts alone, as what is seen and what is treated is just a tip of the iceberg. Surgical removal of fatty tissue and extrication of glandular tissue by laser liposuction under Tumescent anaesthesia helps in avoiding the sub areolar incision.
\end{abstract}

Keywords: Gynaecomastia, laser liposuction, pseudogynaecomastia

\section{Introduction}

The common male problem in an Aesthetic clinic, Gyanecomastia, is truly Pseudo gynaecomastia with only fatty tissue and minimal glandular tissue. The condition is a part of the co existing Obesity disorder and is rarely, a standalone entity. The treatment options shall include an approach to answer the issue of obesity as a whole, not rest contented with surgical removal of the enlarged breasts alone. What is seen and what is treated is just a tip of the iceberg. Gynaecomastia, an innocuous condition that affects $35-70 \%$ of male population immediately after birth, during adolescence and old age is rarely brought to notice as the sufferer makes all attempts to hide it as the condition brings with it a sense of shame and pain in public places and mental suffering. Herein starts the search for the treatment. Medical and multifaceted surgical options evolved over centuries with the current opinion being fat removal by anyone form of liposuction and the gland removal by direct excision.

Gynaecomastia, is increased breast tissue in males composed of glandular and fatty tissue. Physiological gynaecomastia of puberty that normally regresses with age tend to stay back being sustained by the modern lifestyle changes. Processed foods and environmental pollution of air and water, the cosmetics used on the body like deo odorants, perfumes and toiletries, synthetics and chemicals have contributed to explosions of generalised obesity. With this generalised obesity, the tendency to hold back excess fat in the breast developed. This clearly shows the reason for higher incidence of (pseudo) Gynaecomastia of late. Hormonal imbalance due to reasons stated above, aggravate the situation. Gynaecomastia is part of the generalised obesity and it is more fat and little gland. 


\section{Gynaecomastia variants}

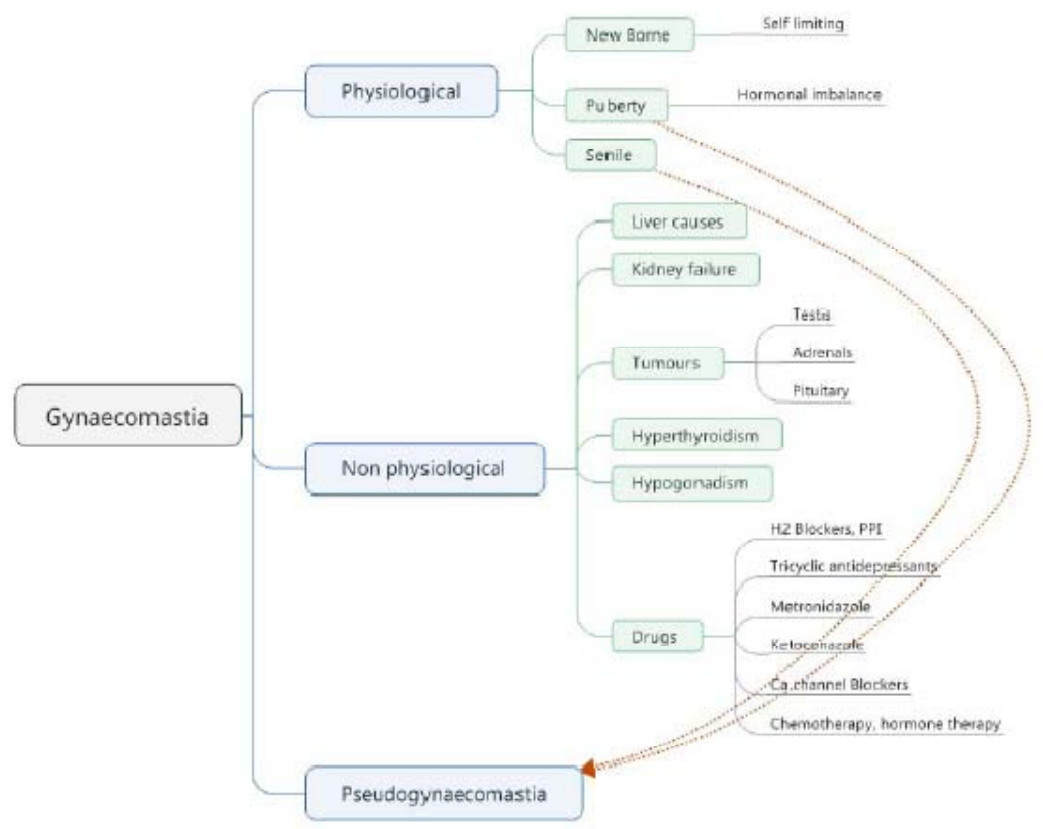

\section{Materials and methods}

The study was conducted in 35 consecutive patients of gynaecomastia. They were in the age group 21-35 $(\mathrm{n}=33)$ and above $45(\mathrm{n}=2)$. Weight $<80 \mathrm{Kgs}(\mathrm{n}=8)$ and $>80 \mathrm{kgs}(\mathrm{n}=27)$. Gynaecomastia Grade Gr2-3(n=33), Gr $1(\mathrm{n}=1)$ and Sagging breast with lax skin $(\mathrm{n}=1)$. BMI Below $25(n=1), 25-29.9(n=5)$, above $30(n=29)$. Ultrasonogram of all showed normal glands and did not show any glandular enlargement in any $(\max$ size $=2.1 \mathrm{~cm}$ ). Clinical examination showed the enlarged breast was fatty tissue and rarely glandular tissue was felt. The two persons above 45 years diagnosed as gynaecomastia had sagging breasts with laxity of skin and displacement of nipples far down below the normal. The sagging was found due to lax chest muscle and when the sag was pulled up, the lookalike of gynaecomastia' disappeared.

\section{Procedure}

Under Tumescent Anaesthesia, with a $3 \mathrm{~mm}$ incision in the ant axillary line, $1470 \mathrm{~nm}$ laser (Alma LipoEZE) 600 micron fibre passed in radial directions across the breasts. The fibre was passed across the gland after the fat was removed and the gland fragmented with the heat. Large chunks of the gland that were not removed by suction were pulled out by fine forceps thro the same path. Tight strapping applied and patients reviewed after 2 days. 1 patient had bleeding that was arrested by inj haemocoagulase and compression. Post operatively, the patient had haematoma. The satisfaction rates as given by the patients were very good to excellent $(n=26)$ and good and satisfied $(n=9)$.

The need to reduce weight by increasing Basal Metabolic Rate and lifestyle changes to prevent recurrence or weight gain was reinforced into the minds. This included a change in dietary composition that avoided all processed foods of any kind and a change in exercise types of High Intensity Intervals and 3Dimensional exercise that could be performed over few seconds to minutes with long lasting effects and hormonal balance restoration. The results were evident by corresponding weight loss

\section{Conclusion}

True Gynaecomastia that requires surgical treatment is not so uncommon. What is commonly believed to be gynaecomastia is truly Pseudo gynaecomastia with a co exiting 
clinical picture of obesity, high BMI, sedentary life and wrong lifestyle. Surgical treatment by laser liposuction under Tumescent Anaesthesia gives very good results with high patient satisfaction and negligible post operative complications. Gland fragmented with laser can be extricated thro' same entry point without sub areolar incision.

\section{References}

[1.] Barros AC, Sampaio Mde C (2012). "Gynecomastia: physiopathology, evaluation and treatment”. Sao Paolo Medical Journal 130 (3): 187-97. doi:10.1590/s1516-31802012000300009

[2.] "Breast enlargement in males". Medline Plus. US National Library of Medicine. Retrieved 15 November 2015.

[3.] Cordova A, Moschella F (2008). "Algorithm for clinical evaluation and surgical treatment of gynaecomastia”. J Plast Reconstr Aesthet Surg 61 (1): 41-9.doi:10.1016/j.bjps.2007.09.033

[4.] "Current concepts in gynaecomastia”. Surgeon7 (2): 114-19. doi:10.1016/s1479-666x(09)800267

[5.] Deepinder F, Braunstein GD (2012). "Drug-induced gynecomastia: an evidence-based review.". Expert opinion on drug safety 11 (5): 779-795.doi:10.1517/14740338.2012.712109

[6.] Erol S, Orhan E, Sevin A, Erdogan B. Trauma: a new pseudogynecomastia cause. Aesth Plast Surg.2010;34:404-405. doi: 10.1007/s00266-009-9435-8

[7.] Erol S, Orhan E, Sevin A, Erdogan B. Trauma: a new pseudogynecomastia cause. Aesth Plast Surg.2010;34:404-405. doi: 10.1007/s00266-009-9435-8. [PubMed] [Cross Ref]

[8.] Narula HS, Carlson HE (August 2014). "Gynaecomastia-pathophysiology, diagnosis and treatment”. Nat Rev Endocrinol 10 (11): 684-698. doi:10.1038/nrendo.2014.139

[9.] Rohrich RJ, Ha RY, Kenkel JM, Adams WP., Jr Classification and management of gynecomastia: defining the role of ultrasound-assisted liposuction. Plast Reconstr Surg. 2003;111:909-923. doi: 10.1097/01.PRS.0000042146.40379.25.

[10.] Venkata Ratnam B. A new classification and treatment protocol for gynecomastia. Aesth Surg J.2009;29:26-31. doi: 10.1016/j.asj.2008.11.003

[11.] Wollina, U; Goldman, A (June 2011). "Minimally invasive esthetic procedures of the male breast”. Journal of cosmetic dermatology 10 (2): 150-155. doi:10.1111/j.1473-2165.2011.00548

\section{Author's profile:}

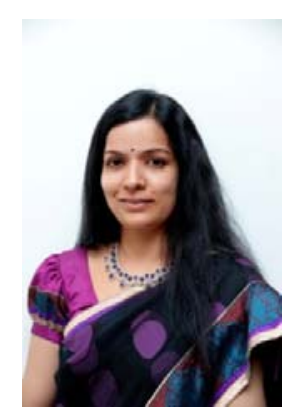

Dr. Sreelatha Murugappan

Cosmetic Laser Surgeon at Silkee Cosmetology Laser Research Institute, Chennai, India Specialising in body sculpting by laser liposuction methods. 


\title{
Level of awareness versus level of participation in the HIV/AIDS response among Non-formal health care providers in Nigeria; a comparative study
}

\author{
${ }^{1}$ Amara F. Chizoba, ${ }^{2}$ Edward I. Madu, ${ }^{3}$ Edith C. Ezeobi, ${ }^{4}$ Mmaduabuchi D. Akujuo, \\ ${ }^{5}$ Johnbull Egharevba \\ ${ }^{1}$ Clinical Research, Centre for Clinical care and Clinical Research Nigeria \\ (CCCRN), Abakaliki, Ebonyi State Nigeria \\ ${ }^{2}$ Care and support, Catholic Caritas Foundation of Nigeria (CCFN), Makurdi, Benue \\ State Nigeria; \\ ${ }^{3}$ Clinical Research, Centre for Clinical care and Clinical Research Nigeria \\ (CCCRN), Abakaliki, Ebonyi State Nigeria; \\ ${ }^{4}$ Clinical Research, Centre for Clinical care and Clinical Research Nigeria \\ (CCCRN), Abakaliki, Ebonyi State Nigeria; \\ ${ }^{5}$ Clinical Research, Centre for Clinical care and Clinical Research Nigeria \\ (CCCRN), Abakaliki, Ebonyi State Nigeria. \\ E-mail:fchizoba.scs@gmail.com
}

\begin{abstract}
Background: Large portion of Nigeria's population use the services of non-formal health care providers like patent medicine vendors (PMV) and traditional birth attendants (TBA), seeing that $65 \%$ of deliveries in Nigeria occur in such non-formal health setting. Though studies demonstrate increase in HIV/AID awareness among PMV/TBAs there is yet an unclear evidence of their level of participation in the HIV/AIDS response, even as health financing and engagement of these private sector becomes important implementation research question in Nigeria. This study aims to compare level of awareness versus level of participation of the non-formal health care providers in the HIV/AIDS response in Nigeria.

Method: By cross-sectional design, questionnaire was used to get responses from 210 PMVs and 135 TBAs across 6 Local Government Areas in Ebonyi State, Nigeria. Responses were analyzed using percentages and frequency distribution.

Results: Mean age is 34 years. Highest education level was secondary school at 59\%. HIV/AIDS awareness level was $>80 \%$ but participation was at $48 \%$.

Conclusion: HIV Awareness has increased among TBA/PMV but their participation level in HIV/AIDS response is still low. Integration of this group into public health sector could increase participation.
\end{abstract}

Keywords: HIV, AIDS, PMV, TBA

\section{Introduction}

According to United States agency for international development (USAID), a large portion of Nigeria's population use the private non-formal health sector and an apparently large number of the population do not perceive them as low-quality practitioners of Western medicine, but instead view them as quality providers of African medicine[1].

The private health non-formal health care providers include Traditional birth attendants (TBAs), Patent medicine Vendors (PMVs), and other traditional healers[2]. World health organization (WHO) also classifies this group of health care providers as traditional and complementary medicine (T\&CM) providers[3]. Patent Medicine Vendors -also referred to 
as chemists in Nigeria- are people who sell over the counter medications while providing basic health services to clients before referral of complicated cases. On the other hand, Traditional Birth Attendants are persons-either men or women- who assists the mother during childbirth and initially acquired her skills by delivering babies herself or through apprenticeship from other TBAs.

The perception of the PMVS and TBAs as quality providers of African medicine has become a socio-cultural factor influencing the high patronage of the PMVs/TBAs as compared to public health sectors in Nigeria. For instance, $65 \%$ and $45 \%$ of deliveries in Nigeria and Malawi respectively, occur in the non-formal settings like the TBA/PMVs [2, 4, 5]. Therefore and only 35\% of deliveries in Nigeria occur in formal hospital settings; $20 \%$ in public sector and $15 \%$ in private health institutions [2, 4]. Also, because public health sector in many developing countries suffers from a lack of financial and human resources [6], the PMVs/TBAs are thus available to bridge the gap. This high patronage of the Nigeria population for private health sector commands the need for policy makers to extend and support HIV service delivery to and through the private non-formal health sectors using a workable and quality strategy. This is highly essential as the nature of the HIV/AIDS response evolves from emergency relief to long-term sustainability and thus, understanding current and potential contributions from the private sector is critical [7].

Services delivered by the private non-formal health sector (including PMVs and TBAs) in the HIV/AIDS response cover a wide range including awareness raising and communication for behavior change, HIV counselling and testing(HCT), some clinical services, drugs distribution and supply chain management, as well as care for the PLWHAs and their families [8].

Studies have demonstrated increase in awareness of HIV among PMV and TBAs due to increased awareness creation and education intervention among this sec [9]. But even as Health financing and engagement of the private sector becomes an important priority implementation research question in Nigeria [10], there is yet an unclear answer to the level of PMVs and TBAs participation in HIV/AIDS response and generally in health care programs in Nigeria. Comparing the level of awareness and level of participation of the PMVs and TBAs in the HIV/AIDS response (using current participation in HCT as a criteria) could prompt and facilitate actions towards the engagement of private non-formal health sector (like PMVs/TBAs) in the HIV/AIDS response in Nigeria and beyond.

\subsection{Factors influencing patronage of PMVs/TBAs}

Large number of the population that patronizes the PMVs and TBAs do not perceive them as low-quality practitioners of Western medicine, but instead view them as quality providers of African medicine ${ }^{1}$. This has become a socio-cultural factor influencing the high patronage of these cadre of health care delivery.

In addition, TBAs (and PMVs), is a critical group within the health sector because of their bond with people in the communities and thus have an important role to play in health care delivery [11].

Another influencing factor is the fact that the public health sector in many developing countries suffers from a lack of financial and human resources [6]. WHO estimates on the density of providers per 100,000 people in Nigeria in 2003 to include; 28 physician; 170 nurses; 5 pharmacists and 91 community health workers. This thus demands compensation of the low health resources from the non-formal health service providers like PMVs and TBAs[1].

This high patronage of the Nigeria population for private non-formal health sector commands the need for policy makers to extend HIV services to and through the private 
sectors using a workable and quality strategy. Execution of such strategies have been ongoing with awareness creation of HIV being a focus and on the increase.

\subsection{Level of Awareness of HIV among PMV/TBAs in Nigeria}

Some studies in Nigeria have shown increase in knowledge of HIV among TBAs/PMVs [9, 12]. For instance, study by Oluwole A at al [9] demonstrated that $81 \%$ of the TBAs had HIV knowledge through training but added that this knowledge has not translated in commensurate effort to engage and monitor them in participation in the HIV service provision [9].

Their participation is eagerly envisioned as the nature of the HIV/AIDS response evolves from emergency relief to long-term sustainability, thus understanding current and potential contributions from the private sector is critical [7].

\subsection{Participation of the PMVs and TBAs in the HIV/AIDS response in Nigeria}

The private health sector in many developing countries like Nigeria contributes $>50 \%$ of personal health care services [13], and $>60 \%$ of the health care in Africa is financed privately [14].

A multi-country analysis conducted by the Private Sector Partnership-One project, a project funded by the US Agency for International Development, found that between 3\% and $45 \%$ of women and between $6 \%$ and $42 \%$ of men reported the private for-profit sector as the source of their most recent HIV test[6, 15]. The private non-formal health care setting has thus been demonstrated to provide HIV counselling and testing (HCT) for up to $45 \%$ of the population. Showing a steady increase in their participation in the HIV/AIDS response through HCT.

In addition, according to WHO, Traditional and complementary medicine(T\&CM)- where PMVs and TBAs are also classified- is an important and often underestimated part of health care and the demand for their services is increasing [3], while Olumide et al [9] opined that TBAs are an essential part of the Nigerian healthcare system. If of proven quality, safety, and efficacy, these service providers contributes to the goal of ensuring that all people have access to care [3]. Many countries now recognize the need to develop a cohesive and integrative approach to health care that allows governments, health care practitioners and, most importantly, those who use health care services, to access T\&CM (PMVs/TBAs) in a safe, respectful, cost-efficient and effective manner. A global strategy to foster its appropriate integration, regulation and supervision will be useful to countries wishing to develop a proactive policy towards this important - and often vibrant and expanding - part of health care $^{3}$.

Services delivered by the private/non-formal health sector (such as PMVs and TBAs) in the HIV/AIDS response cover a wide range including awareness raising and communication for behavior change, testing, laboratory analyses, clinical services, drugs distribution and supply chain management, as well as care for the PLWHAs and their families [8].

The wide range of services have HCT as one of the basics in the HIV/AIDS response. Efforts to increase PMVs/TBAs participation through HCT is thus crucial. Currently it is in the plan of elimination of mother and child health transmission of HIV (EMTCT) in Nigeria to provide multiple HIV testing points as a strategy to increase participation of all health care providers-including private health sectors- in HIV management in Nigeria [2]. Also, integration of the non-formal and the formal health care providers has also been in the plan for the HIV/ADIS response in Nigeria [2].

Though level of awareness of HIV among PMVs/TBA have been demonstrated to be high, there is still yet an unclear answer to the level of PMVs and TBAs participation in HIV/AIDS response and other key health care service provision generally in Nigeria, even as Health 
South American Journal of Medicine

Volume 4, Issue 1, 2016

financing and engagement of the private and non-formal health sector becomes an important priority implementation research question in Nigeria [10].

It is therefore important to assess the level of participation of PMVs/TBAs in the National HIV/AIDS response so as to insight policy makers in the ongoing plan of 'the all health providers' inclusion in the national HIV/AIDS response and other health care activities in general.

\section{Method}

This is a cross sectional study that used questionnaire to elicit level of awareness versus level of participation in HIV response among non-formal health care providers (TBAs and PMVs). 345 private non-formal service providers who met inclusion criteria of being a Patent medicine vendor (PMV) or Traditional birth attendant (TBA) were included in this study. Using simple random sampling, 6 out of 13 Local Government Areas (LGAs) in Ebonyi statethe area of study- were selected. Questions on HIV knowledge/awareness and on participation in HIV counselling and testing (HCT) were translated into local dialect to aid understanding for the level of participants under study. 210 PMVs and 135 TBAs responded to the questions. Self-administered questionnaires were used to get responses from literate respondents after detailed explanations while interviewer guided questionnaires were used to get responses from the illiterate respondents in local dialect. Data was extracted from questionnaire and analyzed using frequency distribution and percentages. Ethical clearance was gotten from Centre for Clinical care and Clinical Research Nigeria. Written consent was gotten from the TBA and PMV committees in the local governments of study. Informed verbal consent was gotten from the participants after detailed explanation of objective and significance of study and right to withdraw from study.

\section{Results}

\subsection{Demographic characteristics}

The TBA/PMV under study were in mean age of 34 years which falls within the active population able to participate actively in the HIV/AIDS response. Table 1 shows that $10 \%$ of study population are illiterates with no formal education whatsoever and among the literates, majority of the respondent constituting 59\% have had secondary education while $19 \%$ had post-secondary education and $11 \%$ had gone to primary school only. With majority having at least secondary education, there is possibility that if trained in documentation, TBA/PMV can read and write (and document) as required. For years of practice, 34\% reported to have practiced for $1-4$ years, $24 \%$ had practiced for $5-9$ years, $17 \%$ for $10-14$ years, $10 \%$ for $15-19$ years while $15 \%$ had practiced for over 20 years. Only $<1 \%$ had practiced for less than 1 year. This demonstrates the early onset and long years of health service delivery among PMV/TBAs. Among the TBA, 55\% of respondents reported number of deliveries to range from 1-4 deliveries per month, 31\% reported 5-9 deliveries, while 9\% and $4 \%$ reported to have average of 10-15 deliveries and above 15 deliveries per month respectively.

\subsection{Level of awareness of HIV among PMV and TBA}

Ninety four percent (94\% (317/345)) of the respondents have heard of HIV before while $6 \%$ (22) have not. Thus majority of the respondent are primarily aware of the term HIV. Also, It can be deduced that 174(51\%) of the respondents have had training/seminar or workshop in HIV and are invariably aware of HIV while 170(49\%) have not had any form of training, seminar nor workshop. This further demonstrates the training need among this population of health care providers. Moreover, out of the options of HIV transmission routes, sexual contact, sharing of sharp objects, and blood transfusion had response frequency of 297, 186 and 233(305). This shows that majority of the respondents are aware of routes of HIV 
transmission including (though low) mother to child transmission. However, the few who are unaware of HIV transmission routes identified sharing of food, sharing of toilets, sharing of hand washing water and urinating in same place and other means of HIV transmission. Though a significant number of respondents $(10 \%)$ answered that a fat person cannot have HIV, majority (90\%) does not agree that a fat person cannot have HIV. In addition, $88 \%$ of the responses agree that HIV infection is determined by testing but a significant $10 \%$ of the responses believes that the weight/stature of a person (thin) can show a HIV positive status whereas just $2 \%$ of the responses included prayers as a way of detecting positive result. Majority of the respondents (81\%) are aware of mother to child transmission of HIV (MTCT) and 85\% aware of use of ARV for PMTCT. This result is displayed in table 2.

\subsection{Level of participation in HIV/AIDS response among PMV and TBA}

With just $48 \%$ of study population participating in HIV counselling and testing HCT (table 3), slightly above half (52\%) do not participate in HCT which is the basic practical participation in the HIV/AIDS response. The comparison of level of awareness versus level of participation in HIV/AIDS response among the participants-which that though awareness of HIV is consistently above $80 \%$, participation in HCT remains at relatively low at $48 \%$ - is displayed in figure 1

\section{Discussion}

Participants have mean age of 34 years old, falling mainly into 20-40 years, which are in the main workforce of the country. However, at that age, $41 \%$ reported to have practiced for up to 5-14 years. This demonstrates the early onset and long years of service delivery among PMV/TBAs. As identified by WHO (WHO traditional medicine strategy 2014-2023) [3], the reason for the long years of experience at relatively young age could be due to generational transfer of skill from the elderly to the younger person, leading to early onset of practice and accumulation of experience at a younger age.

Majority of the respondents (90\%) have had different levels of formal education ranging from primary, secondary and post-secondary education and thus are literates who can read and write though sometimes with assistance. More than half (59\%) of them stopped at secondary school education. This concurs with the findings of Olumide A et al [9]which stated that more than half (52.2\%) of the TBAs studied had completed secondary school. Thus if more than half of the population can read and write, it makes it easier for program implementers to include this cadre of health care providers in the training agenda in HIV service provision and health program generally.

In addition, among the TBA, 55\% of respondents reported number of deliveries to range from 1-4 deliveries while $45 \%$ reported $>5$ deliveries per month. Thus, majority (86\%) have 1-9 deliveries per month and significant $13 \%$ have $>10$ deliveries per months. Since majority (86\%) have 1-9 deliveries per month and significant 13\% having $>10$ deliveries per months agrees with the National health demographic survey [4] that state that $65 \%$ of deliveries in Nigeria occur outside the formal hospital setting. If so, efforts to reach these patients at the private non-formal settings with HIV services needs to be intensified.

To assess level of awareness of HIV among the study population, questions were asked on knowledge of HIV/AIDS. Such questions assessed percentage that have heard of HIV which showed $94 \%$. 51\% agreed to have received a sort of training while $49 \%$ said not to have been trained in HIV care whatsoever. This disagrees with Oluwole A at al [9] finding that shows that $81 \%$ of the TBAs have had PMTCT (and HIV) training. This is probably because their study was done among TBAs who are duly registered and thus able to organize or gain such trainings. 
Also, awareness of HIV transmission routes was sort and out of the options of HIV transmission routes; sexual contact, sharing of sharp objects, and blood transfusion, there was frequency rate of $297(39 \%), 186(24 \%)$ and $233(30 \%)$ respectively. Also, other routes of transmission were agreed to include mother to child transmission. This shows that majority of the respondents are aware of routes of transmission of the HIV. This finding agrees with similar studies in Nigeria that demonstrated increase in knowledge/awareness of HIV among PMVs/TBAs [9, 12]. However, few who are unaware of HIV transmission routes identified sharing of food, sharing of toilets, sharing of hand washing water and urinating in same place as other means of HIV transmissions. This group could be among the $6 \%$ respondent that reported not to have heard of HIV. This knowledge gap still points out need to intensify awareness creation of HIV among these population who still provide health services to Nigerians. Just like the studies that have demonstrated increase in knowledge of HIV among TBAs and PMVs [9, 12], this study also agrees that the awareness of HIV among PMVs and TBAs are high and suspended at above $80 \%$ positive responses to questions asked for HIV knowledge/awareness assessment. This could be as a result of increases in HIV awareness creations and community sensitization/mobilization on HIV in communities in Nigeria.

On the other hand, though Nigerian studies have showed increase in level of training and awareness of HIV among TBA or PMVs, almost no study done in the Nigeria setting could be accessed that demonstrated level of their participation in HIV service provision. Our study showed that despite increase in level of awareness of HIV among PMV/TBAs, their level of participation in HIV/AIDS response through HIV counselling and testing (HCT)- a basic practical activity in the HIV/AIDS response- remains less than $50 \%$.

\section{Conclusion}

Giant strides have been made to increase the awareness of HIV among the non-formal health care providers like TBA/PMV. However, these non-negligible part of the health care system in resource limited settings like Nigeria is yet to be reached substantially with the HIV intervention program such as support for HIV counselling and testing (HCT). Since Nigerian researchers have identified support of this health sector as a priority implementation research question, their integration in HIV/AIDS response could help speed up coverage of HIV service provision to bulk of clients who choose to patronize their services.

\section{Recommendation}

Integration of the non-formal health care providers (TBAs and PMVs) into the public health centers is recommended to help support and monitor HIV service provision in such settings. Further studies on willingness of the TBAs and PMVs to participate in the HIV/AIDS response is recommended. Implementation research on quality assessment/improvement among PMV/TBAs is also recommended.

Table 1. Demographic characteristics of participants

\begin{tabular}{l|l|l}
\hline CHARACTERISTICS & N & \% \\
\hline No of participants:345 & & \\
TBAs & 135 & 39 \\
PMVs & 210 & 61 \\
Age: Mean: 34 years & & \\
$<20$ & 5 & 1.6 \\
$20-29$ & 137 & 44 \\
$30-39$ & 94 & 31 \\
$40-49$ & 31 & 10 \\
$50-59$ & 25 & 8 \\
$60-69$ & 11 & 4
\end{tabular}


$>70$

Education level

None

Primary education

Secondary education

Post-secondary education [CHEW (11), HND (1), OND (1), $\mathrm{RN} / \mathrm{RM}(1), \mathrm{BSC}(2), \mathrm{MSc}(1)]$

TOTAL

Years of practice

$<1$

$1-4$

5-9

$10-14$

$15-19$

$>20$

TOTAL

Average monthly delivery(TBAs only)

$1-4$

5-9

$10-15$

$>15$

TOTAL
South American Journal of Medicine

Volume 4, Issue 1, 2016

\begin{tabular}{|l|l|}
5 & 1.6 \\
34 & 10 \\
37 & 11 \\
197 & 59 \\
64 & 19 \\
& \\
332 & 100 \\
& \\
2 & $<1$ \\
77 & 34 \\
55 & 24 \\
38 & 17 \\
23 & 10 \\
34 & 15 \\
229 & 100 \\
68 & 55 \\
39 & 31 \\
11 & 9 \\
6 & 5 \\
124 & 100
\end{tabular}

CHEW (Community health extension workers), HND (Higher diploma certificate), RN/RM (Registered Nurse/Registered midwife), BSc (Bachelor of Science), MSc (Master’s Degree)

Table 2. Demonstration of responses of participants to questions assessing level of awareness in HIV and HCT

\begin{tabular}{l|l|l}
\hline Questions & N & \% \\
\hline Have you ever heard of HIV & 317 & 94 \\
Yes & 22 & 6 \\
No & 339 & 100 \\
Total & & \\
Have you ever had training/seminar or workshop on HIV & 174 & 51 \\
Yes & 170 & 49 \\
No & 344 & 100 \\
Total & & \\
HIV is gotten from(tick as many as are true) & 297 & 39 \\
Having sex & 186 & 24 \\
Sharing sharp objects & 24 & 3 \\
Sharing food & 24 & 3 \\
Sharing toilet & &
\end{tabular}


South American Journal of Medicine

Volume 4, Issue 1, 2016

Through blood transfusion

Others

Washing hand in same water

Urinating in same place

Mother giving it to child

Total

Is it true that a fat person cannot have HIV

Yes

No

Total

How will you know if somebody has HIV

If the person is thin

By prayers

By testing

Others

Total

HCT (HIV counselling and testing)

Table 3. Participants' participation in HIV counselling and testing (HCT)

\begin{tabular}{l|l|l}
\hline Questions & N & $\mathbf{\%}$ \\
\hline Do you currently test your patients for HIV? & & \\
Yes & 167 & 48 \\
No & 178 & 52 \\
Total & 345 & 100 \\
\hline
\end{tabular}




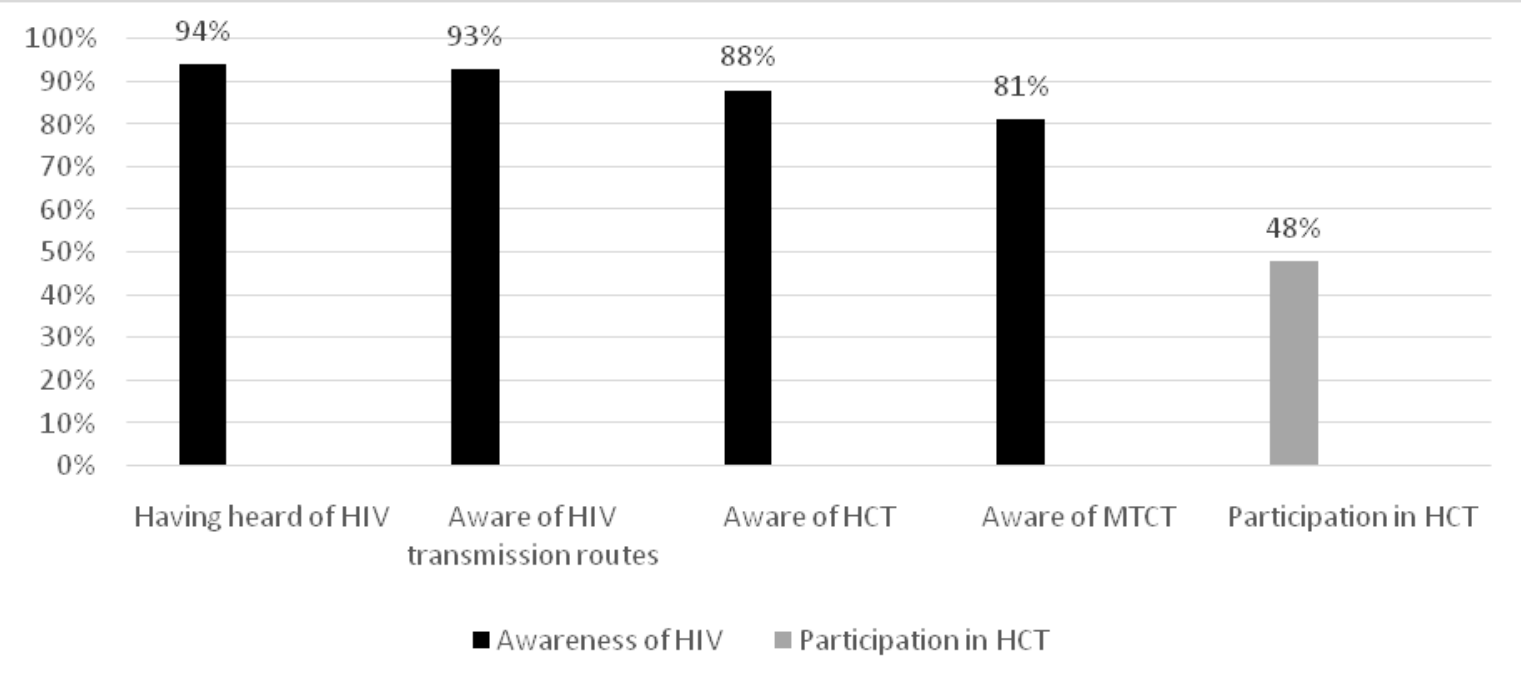

Figure 1. Comparative assessment of level of awareness of HIV versus level of participation in HIV/AIDS response among PMV and TBA MTCT (Mother to child transmission of HIV)

\section{Conflict of interest}

Authors declare no conflict of interest

\section{Acknowledgements}

Author would like to acknowledge Centre for Clinical care and Clinical Research Nigeria (CCCRN) and Ebonyi State PMV and TBA coordinators for their contributions to this study

\section{References}

[1] Abiodun O, Sotunsa J, Ani F, Olaleye A, Taiwo A: Elimination of Mother- To-Child Transmission of HIV in Nigeria: The Roles, Preparedness and Determinants of Successful Involvement of Traditional Birth Attendants. J AIDS Clin Res 2015;6:481.

[2] Catholic Relief Services (CRS) (2004) Training curriculum for traditional birth attendants. http://www.coregroup.org/storage/documents/Diffusion_of_Innovation/trainingAccessed September 2015

[3] François Nankobogo and Nilufar Egamberdi: The Role of Private Sector in the Fight Against HIV/AIDS in Sub-Saharan Africa, Thematic Stakeholder Consultations Bamako, Mali, December 2007; 10:10.

[4] HIV/AIDS Division, Federal Ministry of Health. National Operational Plan for the Elimination of Mother to Child Transmission (EMTCT) of HIV in Nigeria, 2015-2016. 2014. HIV/AIDS Division Federal Ministry of Health, Abuja, Nigeria. Web: www.nascp.gov.ng.

[5] Lagomarsino G, Nachuk S and Kundra SS. Public Stewardship of Private Providers in Mixed Health Systems: Synthesis Report From the Rockefeller Foundation-Sponsored Initiative on the Role of the Private Sector in Health Systems. Washington, DC: Results for Development Institute; 2009.

[6] Ministry of Health. National Sexual and Reproductive Health and Rights Policy 2009: Lilongwe. 2009. http://www.healthpolicyproject.com/pubs/455 FINALPolicyReviewFPHIVIntegration Accessed October 2015

[7] National Population Commission (NPC) [Nigeria] and ICF International. 2014. Nigeria Demographic and Health Survey 2013. https://dhsprogram.com/pubs/pdf/FR293/FR293.pdf Accessed October 2015

[8] Nigel Rollins: Prioritizing National PMTCT Implementation Research, J Acquir Immune Defic Syndr 2014; $67: 2$

[9] Olumide Abiodun, John Sotunsa, Oluwatosin Olu-Abiodun et al. The Effect of Training on Traditional Birth Attendants’ PMTCT Related Knowledge and Care Practices in Nigeria. J AIDS Clin Res 2015;6:9

[10] Pamela Rao, Tesfai Gabre-Kidan, Deus Bazira Mubangizi, and Sara Sulzbach: Leveraging the Private Health Sector, J Acquir Immune Defic Syndr. August 1 2015;57:2,4.

[11] Sara Sulzbach, Susna De and Wenjuan Wang: The private sector role in HIV/AIDS in the context of an expanded global response: expenditure trends in five sub-Saharan African countries. Published by Oxford University Press in association with The London School of Hygiene and Tropical Medicine. Health Policy and Planning 2011;26:72-84 


\section{South American Journal of Medicine}

\section{Volume 4, Issue 1, 2016}

[12] The Business of Health in Africa: Partnering with the Private Sector to Improve People's Lives. Washington, DC: International Finance Corporation; 2007.

[13] USAID: Nigeria Private Sector Health Assessment, 2008. http://www.shopsproject.org/sites/default/files/resources/5137_file_FINAL. Accessed October 2015

[14] World Health Organization: WHO Traditional Medicine Strategy; 2014-2023. 2013. Publications of the World Health Organization are available on the WHO web site (www.who.int) assessed September 2015

[15] Wang W, Sulzbach S and De S. Utilization of HIV-related services from the private health sector: a multicountry analysis. Soc Sci Med. 2011; 72: 216-223. 
Lot A, Goedverwagting, Sparendaam, East Coast Demerara, Guyana, South America.

\section{Telephone: (+592) 2225224 / (+592) 2225225 \\ E-mail: ejournal.assist@tau.edu.org}

